\title{
Using Environmental and Site-specific Variables to Model Current and Future Distribution of Red Spruce (Picea rubens Sarg.) Forest Habitat in West Virginia
}

\author{
Nathan R. Beane \\ West Virginia University
}

Follow this and additional works at: https://researchrepository.wvu.edu/etd

\footnotetext{
Recommended Citation

Beane, Nathan R., "Using Environmental and Site-specific Variables to Model Current and Future Distribution of Red Spruce (Picea rubens Sarg.) Forest Habitat in West Virginia" (2010). Graduate Theses, Dissertations, and Problem Reports. 3177.

https://researchrepository.wvu.edu/etd/3177

This Dissertation is protected by copyright and/or related rights. It has been brought to you by the The Research Repository @ WVU with permission from the rights-holder(s). You are free to use this Dissertation in any way that is permitted by the copyright and related rights legislation that applies to your use. For other uses you must obtain permission from the rights-holder(s) directly, unless additional rights are indicated by a Creative Commons license in the record and/ or on the work itself. This Dissertation has been accepted for inclusion in WVU Graduate Theses, Dissertations, and Problem Reports collection by an authorized administrator of The Research Repository @ WVU. For more information, please contact researchrepository@mail.wvu.edu.
} 


\title{
Using Environmental and Site-specific Variables to Model Current and Future Distribution of Red Spruce (Picea rubens Sarg.) Forest Habitat in West Virginia
}

\author{
Nathan R. Beane \\ Dissertation submitted to the \\ Davis College of Agriculture, Natural Resources and Design \\ at West Virginia University in partial fulfillment \\ of the requirements for the degree of
}

Doctor of Philosophy

in

Forest Resources Science

Dr. James Rentch—Committee Chair

Dr. John Brooks

Dr. Eric Heitzman

Dr. Thomas Schuler

Dr. Michael Strager

\author{
Division of Forestry \\ Morgantown, West Virginia \\ 2010
}

Keywords: red spruce forests, habitat suitability modeling, maximum entropy, Maxent, high-elevation forests, West Virginia 


\title{
ABSTRACT \\ Using Environmental and Site-specific Variables to Model Current and Future Distribution of Red Spruce (Picea rubens Sarg.) Forest Habitat in West Virginia
}

\author{
Nathan R. Beane
}

Red spruce forests are a remnant ecosystem from the interglacial period of the Wisconsin glaciation and today are considered one of the most threatened forest ecosystems in the eastern United States. The extent of red spruce forests in West Virginia prior to exploitative logging which occurred from 1880-1920 is estimated at 190,000 ha, but today, these forests are estimated to occupy no more than 24,000 ha, resulting primarily from intense anthropogenic disturbances. With the extensive loss of presettlement habitat for red spruce in West Virginia, this species is a high priority for restoration, as these forests offer the unique habitat for the endangered Cheat Mountain salamander (Plethodon nettingi Green), and provide optimal habitat for the recently delisted Virginia northern flying squirrel (Glaucomys sabrinus fuscus Miller).

In the first portion of the study, a novel modeling technique, Maximum Entropy (Maxent) was used to model current red spruce forest habitat in West Virginia using 168 red spruce presence localities and 32 environmental and site-specific variables. For this analysis 283,000 ha were identified in 18 counties possessing suitable red spruce habitat in West Virginia. Variables considered important for all replicate model runs were maximum temperature of the warmest month (40.6\%), minimum temperature of the coldest month (13.7\%), slope percent (6.9\%), mean temperature of the coldest quarter $(6.5 \%)$, mean annual temperature $(4.6 \%)$, and soil type $(4.0 \%)$. The environmental and site-specific variables which contributed the most to overall model performance were also assessed further to examine the value or range of values in which red spruce habitat was likely to occur. For maximum temperature of the warmest month the threshold value identified was $25^{\circ} \mathrm{C}$, where areas which had maximum summer temperature less than this value resulted in an increased probability of possessing suitable red spruce habitat. Additionally, for mean temperature of the coldest month, a threshold value was identified where all areas which possessed a mean winter monthly temperature less than $-8.5^{\circ} \mathrm{C}$ resulted in increased probability of suitable habitat for red spruce to a peak of approximately $-10.5^{\circ} \mathrm{C}$.

In the second portion of the study, Maxent was used to model future distribution of red spruce habitat in West Virginia using 24 environmental and site-specific variables. Two climate change scenarios provided by the Intergovernmental Panel on Climate Change (IPCC) for three time periods (i.e., 2020, 2050, and 2080) were examined. Results for both model analyses indentified three variables which contributed significantly to model performance: mean temperature of the coldest quarter, elevation, and minimum temperature of the coldest month. When combined, these variables contributed more than $40 \%$ to model performance for both scenario models. Changes in suitable habitat area were also assessed for both model scenarios at each time period examined, with dramatic reductions identified. Approximately $6.2 \%$ of the land area in West Virginia was modeled to possess suitable red spruce habitat under current conditions. However, by the time period 2020 , only $1.3 \%$ and $2.8 \%$ were identified for the aggressive and conservative climate change models, respectively. By the time period 2080, no suitable red spruce habitat was modeled using the aggressive climate change scenario with 53,866 ha identified using the conservative model, representing less than $1 \%$ of the land area in West Virginia. 


\section{TABLE OF CONTENTS}

ABSTRACT

CHAPTER 1. LITERATURE REVIEW AND JUSTIFICATION ........................................... 1

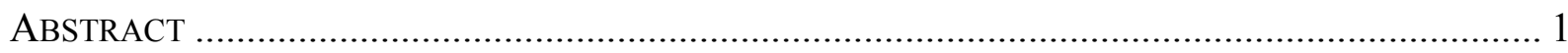

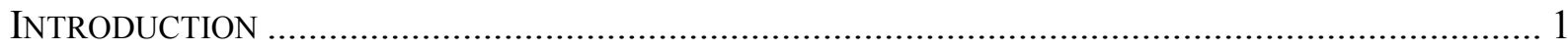

Quaternary History of Red Spruce .............................................................................. 2

Current Red Spruce Distribution in the Appalachian Mountain Region (AMR).................. 5

History of Logging in West Virginia Red Spruce Forests................................................. 7

Autoecology of Red Spruce in West Virginia ................................................................ 10

Current Distribution of Red Spruce Forests in West Virginia.......................................... 14

Impacts of Climatic Change on Terrestrial Ecosystems............................................... 17

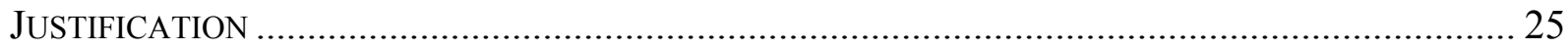

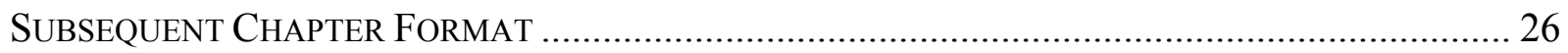

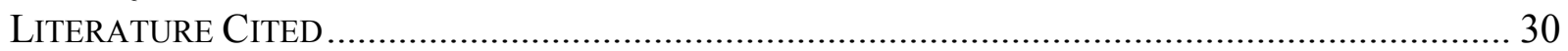

\section{CHAPTER 2. USING ENVIRONMENTAL AND SITE-SPECIFIC VARIABLES TO} MODEL THE CURRENT DISTRIBUTION OF RED SPRUCE FORESTS IN WEST

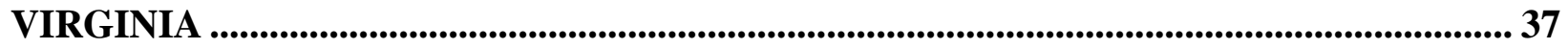

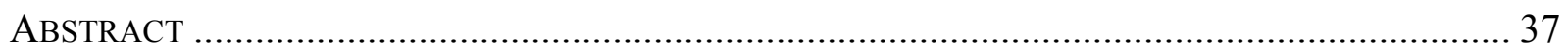

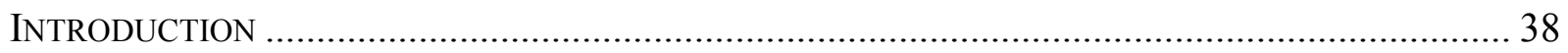

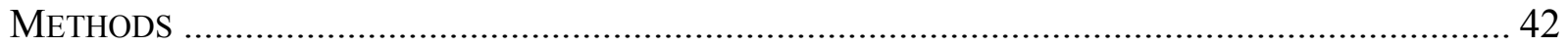

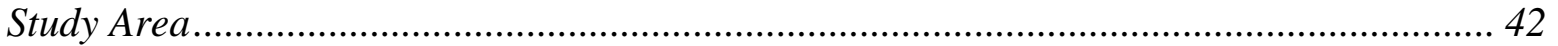

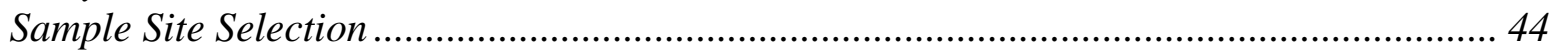

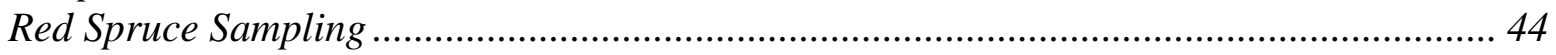

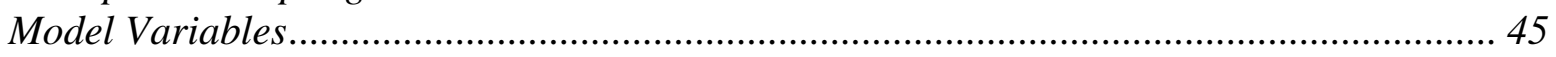

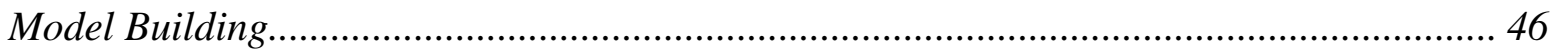

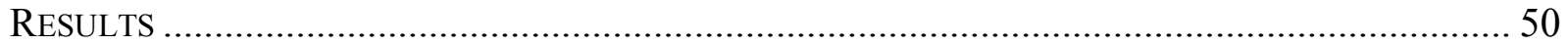

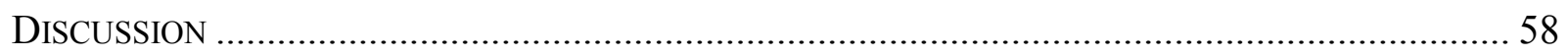

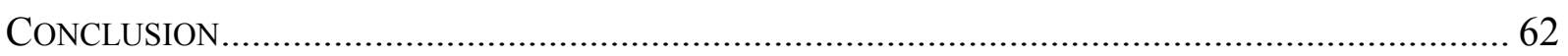

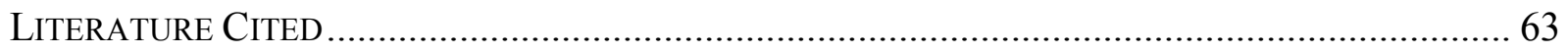

CHAPTER 3. USING ENVIRONMENTAL AND SITE-SPECIFIC VARIABLES TO MODEL THE POTENTIAL DISTRIBUTION OF RED SPRUCE FOREST HABITAT IN WEST VIRGINIA UNDER SELECT CLIMATE CHANGE SCENARIOS........................ 91

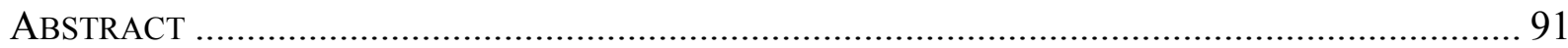

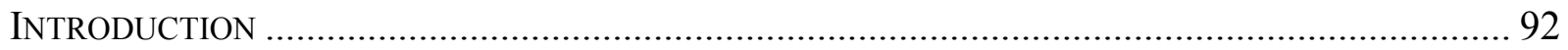




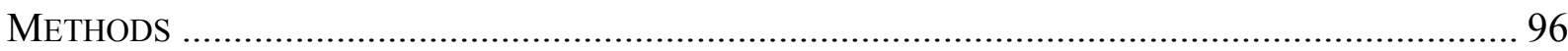

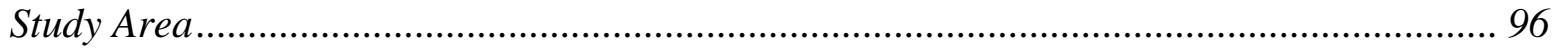

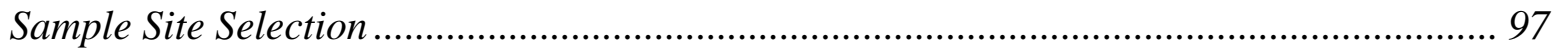

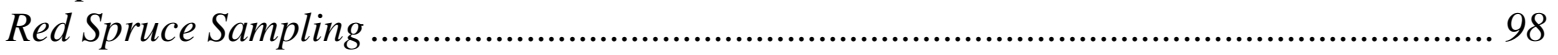

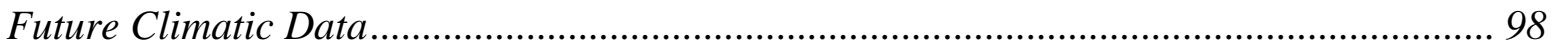

Environmental and Site-specific Variables............................................................. 101

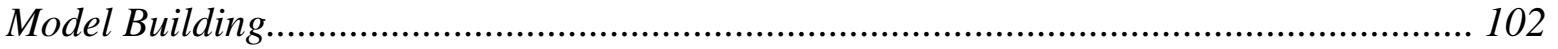

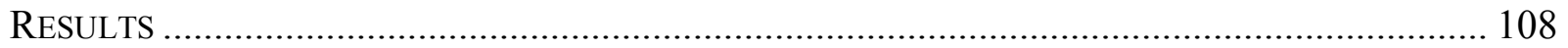

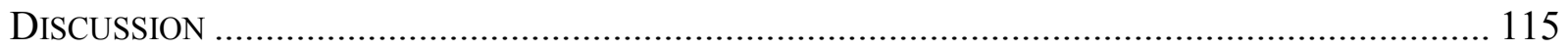

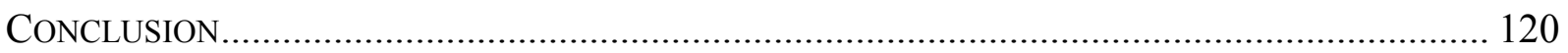

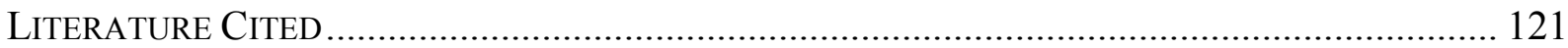




\section{List of Tables}

Table 2.1. Climatic variables calculated using AML (Arc-Info workstation script) from the Worldclim-Global Climate Data website (www.worldclim.org) for the 168 red spruce presence localities.

Table 2.2. Other variables acquired for model building and the range of values associated with the 168 red spruce presence localities.

Table 2.3. Importance value (IV), basal area (BA), and trees per hectare (TPH), and average $\mathrm{DBH}$ for all species or species groups examined.

Table 2.4. Average variable percent contribution for all 10 replicated Maxent analyses........71

Table 2.5. Cumulative and logistic thresholds provided in the Maxent output..................72

Table 2.6. West Virginia area (ha) by county for low, medium, and high suitability for presence of red spruce habitat. .73

Table 3.1. Best estimate and likely range of projected global average surface warming at the end of the $21^{\text {st }}$ Century for all Special Report on Emission Scenarios (SRES) families identified in the IPCC $4^{\text {th }}$ Assessment Summary Report.

Table 3.2. Average values for the 19 bioclimatic variables used for the SRES-A2 scenario with the range of values for all four time steps examined (i.e., Current, 2020, 2050, 2080) using the 168 overstory red spruce presence localities

Table 3.3. Average values for the 19 bioclimatic variables used for the SRES-B2 scenario with the range of values for all four time steps examined (i.e., Current, 2020, $2050,2080)$ using the 168 overstory red spruce presence localities

Table 3.4. Importance value (IV), basal area (BA), and trees per hectare (TPH), and average DBH for all species or species groups examined.

Table 3.5. SRES-A2 Average variable percent contribution for all 10 replicated Maxent analyses.

Table 3.6. SRES-B2 Average variable percent contribution for all 10 replicated Maxent analyses.

Table 3.7. Area (ha) of red spruce habitat suitability modeled using 4 time steps (i.e., Current, 2020, 2050, 2080) under both model scenarios. 


\section{List of Figures}

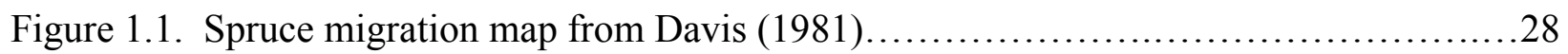

Figure 1.2. Range of red spruce in North America........................................29

Figure 2.1. Field data collected throughout the Appalachian Mountain Region (AMR) of

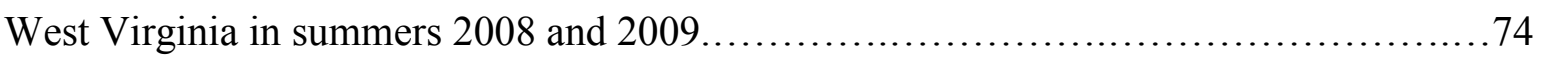

Figure 2.2. Background points generated for our Maxent analysis shown with red spruce

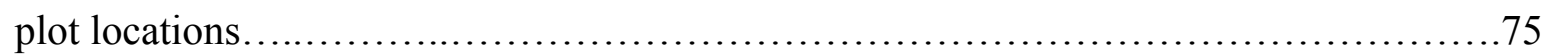

Figure 2.3. Receiver operating characteristic (ROC) curve for current red spruce habitat model, averaged over all ten replicate runs....................................... 76

Figure 2.4. Accuracy assessment of Maxent model showing the training omission rate and predicted area as a function of the cumulative threshold, averaged over the ten replicate runs

Figure 2.5. Jackknife results provided by Maxent, with and without select variables, with respect to training gain, test gain, and AUC values............................ 78

Figure 2.6. Results of training gain, test gain, and AUC values using each variable by itself. .79

Figure 2.7. Graph of maximum temperature of the warmest month (bio_5).................80

Figure 2.8. Graph of minimum temperature of the coldest month (bio_6)...................81

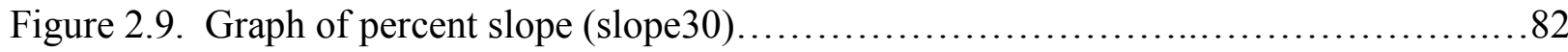

Figure 2.10. Graph of maximum temperature of the warmest month (bio_5).................83

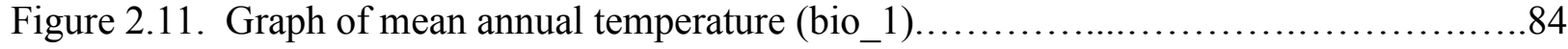

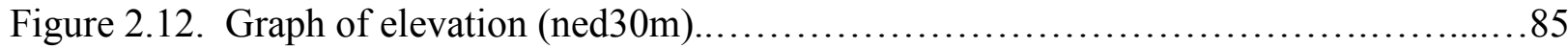

Figure 2.13. Current model results showing suitable and unsuitable habitat for red spruce

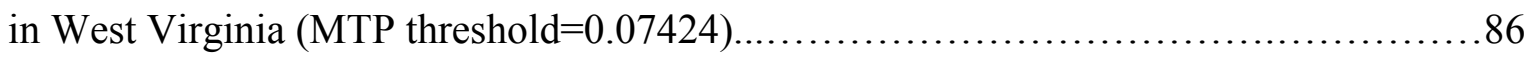

Figure 2.14. Areas modeled having a high probability of suitable red spruce habitat...........87 
Figure 2.15. Areas modeled having a medium probability of suitable red spruce habitat. .88

Figure 2.16. Areas modeled having a low probability of suitable red spruce habitat.

Figure 2.17. Current model results shown at a county level identifying areas of high, medium, and low suitability for red spruce habitat.

Figure 3.1. Field data collected throughout the Appalachian Mountain Region (AMR) of

West Virginia in summers 2008 and 2009.

Figure 3.2. Background points generated for our Maxent analysis shown with red spruce plot locations

Figure 3.3. Scenarios for greenhouse gas emissions (GHG) from 2000 to 2100 in the absence of additional climate policies.

Figure 3.4. Receiver operating characteristic (ROC) curve for the SRES-A2 scenario red spruce habitat model, averaged over all ten replicate runs.... .136

Figure 3.5. Receiver operating characteristic (ROC) curve for the SRES-B2 scenario red spruce habitat model, averaged over all ten replicate runs.

Figure 3.6. Accuracy assessment of the SRES-A2 Maxent model showing the training omission rate and predicted area as a function of the cumulative threshold, averaged over the five replicate runs.

Figure 3.7. Accuracy assessment of the SRES-B2 Maxent model showing the training omission rate and predicted area as a function of the cumulative threshold, averaged over the five replicate runs.

Figure 3.8. Graph of training gain, test gain, and AUC values using each variable by itself for the SRES-A2 model... 140

Figure 3.9. Graph of training gain, test gain, and AUC values using each variable by itself for the SRES-B2 model.

Figure 3.10. Graph of mean temperature of the coldest quarter (bio_11) for the

SRES-A2 model.

Figure 3.11. Graph of mean temperature of the coldest quarter (bio_11) for the

SRES-B2 model. 143 
Figure 3.12. Graph of elevation (ned30m) for the SRES-A2 model....................... 144

Figure 3.13. Graph of elevation (ned30m) for the SRES-B2 model.......................145

Figure 3.14. Graph of minimum temperature of the coldest month (bio_06) for the

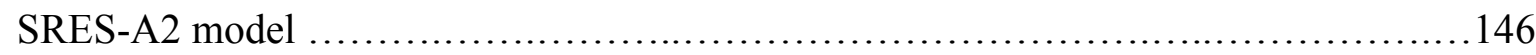

Figure 3.15. Graph of minimum temperature of the coldest month (bio_06) for the SRES-B2 model

Figure 3.16. Areas modeled to possess red spruce habitat by suitability index in West Virginia for all time steps examined for the SRES-A2 model scenario

Figure 3.17. Areas modeled to possess red spruce habitat by suitability index in West Virginia for all time steps examined for the SRES-B2 model scenario....

Figure 3.18. Areas within Pocahontas County, by time steps examined, modeled to possess red spruce habitat by suitability index for the SRES-A2 model scenario...

Figure 3.19. Areas within Pocahontas County, by time steps examined, modeled to possess red spruce habitat by suitability index for the SRES-B2 model scenario. 


\section{Acknowledgments}

I am grateful to many for the completion of my dissertation research. I would like to thank Dr. James Rentch, who served as my major professor for this project, for his countless hours and devotion spent helping me with this modeling research and professional development. I am grateful to my committee members for their helpful comments and assistance on my research project and would also like to especially thank Michael Dougherty of the West Virginia Division of Natural Resources for his necessary assistance in data acquisition and the wealth of knowledge shared with me regarding habitat suitability modeling.

I am indebted to my field assistants Matt Malone and Jon Marden. You both worked diligently and helped me acquire the data necessary for this modeling effort and I thank you greatly. I am also grateful to Joseph McNeel, Director, West Virginia University—Division of Forestry and Natural Resources for making this dissertation research project possible.

I also want to thank my wife, Heather, for her support in all of my endeavors, as well as my family who have been a source of continued encouragement throughout my graduate career. Lastly, I dedicate this dissertation to Eric Sundell and the late Bill Grafton, two mentors in my life that were pivotal in my development as a budding Forest Ecologist. 


\section{THE PRAYER OF THE TREES}

You who pass by and would raise a hand against us, heed well our prayer before you harm us.

We are the fuel for your fires on cold nights, the friendly shade protecting you from the fierce sun and our fruits are refreshments to quench your thirst and cheer you as you journey on.

We are the rafters of your roofs, the bodies of your boats, the seats of your stools and the boards of your beds.

We are the handles of your hoes, the gates of your homes, the wood of your cradles and the shells of your coffins.

We are the saviors of your soil from loss by rain and wind and to your soil we give richness and life for the benefit of all men.

We are the bread of kindness and the flower of beauty. You who pass by, listen to our prayer and harm us not.

*Portugese in origin, author unknown. 
Chapter 1. Literature Review and Justification

\begin{abstract}
For the introductory chapter I provide a literature review on the Quaternary history of red spruce as well as the current distribution of red spruce in the Appalachian Mountain Region. The autoecology of red spruce is discussed, where I examine the growing conditions required for this species' occurrence in West Virginia. Next, an assessment on the impacts of climatic change on terrestrial ecosystems on a regional, national, and global scale is provided. A justification section is also provided which states the purpose and utility of my study as well as the research objectives I have formulated. Lastly, a description of the subsequent chapter format is presented.
\end{abstract}

\title{
Introduction
}

Red spruce (Picea rubens Sarg.) characterizes niche communities at higher elevations throughout the Appalachian Mountain Region (AMR) and is a relict species of the central and southern Appalachians (Audley et al. 1998; Stephenson and Clovis 1983). These high elevation spruce-dominated forests are a remnant ecosystem from the interglacial period of the Wisconsin glaciation and today are considered one of the most threatened forest ecosystems in the eastern United States (White et al. 1993). Trani (2002) estimated that spruce-fir forests in the central and southern AMR have lost approximately $98 \%$ of their presettlement area, while Noss et al. (1995) estimated an 88-90\% loss of red spruce and spruce-fir communities in West Virginia.

In the central AMR, red spruce forests occur primarily in fragmented, island-like distributions among the highest peaks and ridges. The extent of red spruce forests in West Virginia prior to exploitative logging is estimated at 190,000 ha (Clarkson 1964; Millspaugh 1891; Hopkins 1891). Today, these forests are estimated to occupy no more than 24,000 ha, resulting primarily from intense anthropogenic disturbances (Stephenson and Adams 1993).

As a specialist species, with regard to its habitat requirements, red spruce has a greater potential for habitat modeling than species with more general requirements. In West Virginia, 
red spruce is found in areas that possess high-elevation, have a relatively cool climate, and receive high amounts of rainfall and snow. These high-elevation mountainous areas receive as much as $160 \mathrm{~cm}$ of rainfall each year and have an average annual temperature much lower than surrounding areas at lower elevations (Clarkson 1964; Pauley 1989). These areas occur primarily at elevations exceeding $1,000 \mathrm{~m}$. However, red spruce can be found in some areas at elevations as low as 760 m, as found at Cathedral State Park, Preston County (Beane et al. 2010).

The advent of climatic change induced by human activity and the uncertainty of environmental change that will occur in the next century has raised interest in the conservation of threatened ecosystems with limited distributions, such as red spruce forests. The goal of this dissertation research is to model the current distribution of red spruce habitat in West Virginia along suitability gradients using environmental and site-specific variables. In addition, we wish to perform a risk assessment using two hypothesized climate change scenarios to identify how red spruce habitat could potentially change under altered climatic conditions.

\section{Quaternary History of Red Spruce}

The Quaternary period encompasses the past 1.8 million years and is often divided into two epochs: (1) the Pleistocene Epoch, which lasted until 10,000 years ago, and (2) the Holocene Epoch, that extends from 10,000 years ago to present (Delcourt and Delcourt 1988). During the Quaternary period, the Earth experienced progressive cooling with twenty-three known glacialinterglacial cycles occurring (Delcourt and Delcourt 1987). Each glacial-interglacial cycle lasted approximately 100,000 years, of which, roughly 90,000 years were cold, resulting in the formation of continental glaciers at middle and upper latitudes. The remaining 10,000 years were characterized by a markedly warmer climate and are defined as interglacial periods. 
Since the last glacial-interglacial cycle, Watts (1979) identified 18,000 years ago as an important time period. At this time period, the Wisconsin ice sheet was at its greatest extent and the climate was relatively stable. This time period is considered to have varied the most from our present climate. Ocean temperatures were their lowest and the ice sheet had reached its greatest extent in eastern North America. Areas to the south of this large ice mass experienced a climate much dryer and cooler than today (Davis 1981). Then, similar to preceding glaciations, the climate began to warm, melting the ice sheets in a few thousand years. This last interglacial period began approximately 10,000 years ago and is characterized as the Holocene Epoch subdivision of the Quaternary Period.

During the Quaternary period, environmental forces affecting vegetation were primarily driven by climatic change. Although the Wisconsin ice sheet never extended as far south as West Virginia, the vegetation composition and geographic distribution of plants differed greatly from the conditions we observe today (Davis 1981). Bordering the Wisconsin ice sheet was a zone of arctic tundra which extended several hundred kilometers to the south at higher elevations within the central and southern AMR (Watts 1979; Davis1981). At this time, spruce (Picea sp.) was found along the coastal plain with jack pine (Pinus banksiana Lamb.), and as a co-dominant with larch (Larix sp.) in the central plains. Davis (1981) indicated that when the ice sheet was at its maximum, extensive forests of spruce and larch extended westward into many areas which are prairie ecosystems today.

As the Wisconsin ice sheet retreated, spruce rapidly transitioned into areas of treeless tundra, while herbaceous and woody plants of the tundra moved northward into newly exposed areas of glacial till. The rate of migration for spruce is believed to have been $250 \mathrm{~m}$ per year (Davis 1981). This rate of advance was only surpassed by jack and red pine (Pinus resinosa 
Aiton), eastern white pine (Pinus strobus L.), and oak (Quercus sp.), which advanced at rates of 400, 300-350, and $350 \mathrm{~m}$ per year, respectively. Examination of pollen abundance and presence of macrofossils indicate spruce occurred in the central AMR as early as 14,000 years ago (Figure 1.1) (Davis 1981), although these communities likely occurred in warmer, lower elevation areas.

The expansion of red spruce from areas of lower elevation into the higher mountain regions of the central and southern Appalachians took considerable time. It is estimated that nearly 2,000 years lapsed before red spruce occupied the higher elevation regions, placing the initial occurrence of red spruce in the areas it inhabits today around 12,000 years ago (Watts 1979; Davis 1981). Watts (1979) studied a high elevation bog within Cranberry Glades, West Virginia, and found that Cranberry Glades was an area of treeless tundra until the establishment of spruce, pine (Pinus sp.), and fir (Abies sp.), approximately 12,000 years ago. Examination of pollen and plant macrofossils in the upland forests of West Virginia also confirms the proposed history of spruce during the Quaternary period (Davis 1981; Watts 1979). After initial establishment of spruce, pine, and fir, pollen records indicate a dramatic peak in hemlock (Tsuga sp.), occupying as much as 30 percent of the pollen rain. Accompanying hemlock were species of hornbeam/hophornbeam (Carpinus sp. and Ostrya sp.), basswood (Tilia sp.), and butternut (Juglans cinerea L.). Following the establishment of these hardwood species, ash (Fraxinus spp.), beech (Fagus sp.), and American chestnut (Castanea sp.) were also identified (Watts 1979).

This assemblage of species following the initial occurrence of spruce, pine, and fir represented a decidedly mesic forest condition. This mesic forest condition is believed to have occurred from 10,000 years ago until 6,000 years ago; a time period at which the climate of the Holocene Epoch was the warmest. During this time, infrequent pine and spruce pollen indicate 
that these trees migrated to areas of higher elevation in response to climatic warming. However, in the later Holocene period, as the climate again began to cool, spruce and pine contributed significantly to the pollen rain, as well as species of birch (Betula sp.) and sugar maple (Acer saccharum Marsh.). This expansion of spruce back down the mountain from higher regions produced the extensive mixed spruce-hardwood forests encountered by early European settlers.

Pollen analysis and forest reconstruction indicate that the forest types that persisted in West Virginia prior to the extensive removal from European settlers had only been present over roughly the past 10,000 years. Interglacial intervals were previously believed to have occurred over hundreds of thousands of years. However, evidence now suggests that the temperate forest communities present today are chance combinations of species without a persistent evolutionary history (Davis 1981). Species responded individually to glacial retreat and climate change migrating at different rates and by different routes. These findings are important for the understanding of how this ecosystem type has developed and the time necessary for the creation of this unique habitat. Understanding the fact that the forest types of today's temperate regions are believed to have rarely maintained their species composition for more than a few thousand years at a time allows us to develop a more accurate time-scale regarding the evolution of red spruce in the mountainous regions of West Virginia. Lastly, these historical red spruce range contractions identified during periods of climatic warming provide a significant impetus for the careful examination of potential range shifts for red spruce forest habitat in West Virginia; particularly in the face of accelerated climatic change.

\section{Current Red Spruce Distribution in the Appalachian Mountain Region (AMR)}

The native range of red spruce occurs from the Maritime Provinces of Canada into northern portions of New York, extending southward from Massachusetts to eastern 
Pennsylvania, and is found along the highest peaks of the Appalachian Mountain system extending as far south as western North Carolina and eastern Tennessee (Blum 1990) (Figure 1.2). The Appalachian Mountains are often subdivided into northern, central, and southern regions and are easily distinguished by the abundance of particular fir species (Abies sp. Mill.) which may be found there. In the northern AMR, balsam fir (Abies balsamea (L.) Mill.) is commonly found as a co-dominant species with red spruce; however, in the central AMR (approximately $38^{\circ}-42^{\circ} \mathrm{N}$ latitude), balsam fir occurs at significantly lower densities and reaches its southernmost extent. In West Virginia, balsam fir has been identified occurring naturally in only four counties: Grant, Pocahontas, Randolph, and Tucker (Harmon et al. 2006). In the southern AMR, balsam fir is replaced with an endemic species, fraser fir (Abies fraseri (Pursh) Poir.). Fraser fir occurs south of $38^{\circ} \mathrm{N}$ latitude at elevations primarily above 1,350 $\mathrm{m}$, and is often represented as a co-dominant with red spruce (Oosting and Billings 1951; White et al. 1993).

The spruce-fir forests of the northern AMR have a similar appearance to boreal coniferous stands to the north and occur at elevations as low as $152 \mathrm{~m}$ (Oosting and Billings 1951; Stephenson and Clovis 1983). In the central AMR, the spruce-fir forests are less extensive due to the relatively lower elevations of the Allegheny Mountains of Pennsylvania, West Virginia, and Virginia. However, in the southern AMR the spruce-fir forests cover much broader areas, attaining their best development and found among all the highest peaks and ridges, particularly in the Great Smoky Mountains (Oosting and Billings 1951). Cogbill and White (1991) estimated that the spruce/deciduous forest ecotone boundary in West Virginia occurred at an elevation of $1,310 \mathrm{~m}$. Using temperature-based climatic parameters they identified the 
ecotone boundary at a mean annual temperature of $6.4^{\circ} \mathrm{C}$, and January and July mean temperatures of $-4.5^{\circ} \mathrm{C}$ and $17.3^{\circ} \mathrm{C}$, respectively.

\section{History of Logging in West Virginia Red Spruce Forests}

Prior to European settlement, sub-alpine coniferous forests in the central and southern Appalachians were estimated at nearly 607,000 ha, where red spruce occupied approximately $50 \%$ of the overstory (Hopkins 1899; Wahlenberg 1951). The extent of red spruce forests in West Virginia prior to exploitative logging was estimated at 190,000 ha (Clarkson 1964; Millspaugh 1891; Hopkins 1891). The majority of these spruce forests occurred in Pocahontas (89,000 ha), Randolph (56,900 ha), Tucker (20,200 ha), Greenbrier (13,500 ha), and Mineral (10,000 ha) counties (Clarkson 1964; Hopkins 1891). Red spruce occurred to a much lesser extent in Webster, Nicholas, Pendleton, and Preston counties (Clarkson 1964).

With the expansion of railroad systems in West Virginia and the development of the band sawmill and Shay locomotive, the exploitation of timber and pulpwood led to an almost complete removal of West Virginia's red spruce forests (Clarkson 1964). Over a period of 30 years, more than 4,800 km of railroad were laid (Lewis 1998) and 48 band sawmills (Brooks 1910) were constructed to remove and process this timber. The extensive logging practices were generally followed by fire, resulting from the accumulation of slash and logging residues. Today, the extent of spruce forests in West Virginia are estimated to occupy 24,000 ha, which constitutes roughly $10 \%$ of the red spruce in West Virginia prior to logging (Stephenson and Adams 1993).

The exploitation of red spruce was largely due to demands for pulpwood; however, many valuable products were derived from its lumber (Newins 1931). In addition to use of red spruce lumber for constructional utility (i.e., dimensional lumber, plywood, and flakeboard), limited 
amounts were used for boatbuilding and cooperage stock, with some trees sold as pole timber. Interestingly, spruce lumber was also used during World War I by the U.S. Air Service as a wing beam stock in combat airplanes. Newins (1931) noted that following the end of World War I the surplus of this high class lumber, which had been assembled at various West Virginia lumberyards for war purposes, was marked as —-eport stock" and largely shipped abroad.

Red spruce lumber is notably straight-grained and light in color, and therefore is also sought after as a preferred wood for stringed-musical instruments including guitars, mandolins, and violins (Blum 1990). Gibson (1913) adds that red spruce was also used by makers of piano frames for certain parts. The multiple uses of this species` ${ }^{`}$ wood resulted in great demand, leading to the near depletion of this forest type in West Virginia.

By 1920, the original spruce/spruce-hardwood forests of West Virginia were almost completely removed with the exception of a few isolated stands. The total lumber cut in West Virginia between 1870 and 1920 is estimated at more than 30 billion board-feet, and does not take into account the millions of board-feet burned and wasted by pioneers and by fires that followed logging (Clarkson 1964). Steer (1948) estimated a total of 32 million board-feet of red spruce that was logged in West Virginia by 1911. Areas not subjected to intense fire regenerated over time into a forest type much different than the forests that existed prior to logging. In many of the areas which burned, repeated burns followed, consuming any remaining slash and much of the organic material in the soil.

Korstian (1937) examined stand composition on burned and unburned spruce lands on a variety of sites in West Virginia, Tennessee, and North Carolina. Although statistical comparisons were not conducted, a considerably greater amount of red spruce occurred on unburned sites. For example, in two areas that had been cut-over five years earlier, more than 
2,500 red spruce seedlings/small saplings occurred on the unburned site, in comparison to less than 20 red spruce seedlings/small saplings found in the area which had burned.

The red spruce-mixed hardwood forests encountered by early settlers and loggers were primarily the result of small-gap disturbances that affected stand composition and structure through individual tree or small cohort mortality. The large-scale disturbances, which did occur on the landscape level, were most often caused from catastrophic blowdowns or insect outbreaks (Hopkins 1899). Extensive fires in this forest type often followed in areas where large-scale disturbances and extended periods of drought co-occurred (Hopkins 1899).

Following logging the soil quickly dried and fires that did ignite often burned intensely and without resistance. Minckler $(1940 ; 1945)$ noted that fire destroyed the opportunity for spruce regeneration success by consuming the organic material of the predominately shallow soils in which red spruce grew. What soil remained was thereby susceptible to erosion by wind, precipitation, and steep terrain. In fact, some areas were observed where as much as $0.6 \mathrm{~m}$ of organic soil was destroyed or removed (Minckler 1945).

Minckler (1945) also identified three types of vegetative conditions on burned sites in the central and southern AMR: 1) dense herbaceous and shrubby vegetation, 2) young stands of undesirable, brushy hardwoods, and 3) severe rocky sites with very thin soil and sparse vegetation. Sites with dense herbaceous and shrubby vegetation were described as possessing predominantly ferns, weeds, blackberries (Rubus sp.), and low shrubs less than $1.5 \mathrm{~m}$ tall. Areas with undesirable, brushy hardwoods were characterized as having greater than $70 \%$ composition of species such as fire cherry (Prunus pensylvanica L. f.), red maple (Acer rubrum L.), mountain holly (Ilex montana Torr. \& Gray ex A. Gray), etc.; with a varying ground cover density of fern and blackberry. The severe rocky sites with thin soil and sparse vegetation were described as 
areas which burned severely leaving little organic soil. These areas were characterized as having a vegetative density of less than 40 percent. Minckler (1945) also added that many areas in the spruce forest type could readily be planted without special treatment, and characterized these sites as having greater than $75 \%$ vegetation and possessing sufficient soil for good tree growth.

Woody species that regenerated in both burned and unburned areas were primarily yellow birch (Betula alleghaniensis Britton), red maple, black cherry (Prunus serotina Ehrh.), sugar maple (Acer saccharum Marsh.), sweet birch (Betula lenta L.), American beech (Fagus grandifolia Ehrh.), and eastern hemlock (Tsuga canadensis (L.) Carriere) (Korstian 1937). Dependent upon site conditions and prior stand composition, mountain holly, striped maple (Acer pensylvanicum L.), common serviceberry (Amelanchier arborea (Michx. f.) Fernald), and mountain maple (Acer spicatum Lam.) also competed for growing space. In many areas that burned, fire cherry and American mountain ash (Sorbus americana Marsh.) also established and in few areas grew prolifically. These species were readily established in soil which permitted enough space for occupancy and were a hindrance to what red spruce regeneration was available. In these burned areas, red spruce regeneration was only possible if a nearby seed source was present or either advance regeneration or seed had survived fire.

\section{Autoecology of Red Spruce in West Virginia}

Clarkson (1964) noted that in West Virginia red spruce flourished along steep mountain slopes where the bedrock was covered by a dense humus layer and also in poorly-drained plateaus at higher elevations. The virgin spruce forests possessed thick canopies which inhibited sunlight, and contained moist, frigid soils which were typically accompanied by a dense ground cover of bryophytes (Core 1950; Carvell 1993). Frigid soils have a mean annual soil temperature (MAST) which ranges from $1^{\circ}-7^{\circ} \mathrm{C}$, and at $50 \mathrm{~cm}$ below ground, the difference between mean 
summer (June, July, August) and winter (December, January, February) temperatures exceeds $5^{\circ} \mathrm{C}$ (Crews and Wright 2000; Soil Survey Staff 2006). Frigid soils differ from mesic soils, in that the latter has a MAST of $8^{\circ}-15^{\circ} \mathrm{C}$. Frigid soils are associated with northern hardwood and northeastern conifer forest types and have plant community dynamics that vary greatly compared to the eastern and deciduous forest types found on mesic soils (Crews and Wright 2000).

Red spruce is a shade tolerant species and typically develops as advanced growth in shaded understories (Blum 1990; Seymour 1995). Red spruce seedlings are vulnerable to full light conditions, frost, and high temperatures, and therefore are dependent upon an understory microclimate which minimizes these conditions (Prevost 2008). These microclimates are mitigated in stands that possess gap-phase dynamics as their primary disturbance regime.

Gap-phase dynamics is a forest succession pattern that is driven by the death of one or a few overstory trees, creating a small disturbance in the canopy. This disturbance allows a small, single-cohort stand to develop from advance regeneration present in the understory (Oliver and Larson 1996). This disturbance regime is easily recognized within old-growth stands and is advantageous for species with higher shade tolerance and slower growth rates, such as red spruce.

White et al. (1985) examined the natural disturbance and gap-phase dynamics of sprucefir forests in the southern Appalachians and hypothesized that spruce-fir disturbance patterns were driven by spatially small gaps (mean canopy gap size $=66 \mathrm{~m}^{2}$ ) which dominated natural patch dynamics, compared to a successional pattern dependent upon fire. Fire is less important in the spruce-fir forest type because fuel moisture and humidity are often high, and rainfall often accompanies lightning storms, making ignitions unlikely. Gorman (2005) noted that natural fires 
in the southeastern spruce-fir forest type are rare and estimated the return interval at 500 years; with resulting burns being severe and affecting large areas.

Other disturbances such as insect attack and disease, wind-throw, and ice storms are considered to play a more important role in the patterns of succession within spruce forest types. Rentch et al. (2010) found that standing snags resulting from beech-bark disease mortality were the most common form of tree death in second-growth northern hardwood stands that had a small red spruce component. Gorman (2005) indicated that extreme wind events (i.e., large blowdowns) occur more frequently than fire, recurring on a 100-200 year interval, and indicated the importance of extreme weather events in the succession of red spruce forests. White et al. (1985) identified wind as the most important kind of disturbance, with two types recognized: large blowdowns $\left(>200 \mathrm{~m}^{2}\right)$ and smaller windfall gaps $\left(<200 \mathrm{~m}^{2}\right)$. They found that smaller windfall gaps were the most important and widely distributed disturbance in their study area of the Great Smoky Mountains.

White et al. (1985) also identified red spruce occurring in denser patches within gaps compared to forest shade (i.e., 2.5 to 1), although birch (Betula sp. L.) was found more prevalently (i.e., 20 to 1 ). This strong competition by birch was only countered by the greater survivorship of red spruce (i.e., red spruce was the longest lived species in the study and yielded the highest mean number of years prior to growth release). This adaptive trait of red spruce to maintain its persistence in the understory is the primary advantage used to successfully compete with birch and other faster growing hardwood species. White et al. (1985) added that all species examined had seedling or saplings in gaps and that regeneration of the stand was dependent upon the probabilistic competition between advanced regeneration present and the gap exploiting species. Lastly, they concluded that growth rates in the shade suggested that all species required 
gaps to reach canopy position and that red spruce and Fraser fir required multiple release events to attain canopy status. In an examination of West Virginia red spruce/northern hardwood stands, Rentch et al. (2010) estimated that over $40 \%$ of the existing small canopy gaps where red spruce was present would be eventually captured by understory red spruce; however, because of the speed of gap closure from above, most red spruce would require more than one overhead release.

Spruce-fir forests are considered a late-successional community, with development patterns generally associated with extensive partial disturbances that kill mainly large, old trees, and release growing space for species within lower strata (Seymour 1995). As these stands mature, trees become larger as do crown sizes, creating larger canopy gaps (Rentch et al. 2007). These larger gaps have increased likelihood to be filled by in-growth rather than lateral crown expansion. These traits are typical of forests within the understory reinitiation or old-growth stages of stand development because of the large, older trees present and the patterns of succession that are taking place, such as the individual mortality of large, older trees.

Red spruce, being more shade tolerant and long-lived than most of its competitors, has the ability to respond to release even after enduring over a century of suppression (Blum 1990; Seymour 1995). This pattern of succession has great implications regarding its success against faster growing hardwood species. In addition, its longevity plays an important role in comparison to other similar species such as Fraser and balsam fir. Its ability to maintain its suppressed condition until a large enough canopy gap has been created has allowed this species to maintain its existence in areas of low human impact at typically higher elevations, as well as to initiate and persist in areas dominated by northern hardwoods. Seymour (1995) indicated that historical evidence, including analysis of surveyors ' records and descriptive studies of old- 
growth stands, suggests that this disturbance regime maintained a presettlement landscape dominated by multi-aged stands.

\section{Current Distribution of Red Spruce Forests in West Virginia}

The upland forests of West Virginia (i.e., elevations exceeding $915 \mathrm{~m}$ ) comprise two distinct physiographic regions that possess red spruce forest communities: the Allegheny Mountain section and the Ridge and Valley section (Strausbaugh and Core 1964; Stephenson 1993). These two physiographic regions differ in both geography and climate and therefore vary greatly in regard to forest vegetation. The ridges of the Allegheny Mountain section consist primarily of Paleozoic sandstones and conglomerates, with underlying rocks of the valleys composed primarily of shale and limestone (Stephenson 1993; Stephenson and Clovis 1983). The Ridge and Valley region, as its name suggests, consists of lowland areas surrounded by many parallel longitudinal ridges. This region is characterized by extensively folded and thrustfaulted Paleozoic strata composed of resistant quartzite, conglomerates, and sandstone on ridges. However, the valleys are composed mostly of less resistant shale and limestone which have eroded over time creating the intervening valleys throughout this region (Stephenson 1993).

The highest elevation zones within these two regions comprise part of NatureServe's Central and Southern Appalachian Spruce-Fir Forest Ecological System and provide habitat for the majority of red spruce in West Virginia (Comer et al. 2003; Byers et al. 2010). Within this ecological system, red spruce occurs primarily within the Allegheny Mountain section and to a much lesser extent in the Ridge and Valley region. This is due primarily to the climate of this region, which is much drier than its neighboring Allegheny Mountain section to the west. The western boundary of the Ridge and Valley region is the Allegheny Front Mountain, and is therefore subjected to a rain-shadow" effect in which a marked difference occurs between the 
amounts of precipitation in these two regions (Clarkson et al. 1980). Indeed, Strausbaugh and Core (1964) identified as much as $213 \mathrm{~cm}$ per year in the Allegheny Mountain section in comparison to as little as $64 \mathrm{~cm}$ in the Ridge and Valley region. In addition, annual differences in snowfall may vary from $480 \mathrm{~cm}$ at Pickens, Randolph County (Allegheny Mountain section), compared to $127 \mathrm{~cm}$ at Moorefield, Hardy County (Ridge and Valley section), as recorded in 1961; a distance of merely $129 \mathrm{~km}$ apart (Strausbaugh and Core 1964).

Red spruce is the most characteristic species of the subalpine coniferous forest in West Virginia and occurs at higher elevations which offer abundant rainfall and a relatively cool climate (Strausbaugh and Core 1964). In the Ridge and Valley region, the limited amount of red spruce forests that occur are primarily situated along North Fork Mountain, where elevations often exceed 1,219 m. However, in the Allegheny Mountain section, red spruce occurs along many of the higher ridges and may also be found along slopes and valleys that offer protection from sun and wind exposure (Baldwin 1933; Stephenson 1993).

The current red spruce forests in West Virginia are second- or third-growth stands, and are the result of widespread cutting and subsequent fire. Rentch et al. (2010) described the result of these disturbances as producing a homogenous landscape where even-aged northern hardwood species established and replaced the multi-aged forests which were once dominated by red spruce. Perhaps the finest living example of the multi-cohort, complex red spruce community may be seen at Gaudineer Knob, a 57 ha scenic area bordering Randolph and Pocahontas counties. Gaudineer Knob is an old-growth red spruce and northern hardwood stand that was spared from the widespread turn of the century logging and serves as a legacy of the unique red spruce forest communities that once occurred to a much larger extent in West Virginia. 
Heitzman et al. (2010) found 400 year old red spruce cohorts in this stand, with abundant regeneration in small and large canopy gaps.

The tree composition among red spruce stands in West Virginia may vary from nearly pure stands of red spruce with little to no woody species diversity to red spruce communities with numerous associate tree and shrub species. Stephenson and Clovis (1983), in an examination of overstory tree stratum (diameter at breast height $(\mathrm{DBH})$ greater than $10 \mathrm{~cm})$ of eight spruce stands in West Virginia, identified 16 species occurring in association with red spruce. Of these, the most common species were yellow birch, red maple, eastern hemlock, American beech, sweet birch, and black cherry.

While overstory and understory tree diversity can often be quite variable, the herbaceous and shrub layers within spruce stands are often poorly developed or absent (Strausbaugh and Core 1964; Stephenson 1993). Shrub species most commonly associated with red spruce are mountain holly, hobblebush (Viburnum lantanoides Michx.), great laurel (Rhododendron maximum L.), and mountain laurel (Kalmia latifolia L.) (Stephenson 1993). In the herbaceous layer, Strausbaugh and Core (1964) noted mountain woodsorrel (Oxalis montana Raf.) as nearly the only flowering herbaceous plant, while Stephenson (1993) identified species of bluebead (Clintonia borealis (Aiton) Raf.), Canada mayflower (Maianthemum canadense Desf.), and painted trillium (Trillium undulatum Willd.).

Accompanying the relatively few herbaceous flowering plants are often thick carpets of mosses, primarily hypnum mosses (Hypnum sp.) and hylocomium feather mosses (Hylocomium sp.), and dense populations of ferns which often occupy more than $50 \%$ of the herbaceous cover (Stephenson and Clovis 1983). Intermediate wood fern (Dryopteris intermedia (Muhl. ex Willd.) A. Gray), spinulose woodfern (Dryopteris carthusiana (Vill.) H.P. Fuchs), eastern 
hayscented fern (Dennstaedtia punctiloba (Michx.) T. Moore), and rock polypody (Polypodium virginianum L.) are the most commonly encountered (Stephenson 1993). Due to the humid atmosphere of this forest type, lichens are often present, covering the branches and boles of trees. Lichens of the genera Usnea (beard lichens) and Alectoria (witch's hair lichens) are considered among the most common (Strausbaugh and Core 1964). In addition, Carvell (1993) listed three species of liverworts characteristic of upland forests: common bazzania (Bazzania trilobata (L.) A. Gray), frullania (Frullania eboracensis Gottsche), and cone-headed liverwort (Conocephalum conicum (L.) Dumort).

\section{Impacts of Climatic Change on Terrestrial Ecosystems}

Climate plays a vital role in the natural distribution of plants. Climate may be defined as the patterns, means, and extremes of weather (i.e., local atmospheric conditions over a short term) over an extended period of time, typically decades or longer (Barnes et al. 1998; IPCC-AR4 2007). Microclimate (i.e., local variation in climate) influences the spatial patterning of species distributions, with both natural and anthropogenic changes in climate potentially altering the distribution of tree species and their associated productivity (Barnes et al. 1988). Both historical (e.g., Davis 1981; Delcourt \& Delcourt 1987; Johnson et al. 1988) and recent studies (e.g., McKenney-Easterling et al. 2000; Walther et al. 2002; Kelly \& Goulden 2008; Woodall et al. 2009) have identified trends between climate and species distribution patterns, involving both range expansion and contraction. Since the pre-industrial era, the earth's climate system has changed dramatically, with anthropogenic activity identified as the primary causal agent (Griggs and Noguer 2002; Knapp et al. 2008). In fact, recent greenhouse gas emissions (GHG) have exceeded the latest Intergovernmental Panel on Climate Change (IPCC) Special Report on Emissions Scenarios (SRES) released in 2007, and thus global average temperatures are 
expected to exceed the $1.5^{\circ} \mathrm{C}$ lower limit cited in the IPCC $4^{\text {th }}$ Assessment Report (Huntley et al. 2010). If this $1.5^{\circ} \mathrm{C}$ lower limit is exceeded, IPCC-AR (2007) project major changes in ecosystem structure and shifts in species' geographical ranges.

The Intergovernmental Panel on Climate Change (IPCC) has confirmed that consistent warming of both land and ocean surface temperatures have occurred over the $20^{\text {th }}$ century. During the past 50 years, temperatures are believed to have been higher than during any 50 -year period over the last 1,300 years (Dokken et al. 2002). Research indicates a $0.6^{\circ} \mathrm{C}$ increase in global mean surface temperature over the past 100 years, with a $0.27^{\circ} \mathrm{C}$ increase indentified in the last two decades (Dokken et al. 2002; IPCC 2007). Indeed, global surface air temperatures in 1998 and 2005 served as the warmest years on record since 1850, with the 1990's considered the warmest decade (Dokken et al. 2002).

The IPCC Synthesis Report showed strong evidence that recent global warming is strongly affecting terrestrial biological systems, including earlier timing of spring events (e.g., leaf unfolding) and poleward and upward shifts in plant distributions (IPCC 2007). Since the pre-industrial era, human activities have caused unprecedented changes in the global physical and chemical environment, including increased atmospheric carbon dioxide $\left(\mathrm{CO}_{2}\right)$ concentrations and mean annual temperature (Griggs and Noguer 2002; Knapp et al. 2008). These climatic changes will have direct impacts on plant distributions worldwide, affecting plant growth and physiology as increased atmospheric $\mathrm{CO}_{2}$ and other trace gases result in greenhouse warming (Birdsey 1997).

In North America, many plants species have been modeled under various climate change scenarios, with significant range shifts in their distributions predicted (e.g., Iverson and Prasad 2001; Iverson et al. 2008). However, few studies have identified plant distribution shifts already 
occurring due to climate change. These studies are limited primarily in that long-term studies are not available. Most short-term studies which identify local changes are not necessarily caused by climate change, but may be driven by changes in land-use and/or natural fluctuations in species abundance and distribution (Parmesan and Yohe 2003). Studies that identify current plant distribution shifts induced by climate change are therefore of great importance.

Bradley et al. (1999) examined phenological changes in springtime events over a 61-year period in Wisconsin. Regarding plant distributions, they examined 36 phenophases (i.e., seasonal biological events), with 10 species blooming significantly $(\alpha=0.05)$ earlier over the study period and none flowering significantly later. There was also a trend toward earlier flowering in an additional 15 plants, with 11 species showing nonsignificant trends toward later flowering. Species examined with significantly earlier blooming included: hepatica (Hepatica acutiloba), forest phlox (Phlox divaricata), columbine (Aquilegia candensis), shooting star (Dodecatheon media), Canadian anemone (Anemone canadensis), baptisia (Baptisia leucantha), rudbeckia (Rudbeckia hirta), butterfly weed (Asclepias tuberosa), common milkweed (Asclepias syriaca), and marsh milkweed (Asclepias incarnata). These earlier blooming times were recognized as a response to climatic warming and suggested that some organisms may be more readily adapted to changing their seasonal progressions in response to climatic changes (Bradley et al. 1999).

Barber et al. (2000) found reduced growth of Alaskan white spruce (Picea glauca (Moench) Voss) in the twentieth century from temperature-induced drought stress in interior Alaska. Their study documented a strong and consistent relationship over the past 90 years of decreased radial growth with increasing temperature. They showed that temperature-induced drought stress had disproportionately affected the most rapidly growing white spruce, and that 
under recent climatic warming, drought may have played a major role in limiting carbon uptake. These findings indicate that the future capacity of North American boreal forests to sequester carbon may be less than currently expected.

While the potential impacts of climate change on terrestrial ecosystems are not fully understood, northern and upslope migration pathways have been predicted for many plant species; particularly montane and alpine plants (e.g., Grabherr et al. 1994; Breshears et al. 2008; Hughes 2000; Dokken et al. 2002; Dullinger et al. 2004; Walther et al. 2005; Danby \& Hik 2007; Iverson et al. 2008; Kelly and Goulden 2008). Kelly and Goulden (2008) examined two vegetation surveys collected in 1977 and 2006-2007 to determine whether the distribution of plants in Southern California's Santa Rosa Mountains had shifted in elevation in response to recent climate change. In their study, ten plant species occurring at three or more elevations were analyzed and their findings indicated that individual species distributions changed markedly, with nine of the ten species gaining an average $64.7 \mathrm{~m}$ in elevation. Interestingly, their species distribution results did not vary by plant community type, with mean elevation of desert, chaparral, and montane plants all increasing at approximately the same rate. Because these vegetation responses were uniformly distributed among elevations, climate zones, and plant community types, these results provide striking evidence that the observed changes are attributable to climate.

In response to global warming, the hydrologic cycle is also expected to change, with larger rainfall events and longer intervals between events (IPCC 2007; Knapp et al. 2008; Woodall et al. 2009). Additionally, increased cloudiness, latent heat fluxes, and more frequent climate extremes are predicted (Knapp et al. 2008). The mid- and high-latitudes of the Northern Hemisphere have experienced the largest increases in temperature, with precipitation considered 
to have increased by $5-10 \%$ (Dokken et al. 2002). With amplification of the hydrological cycle, increased risk of drought and heat waves are predicted due to the longer intervals between events. An increased probability of intense precipitation and flooding events are also expected due to the larger individual rainfall events that have been predicted (Knapp et al. 2008).

In addition, ecosystems worldwide will likely be exposed to atmospheric carbon dioxide $\left(\mathrm{CO}_{2}\right)$ levels higher than recorded for the past 650,000 years (Parry et al. 2007). Model projections forecast Earth's mean surface temperature to increase by $1.4-5.8^{\circ} \mathrm{C}$ by the end of the $21^{\text {st }}$ Century (Dokken et al. 2002). These climatic changes will have direct impacts on tree growth and physiology, as increased atmospheric $\mathrm{CO}_{2}$ (and other trace gases) results in greenhouse warming (Birdsey 1997).

Using Forest Inventory and Analysis (FIA) data across 30 states of the eastern U.S., Woodall et al. (2009) examined tree migration patterns using current geographic distributions of tree seedlings $(\mathrm{DBH} \leq 2.5 \mathrm{~cm})$ and biomass $(\mathrm{DBH}>2.5 \mathrm{~cm})$. This comparison was a novel approach to assessing tree migration rates because long-term forest inventory datasets are limited. Their findings showed that northern species were exhibiting a northward migration, with over $70 \%$ of the study's northern species having mean locations of seedlings significantly farther north compared to their respective biomass. Results of their study showed a mean change in latitude $>20 \mathrm{~km}$ northward for seedlings compared to biomass for northern species. Southern species exhibited no significant shift northward despite greater regeneration in northern latitudes. Interestingly, generalist species exhibited an expansion southward indicating their ability to adapt to climate change more readily than specialist species.

Finally, Woodall et al. (2009) identified that given the current regeneration trends that tree migration may accelerate in the near future, with rates of up to $100 \mathrm{~km}$ per century for many 
northern species. Although the authors indicated that many caveats existed with their study, these stark findings indicated that plant distribution changes in North America are currently underway. Further research in these areas is warranted in order to fully understand the impact of climate change on tree distributions in North America.

Other studies have measured ecological changes attributed to climate change for various fauna, including amphibians, reptiles, insects, birds, and mammals (e.g., Hersteinsson and MacDonald 1992; Parmesan 1996; McCarty 2001; Walther et al. 2002; Rodenhouse et al. 2008). Hersteinsson and MacDonald (1992) revealed a northward range expansion of red fox (Vulpes vulpes L.) attributable to climate change, resulting in a simultaneous retreat of Arctic fox (Alopex lagopus L.) due to interspecific competition. Parmesan (1996) censused populations of Edith`s checkerspot butterfly (Euphydryas editha Boisduval) throughout its range in the western U.S., finding significant latitudinal and elevational shifts in the species' range. Clines in species range for Edith's checkerspot butterfly were also identified at sites undegraded by human activity, suggesting climate change as the cause of the observed shift. At the time of this study, it represented the clearest indication that global climate change was already beginning to influence species` distributions.

Ecological consequences of recent climate change have also been identified for reptiles and amphibians (Janzen 1994; Beebee 1995). Beebee (1995) examined breeding cycles of three native anurans in Europe with observations suggestive that amphibian reproductive cycles in temperate regions may respond sensitively to climate change. These findings identified all three anuran species exhibiting dramatic and significant trends toward earlier spawning over 17 years of observation; with two species exhibiting average times of first spawning in the most recent 5 years (i.e., 1990-1994) two to three weeks earlier than in the first 5 years (i.e., 1978-1982). 
Following the study by Beebee (1995), Blaustein et al. (2001) examined amphibian breeding in North America with results suggesting that climate change had not influenced timing of breeding. Blaustein et al. (2001) results indicated that findings by Beebee (1995), of amphibians breeding earlier in temperate regions, may be premature. They added, however, that changes in ambient temperature may influence amphibian behavior, including reproduction. Although the reason some amphibian populations show trends toward earlier breeding and others do not is unknown, they serve as useful biological indicators for climate studies because they are cold-blooded (i.e., ectotherms) and are therefore sensitive to alterations in climate (Beebee 1995; Blaustein et al. 2001).

Janzen (1994) monitored 390 nests of painted turtles (Chrysemys picta Emydidae) in Illinois, a species that exhibits temperature-dependent sex determination. Janzen's study identified the annual offspring sex ratio of the painted turtle to be highly correlated with mean July air temperatures, and indicated that even modest increases in mean temperature, as little as $2^{\circ} \mathrm{C}$, could drastically skew the sex ratio of this species. With predictions of a $4^{\circ} \mathrm{C}$ rise in mean July temperature over the next 100 years, Janzen (1994) speculated that eventual extinction may result because no males will be produced.

Rodenhouse et al. (2008) examined the potential effects of climate change on birds of the Northeast U.S. Under all climate change scenarios examined, their results indicated that many avian species, including neotropical migrants, are projected to decline significantly. To assess the impact of climate change on high-elevation forest birds, Rodenhouse et al. (2008) conducted a modeling effort for Bicknell's thrush (Catharus bicknelli Ridgway), a species known to breed in high-elevation spruce-fir forest of the Northeast. To project the effects of climate change on Bicknell's thrush, mean July temperature was modeled in the mountainous regions of New York 
and northern New England, and a temperature range that corresponded to the species ${ }^{6}$ current distribution was identified. By simulating warming in $1^{\circ} \mathrm{C}$ increments, their findings indicated that a regional warming of even $1{ }^{\circ} \mathrm{C}$ would reduce the potential habitat of Bicknell's thrush by more than $50 \%$, with an increase in $2^{\circ} \mathrm{C}$ possibly sufficient to eliminate all breeding sites occurring in the Catskill Mountains of New York and Vermont. With a regional warming of $6^{\circ} \mathrm{C}$, no habitat for the Bicknell's thrush was projected to exist in the Northeast.

The adaptation of forest communities to extreme environmental change will depend upon the rate of change and barriers that impede or prevent successful migration. Species considered vulnerable or at risk of extinction are those with limited climatic ranges and restricted habitat requirements (Dokken et al. 2002; Schwartz et al. 2006). Birdsey (1997) identified trees growing near their ecological limit as a characteristic of vulnerable forest ecosystems; with highelevation red spruce in the Northeast U.S. considered a primary ecosystem at risk.

In West Virginia, habitat fragmentation and land-use will likely restrict the ability of red spruce to adapt to climatic change. With its current range restricted to fragmented, island-like localities, red spruce is geographically isolated among the highest peaks and ridges and lacks the connectivity needed to successfully advance northward with rapid climatic change. It is, however, important to note that the majority of red spruce occurs on public land in West Virginia. The majority of red spruce occurs on the Monongahela National Forest (MNF), and is protected from extensive cutting practices and unguided management. The MNF has, within their Land and Resource Management plan, performed a management prescription specifically focused on spruce and spruce hardwood ecosystem restoration. The prescription area comprises a total of 62,000 ha to be used for active and passive restoration (USDA 2006). 
In addition, the MNF also offers the potential for restoration efforts to be implemented in areas surrounded by red spruce dominated stands (i.e., core habitat); an advantage not always possible on private lands. With the majority of red spruce occurring on public land, this further stresses the importance of understanding and interpreting the potential impacts that climate change will have on red spruce forests in West Virginia, and also indicates the need to identify optimal areas in which red spruce regeneration efforts should be concentrated.

\section{Justification}

The objective of my research is to use environmental and site-specific variables to model the current and future distribution of red spruce forest habitat in West Virginia. Environmental variables used for modeling included topographic, climatic, and edaphic data. Specifically, I wished to model current red spruce habitat along abundance gradients of low, medium, and high predicted suitability. Finally, I wished to perform a risk assessment using hypothesized climate change scenarios derived from statistically-downscaled global climate models (GCM`s). This assessment was done by manipulating the climatic variables of my models to simulate predicted changes in climate.

This analysis allowed me to model the future potential distribution of red spruce forest habitat in West Virginia, identifying areas where red spruce would likely occur under various climate change scenarios. Modeling current distribution will benefit restoration efforts by identifying areas that possess the habitat-specific requirements for red spruce but lack its presence, as well as to define what independent variables examined are useful for identifying suitable red spruce forest habitat on the landscape. Modeling future potential distribution will serve to identify areas that would possess the habitat-specific requirements of red spruce under 
an altered climate regime. To assess these research goals the following objectives were formulated:

1. Model current red spruce habitat in West Virginia using maximum entropy (Maxent) statistical analyses. Model variables to be incorporated are site-specific and environmental data including topographic, climatic, and edaphic data. Using modeled areas, create habitat suitability maps showing high, medium, and low suitability for red spruce habitat.

2. Model potential future red spruce habitat in West Virginia under hypothesized climate change scenarios using Maxent statistical analyses and statistically downscaled projected climate scenarios. Using future potential distribution model results, create potential future distribution habitat maps for red spruce at three select 30-year time intervals: 2020, 2050, and 2080.

\section{Subsequent Chapter Format}

The following chapters are formatted for general peer-reviewed journal submission. Therefore, each chapter will contain the following sections: abstract, introduction, methods, results, discussion, and conclusion. Due to this format selection and the use of the same study area for the current and future red spruce habitat model, the introduction and methodology sections will be similar.

Chapter 2 will focus on the current red spruce distribution model using 32 environmental and site-specific variables, taking into consideration the habitat assessment at the county level for demarcating areas of low, medium, and high suitability for red spruce habitat. Chapter 3 will describe the data and analysis methods for our climate change simulation models. This chapter will focus on the state-wide potential shifts of suitable red spruce habitat in West Virginia using 
varying climatic change scenarios over three select 30 -year time intervals. Our future scenario models will incorporate 24 independent variables. These 24 variables will include 19 bioclimatic variables with expected future change by scenario as well as five site-specific variables that are believed to be constant over the time period modeled that could potentially be useful in identifying suitable red spruce habitat suitability. 


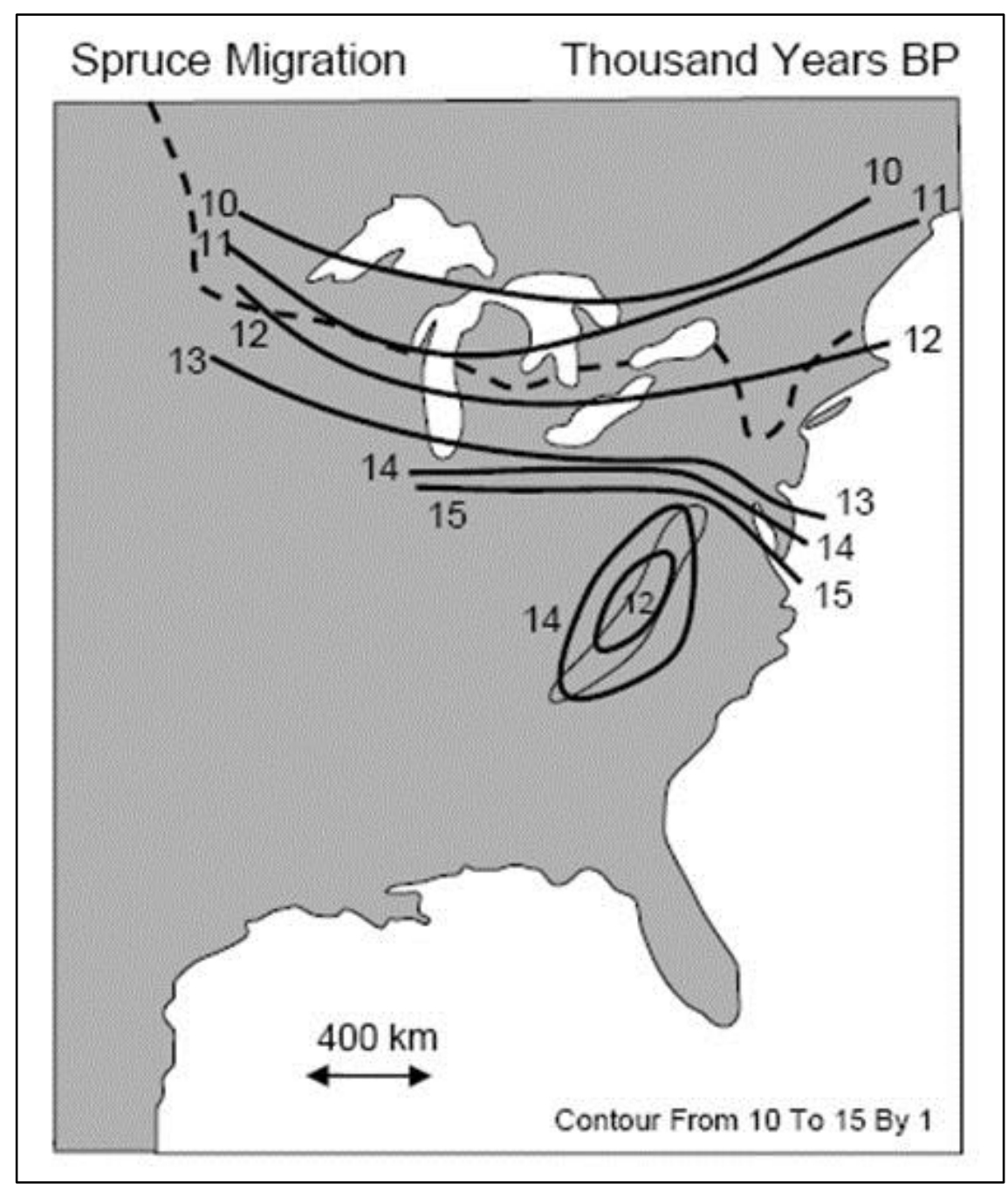

Figure 1.1. Spruce migration map from Davis (1981). 


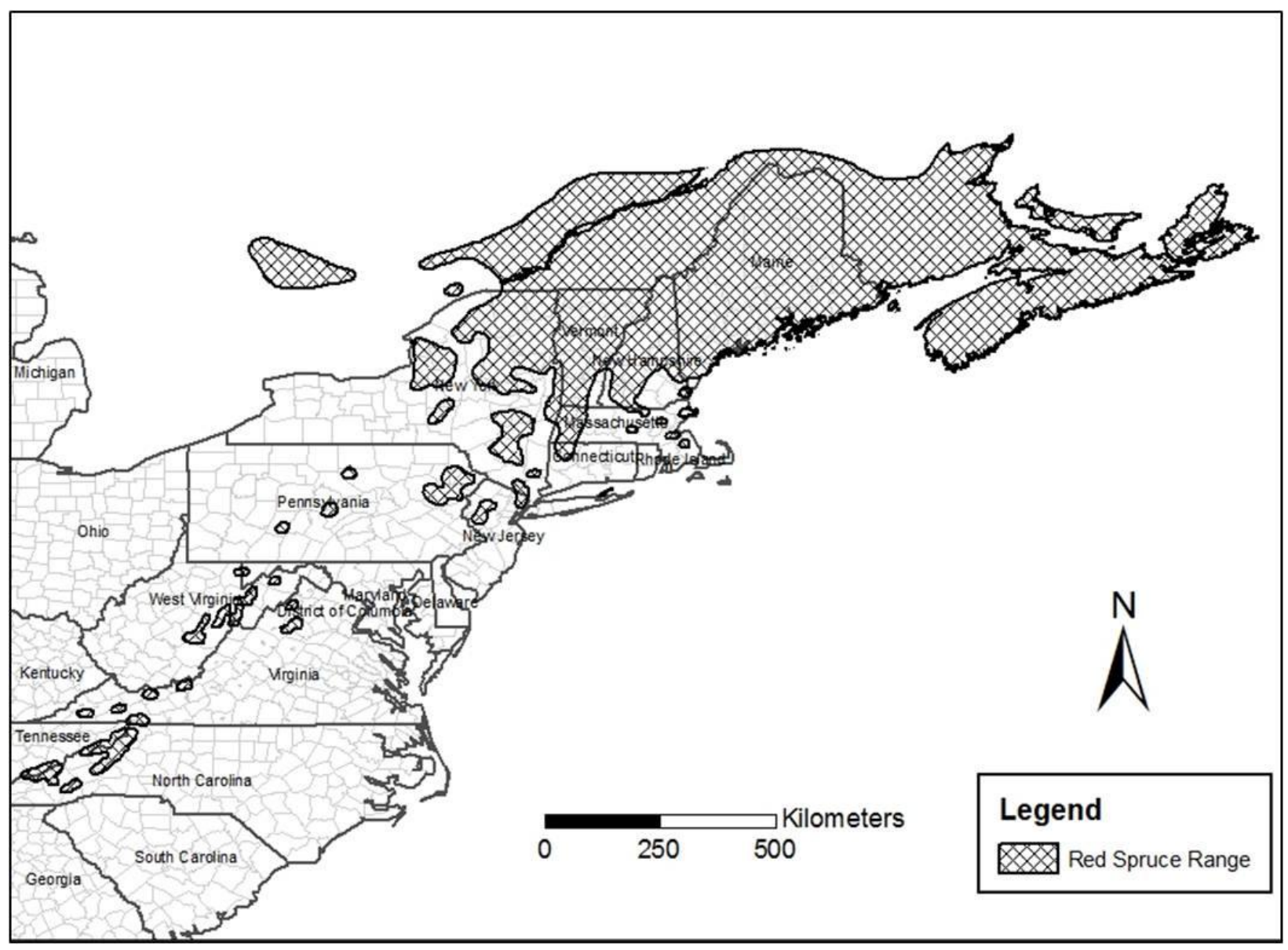

Figure 1.2. Range of red spruce in North America (USGS 1999). 


\section{Literature Cited}

Audley, D.E., J.M. Skelly, L.H. McCormick, and W.A. Jackson. 1998. Crown condition and nutrient status of red spruce (Picea rubens Sarg.) in West Virginia. Water, Air, and Soil Pollution 102:177-199.

Baldwin, H.I. 1933. The density of spruce and fir reproduction related to the direction of exposure. Ecology 14(2):152-156.

Barber, V.A., G.P. Juday, and B.P. Finney. 2000. Reduced growth of Alaskan white spruce in the twentieth century from temperature-induced drought stress. Nature 405:658-673.

Barnes, B.V., D.R. Zak, S.R. Denton, and S.H. Spurr. 1998. Forest Ecology. Fourth edition. John Wiley and Sons, Inc. New York. 774p.

Beane, N.R., Heitzman, E., and T.M. Schuler. 2010. Stand dynamics of an old-growth hemlock -hardwood forest in West Virginia. Natural Areas Journal 30(1):64-72.

Beebee, T.J.C. 1995. Amphibian breeding and climate. Nature 374:219-220.

Birdsey, R. 1997. Potential Impacts of Climate Change on Forest Resources in New England. Pages 88-92 In: New England Regional Climate Change Impacts Workshop: Workshop Summary Report, Fithian, J., Hart, D., Kustra, C., and Spencer, S. (eds.). Institute for the Study of Earth, Oceans, and Space, University of New Hampshire, Durham, New Hampshire.

Blaustein, A.R., L.K. Belden, D.H. Olson, D.M. Green, T.L. Root, and J.M. Kiesecker. 2001. Amphibian breeding and climate change. Conservation Biology 15(6):1804-1809.

Blum, B.M. 1990. Red spruce, Picea rubens Sarg. Pages 250-259 In: R.M. Burns and B.H. Honkala, technical editors. Silvics of North America. Vol. 1. Conifers. USDA Forest Service Agricultural Handbook 654, Washington D.C.

Bradley, N.L., A.C. Leopold, J. Ross, and W. Huffaker. 1999. Phenological changes reflect climate change in Wisconsin. Proc. Natl. Acad. Sci. 96:9701-9704.

Breshears, D.D., T.E. Huxman, H.D. Adams, C.B. Zou, and J.E. Davison. 2008. Vegetation synchronously leans upslope as climate warms. PNAS 105(33):11591-11592.

Brooks, A.B. 1910. Forestry and wood industries. Acme Publishing Company, Morgantown., WV. pp. 481.

Byers, E.A., Vanderhorst, J.P., and B.P. Streets. 2010. Classification and conservation assessment of upland red spruce communities in West Virginia. WV Natural Heritage Program, WVDNR, Elkins, WV, 68p. 
Carvell, K.L. 1993. Bryophytes and their ecological role in the upland forests. Pp. 87-100. In Upland forests of West Virginia. Stephenson, S.L., (ed.). McClain Printing Co., Parsons, West Virginia.

Clarkson, R.B. 1964. Tumult on the Mountains. McCain Printing Co., Parsons, West Virginia.

Clarkson, R.B., W.H. Duppstadt, and R.L. Guthrie. 1980. Forest wildlife plants of the Monongahela National Forest. Boxwood Press, Pacific Grove, CA. 283 p.

Cogbill, C.V., and P.S. White. 1991. The latitude-elevation relationship for spruce-fir forest and treeline along the Appalachian mountain chain. Vegetatio 94:153-175.

Comer, P., Faber-Langendoen, D., Evans, R. Gawler, S., Josse, C., Kittel, G., Menard, S., Payne, M., Reid, M., Schulz, K., Snow, K., and J. Teague. 2003. Ecological systems of the United States: A working classification of U.S. terrestrial systems. NatureServe, Arlington, VA.

Core, E.L. 1950. Notes on the plant geography of West Virginia. Castanea 15(2):61-79.

Crews, J.T., and L. Wright. 2000. Temperature and soil moisture regimes in and adjacent to the Fernow Experimental Forest. U.S, Department of Agriculture, Forest Service, Northeastern Research Station, Newtown Square, PA, Research Paper NE-713.

Danby, R.K., and D.S. Hik. 2007. Variability, contingency and rapid change in recent subarctic alpine tree line dynamics. Journal of Ecology 95:352-363.

Davis, M.B. 1981. Quaternary history and the stability of forest communities. Pp. 132-153. In Forest succession: concepts and applications. Edited by D.C. West, H.H. Shugart and D.B. Botkin. Springer-Verlag, New York.

Delcourt, H.R., and P.A. Delcourt. 1988. Quaternary landscape ecology: relevant scales in space and time. Landscape Ecology 2(1):23-44.

Delcourt, P.A. and H.R. Delcourt. 1987. Long-term forest dynamics of the temperate zone: A case study of late-Quaternary forests in eastern North America. Springer-Verlag, New York. 439 p.

Dokken, D.J., H. Gitay, A. Suarez, and R.T. Watson, editors. 2002. Climate change and biodiversity: IPCC Technical Paper V. Intergovernmental Panel on Climate Change, Geneva. 77 p.

Dullinger, S., Dirnbock, T., and G. Grabherr. 2004. Modelling climate change-driven treeline shifts: relative effects of temperature increase, dispersal and invisibility. Journal of Ecology 92:241-252.

Gibson, H.H. 1913. American Forest Trees. Hardwood Record, Chicago, 708 pp. 
Gorman, K. A. 2005. Potential natural vegetation group description for southeastern spruce-fir. http://frcc.gov/docs/PNVG/EastNew/ESPF1.pdf. [Accessed 16 February 2008].

Grabherr, G., M. Gottfried, and H. Pauli. 1994. Climate effects on mountain plants. Nature 369: p.448.

Griggs, D.J. and M. Noguer. 2002. Climate change 2001: The scientific basis. Contribution of Working Group I to the third assessment report of the Intergovernmental Panel on Climate Change. Weather 57:267-269.

Harmon, P.J., Ford-Werntz, D., and W. Grafton. 2006. Checklist and Atlas of the Vascular Flora of West Virginia. West Virginia Division of Natural Resources, Wildlife Resources Section, Elkins, WV. 381 p.

Heitzman, E., S. Dougherty, J. Rentch, S. Adams, and S. Stephenson. 2010. 25+ year changes in forest structure and tree-ring patterns in three old-growth red spruce stands in West Virginia. Pp 211 in Rentch, J.S. and T.M. Schuler (eds.). Proceedings from the conference on the ecology and management of high-elevation forests in the central and southern Appalachian Mountains. 2009 May 14-15; Slatyfork, WV. Gen. Tech. Rep. NRS-P-64. Newtown Square, PA: U.S. Department of Agriculture, Forest Service, Northern Research Station.. 242 p.

Hersteinsson, P. and D.W. MacDonald. 1992. Interspecific competition and the geographical distribution of red and artic foxes Vulpes vulpes and Alopex lagopus. Oikos 64:505-515.

Hopkins, A.D. 1891. Black Spruce: Preliminary report. West Virginia Agricultural Experiment Station Bulletin 17:93-102.

Hopkins, A.D. 1899. Report on Investigations to determine the cause of unhealthy conditions of the spruce and pine from 1880-1893. Part I. The Spruce Investigation. West Virginia Agricultural Experiment Station Bulletin 56:203-270.

Hughes, L. 2000. Biological consequences of global warming: is the signal already apparent? Trends Ecol. Evol. 15(2):56-61.

Huntley, B., B. Phoebe, R. Altwegg, L. Chambers, B.W.T. Coetzee, L. Gibson, P.A.R. Hockey, D.G. Hole, G.F. Midgley, L.G. Underhill, and S.G. Willis. 2010. Beyond bioclimatic envelopes: dynamic species' range and abundance modeling in the context of climatic change. Ecography 33(3):621-626.

IPCC, 2007. Climate change 2007: the physical science basis. In: Solomon, S., Qin, D., Manning, M., Chen, Z., Marquis, M., Avery, B., Tignor, M., Miller, H.L. (eds.), Contribution of working group I to the fourth assessment report of the Intergovernmental Panel on Climate Change. Cambridge University Press, Cambridge, United Kingdom and New York, USA. p. 996. 
IPCC-AR4. 2007. Climate change 2007: synthesis report. Contribution of working groups I, II, and III to the fourth assessment report of the Intergovernmental Panel on Climate Change. Geneva, Switzerland. Pp 104.

Iverson, L.R., and A.M. Prasad. 2001. Potential changes in tree species richness and forest community types following climate change. Ecosystems 4:186-199.

Iverson, L.R., Prasad, A.M., Matthews, S.N., Peters, M. 2008. Estimating potential habitat for 134 eastern US tree species under six climate scenarios. Forest Ecology and Management 254:390-406.

Janzen, F.J. 1994. Climate change and temperature-dependent sex determination in reptiles. Proc. Natl. Acad. Sci. USA 91:7487-7490.

Johnson, A.H., E.R. Cook, and T.G. Siccama. 1988. Climate and red spruce growth and decline in the northern Appalachians. Proceeding of the National Academy of Sciences of the United States of America 85(15):5369-5373.

Kelly, A.E., and M.L. Goulden. 2008. Rapid shifts in plant distribution with recent climate change. Proceedings of the National Academy of Sciences [PNAS] 105(33):1182311826.

Knapp, A.K., C. Beier, D.D. Briske, A.T. Classen, Y. Luo, M. Reichstein, M.D. Smith, S.D. Smith, J.E. Bell, P.A. Fay, J.L. Heisler, S.W. Leavitt, R. Sherry, B. Smith, and E. Weng. 2008. Consequences of more extreme precipitation regimes for terrestrial ecosystems. Bioscience 58(9):811-821.

Korstian, C.F. 1937. Perpetuation of spruce on cut-over and burned lands in the higher southern Appalachian Mountains. Ecological Monographs 7:125-167.

Lewis, R.L. 1998. Transforming the Appalachian Countryside: Railroads, Deforestation, and Social Change in West Virginia, 1880-1920. Chapel Hill: University of North Carolina Press.

McCarty, J.P. 2001. Ecological consequences of recent climate change. Conservation Biology 15(2):320-331.

McKenney-Easterling, M., D.R. Dewalle, L.R. Iverson, A.M. Prasad, and A.R. Buda. 2000. The potential impacts of climate change and variability on forests and forestry in the MidAtlantic Region. Climate Research 14:195-206.

Millspaugh, C.F. 1891. Forest and shade tree insects. Part II. Black spruce, (Picea mariana (Mill.)). West Virginia University. Agricultural Experiment Station Report 3:171-180.

Minckler, L.S. 1940. Early planting experiments in the spruce-fir type of the Southern Appalachians. Journal of Forestry 38(8):651-654. 
Minckler, L.S. 1945. Reforestation in the spruce type in the Southern Appalachians. Journal of Forestry 43(5): 349-356.

Newins, H.S. 1931. Forest conditions in West Virginia. Journal of Forestry 29(4): 565-571.

Noss, R.F., E.T. LaRoe, and J.M. Scott. 1995. Endangered ecosystems of the United States: a preliminary assessment of loss and degradation. Biological Report 28, National Biological Services, Washington D.C.

Oliver, C.D. and B.C. Larson. 1996. Forest stand dynamics. Update edition. John Wiley \& Sons, Inc. 520p.

Oosting H.J. and W.D. Billings. 1951. A comparison of virgin spruce-fir forest in northern and southern Appalachian system. Ecology 32(1):84-103.

Parmesan, C. 1996. Climate and species‘ range. Nature 382:765-766.

Parmesan, C., and G. Yohe. 2003. A globally coherent fingerprint of climate change impacts across natural systems. Nature 421:37-42.

Parry, M.L., O.F. Canziani, J.P. Palutikof, and Co-authors. 2007. Technical Summary. Climate Change 2007: Impacts, Adaptation, and Vulnerability. Contribution of Working Group II to the Fourth Assessment of the Intergovernmental Panel on Climate Change, M.L. Parry, O.F Canziani, J.P. Palutikof, P.J. van der Linden, and C.E.Hanson (eds). Cambridge University Press, Cambridge, UK. 56p.

Pauley, E.F. 1989. Stand composition and structure of a second-growth red spruce forest in West Virginia. Castanea 54(1):12-18.

Prevost, M. 2008. Effect of cutting intensity on microenvironmental conditions and regeneration dynamics in yellow birch-conifer stands. Can. J. For. Res. 38:317-330.

Rentch, J.S., Schuler, T.M., Nowacki, G.J., Beane, N.R., and W.M. Ford. 2010. Canopy gap dynamics of second-growth red spruce-northern hardwood stands in West Virginia. Forest Ecology and Management 260:1921-1929.

Rentch, J.S., T.M. Schuler, W.M. Ford, and G.J. Nowacki. 2007. Red spruce stand dynamics, simulations, and restoration opportunities in the central Appalachians. Restoration Ecology 15(3):440-452.

Rodenhouse, N.L., S.N. Matthews, K.P. McFarland, J.D. Lambert, L.R. Iverson, A. Prasad, T.S. Sillett, and R.T. Holmes. 2008. Potential effects of climate change on birds of the Northeast. Mitig Adapt Strat Glob Change 13:517-540.

Schwartz, M.W., L.R. Iverson, A.M. Prasad, S.N. Matthews, and R.J. O`Connor. 2006. Predicting extinctions as a result of climate change. Ecology 87(7):1611-1615. 
Seymour, R.S. 1995. The northeastern region. Pages 31-79. In J.W. Barrett, ed. Regional silviculture of the United States. John Wiley and Sons, New York.

Soil Survey Staff. 2006. Keys to Soil Taxonomy, $10^{\text {th }}$ ed. USDA-Natural Resources Conservation Service, Washington, DC. 333 p.

Steer, H.B. 1948. Lumber production in the United States 1799-1946. U.S. Dept. of Agriculture, Misc. Publ. No. 669. Washington, D.C. 233p.

Stephenson, S.L. 1993. Upland Forest Vegetation. Pp.11-34 in S.L. Stephenson ed., Upland forests of West Virginia. McClain Printing Co., Parsons, West Virginia.

Stephenson, S.L., and H.S. Adams. 1993. Threats to the upland forests. Pp.261-273 in S.L. Stephenson ed., Upland Forests of West Virginia. McClain Printing, Parsons, W.Va.

Stephenson, S.L., and J.F. Clovis. 1983. Spruce forests of the Allegheny Mountains in Central West Virginia. Castanea 48(1):1-12.

Strausbaugh, P.D., and E.L. Core. 1964. Flora of West Virginia. Introductory Section. West Virginia University Bulletin. Series 65. No. 3-1.

Trani, M.K. 2002. Southern forest resource assessment highlights: terrestrial ecosystems and wildlife conservation. Journal of Forestry 100(7):35-40.

USDA 2006. Monongahela National Forest - Land and Resource Management Plan. United States Department of Agriculture-Forest Service. 246p.

[USGS] United States Geological Survey. 1999. Digital representation of Atlas of United States Trees" by Elbert L. Little. (http://esp.cr.usgs.gov/data/atlas/little/, January 20, 2009).

Wahlenberg, W.G. 1951. Planting in the Appalachian spruce-fir type. Journal of Forestry 49(8): 569-571.

Walther, G.-R., E. Post, P. Convey, A. Menzel, C. Parmesan, T.J.C. Beebe, J.-M. Fromentin, O. Hoegh-Guldberg, and F. Bairlein. 2002. Ecological responses to recent climate change. Nature 416:389-395.

Walther, G.-R., Beißner, S., and C.A. Burga. 2005. Trends in the upward shift of alpine plants. Journal of Vegetation Science 16:541-548.

Watts, W.A. 1979. Late Quaternary Vegetation of Central Appalachia and the New Jersey Coastal Plain. Ecological Monographs 49(4): 427-469. 
White, P.S., E.R. Buckner, J.D. Pittillo, and C.V. Cogbill. 1993. High-elevation forests: sprucefir forests, northern hardwoods forests, and associated communities. Pp 305-337. In W.H. Martin, S.G. Boyce, and A.C. Echternacht, (eds.). Biodiversity of the Southeastern United States: upland terrestrial communities. John Wiley \& Sons, Inc., New York.

White, P.S., M.D. MacKenzie, and R.T. Busing. 1985. Natural disturbance and gap phase dynamics in southern Appalachian spruce-fir forests. Can. J. For. Res. 15:233-240.

Woodall, C.W., C.M. Oswalt, J.A. Westfall, C.H. Perry, M.D. Nelson, and A.O. Finley. 2009. An indicator of tree migration in forests of the eastern United States. Forest Ecology and Management 257:1434-1444. 
Chapter 2. Using Environmental and Site-specific Variables to Model the Current Distribution of Red Spruce Forests in West Virginia

\begin{abstract}
The extent of red spruce forests in West Virginia prior to exploitative logging is estimated at 190,000 ha but today is believed to occupy no more than 24,000 ha. With the extensive loss of presettlement habitat for red spruce in West Virginia this species is a high priority for restoration, as these forests offer the unique habitat for the endangered Cheat Mountain salamander (Plethodon nettingi Green), and provide optimal habitat for the recently delisted Virginia northern flying squirrel (Glaucomys sabrinus fuscus Miller). In this study, a novel modeling technique, Maximum Entropy (Maxent) was used to model the current distribution of red spruce habitat in West Virginia using 168 red spruce presence localities. Incorporating 32 environmental and site-specific variables, 283,000 ha were identified in 18 counties possessing suitable red spruce habitat in West Virginia. Variables considered important for all replicate model runs were maximum temperature of the warmest month (40.6\%), minimum temperature of the coldest month $(13.7 \%)$, slope percent $(6.9 \%)$, mean temperature of the coldest quarter $(6.5 \%)$, mean annual temperature (4.6\%), and soil type (4\%).
\end{abstract}

The environmental and site-specific variables which contributed the most to overall model performance were also assessed further to examine the value or range of values in which red spruce habitat is likely to occur. For maximum temperature of the warmest month the threshold value identified was $25^{\circ} \mathrm{C}$, where areas which had maximum summer temperature less than this value resulted in an increase probability of possessing suitable red spruce habitat. Additionally, for mean temperature of the coldest month a threshold value was identified where all areas which possessed a mean winter monthly temperature less than $-8.5^{\circ} \mathrm{C}$ resulted in increased probability of suitable habitat for red spruce to a peak of approximately $-10.5^{\circ} \mathrm{C}$.

Examination of high, medium, and low suitability was also assessed, with approximately 7,800, 83,000 , and 192,000 ha of suitable red spruce habitat identified for each category, respectively. Although 18 counties were identified which possessed suitable red spruce habitat, five counties possessed greater than $85 \%$ of the total area. These counties included Randolph (33\%), Pocahontas (31\%), Tucker (12\%), Grant (8\%), and Greenbrier (6\%). In addition, nine counties were identified which possessed high suitability, with Randolph, Pocahontas, Pendleton, Grant, and Tucker counties accounting for more than $99 \%$ of the areas identified with high suitability for red spruce habitat.

This modeling effort will benefit the current restoration efforts in West Virginia regarding this unique and threatened ecosystem. This research not only provides a statewide assessment of red spruce habitat but was also performed at a county level, examining areas of high, medium, and low suitability. Conservation managers may use the outcomes of this research to guide future restoration efforts in areas identified with high suitability to ensure red spruce plantings are being conducted in areas most likely to possess the habitat requirement identified in this analysis. Restoration and recovery of red spruce forests would increase forest diversity and provide habitat for numerous endemic species dependant on this unique ecosystem. 


\section{Introduction}

Red spruce (Picea rubens Sarg.) characterizes niche communities at higher elevations throughout the Appalachian Mountain Region (AMR) and is a relict species of the central and southern Appalachians (Audley et al. 1998; Stephenson and Clovis 1983). These high elevation spruce-dominated forests are a remnant ecosystem from the Wisconsin glaciation of the Quaternary Period and today are considered one of the most threatened forest ecosystems in the eastern United States (White et al. 1993). The extent of red spruce forests in West Virginia prior to exploitative logging is estimated at 190,000 ha (Clarkson 1964; Millspaugh 1891; Hopkins 1891), but today are estimated to occupy no more than 24,000 ha (Stephenson and Adams 1993).

With extensive loss of presettlement habitat for red spruce, this species is a high priority for restoration in West Virginia. Exploitative logging and repeated burning often degraded the original spruce-dominated forests into low-quality northern hardwood forests or shrubdominated glades (Schuler et al. 2002; Stephenson 1993). Minckler (1945) estimated that on severely altered spruce sites which had been clearcut, burned, and subjected to erosion, that it would require as long as 500 to 1,000 years for red spruce to fully recover without assistance by mankind. Although this recovery time period is not likely for most cutover areas in West Virginia, it does indicate the necessity for active restoration efforts to assist red spruce in reoccupying its once extensive range throughout the high-elevation mountainous regions in West Virginia.

Restoration and recovery of red spruce forests would increase forest diversity and provide habitat for numerous endemic species that occur there (McDonald 1993; White et al. 1993). These high elevation forests play an important role in watershed protection and boast strong aesthetic values because of the evergreen mountaintop scenery that provides a unique contrast to 
the dominant hardwood forests of the region. Red spruce forests also have high economic value with respect to timber and recreation activities including hunting, fishing, hiking, and camping (Hornbeck and Kochenderfer 1998).

Red spruce forests provide the preferred habitat for the endangered Cheat Mountain salamander (Plethodon nettingi Green), and provide optimal habitat for the recently delisted Virginia northern flying squirrel (VNFS) (Glaucomys sabrinus fuscus Miller) (Odom et al. 2001; Menzel et al. 2006a; Menzel et al. 2006b). VNFS habitat can be described as high elevation islands" surrounded by a matrix of less- or unsuitable forest habitat (Menzel et al. 2006a; Wiegl 2007). This island-like distribution has already been shown to restrict gene flow and is most likely a result of reduced population size and isolation (Menzel et al. 2006a; Wiegl 2007). This loss of genetic variability for VNFS populations increases the likelihood of localized extirpation of this subspecies, especially under a changing environment (Menzel et al. 2006a; Wiegl 2007). Wiegl (2007) stressed the importance of large, inter-connected populations for survival of the northern flying squirrel throughout its range, provided by large habitat reserves and maintenance of forested corridors. Red spruce forest restoration may be critical to maintaining genetic diversity of future VNFS populations.

Several species of hypogeal fungi consumed by VNFS have also been identified that occur within red spruce forests (Odom et al. 2001). In West Virginia, the most common fungal species belong to the genera Elaphomyces, Gautieria, Glomus, Hydnotrya, and Tuber (Ford et al. 2004). Associations like this are often poorly understood or unknown and reinforce the importance of preserving such unique and important forest ecosystems.

Other high elevation species of conservation concern in West Virginia are the saw-whet owl (Aegolius acadicus Gmelin), snowshoe hare (Lepus americanus Erxleben), northern 
goshawk (Accipiter gentilis L.), and the fisher (Martes pennanti Erxleben) (Menzel et al. 2006b).

The acceleration of red spruce recovery has the potential to enhance or increase habitat availability for these species, and is likely to benefit an array of insects and other invertebrates which have been poorly researched and possibly not yet described (Schuler et al. 2002; Acciavatti et al. 1993). The recovery and/or expansion of red spruce habitat will benefit numerous wildlife species and further protect those with limited distributions and conservation concern. These species all play important roles within red spruce forest ecosystems and stress the need for restoration of this rare forest type in West Virginia. Modeling efforts focused on identifying areas best suited for red spruce restoration would therefore be of great importance. As a specialist species, with regard to its habitat requirements, red spruce has a greater potential for habitat modeling than species with more general requirements. In West Virginia, red spruce is found in areas of high-elevation which offer a relatively cool climate and receive high amounts of rainfall and snow. These areas occur primarily at elevations exceeding 1,000 m; however, red spruce can be found in some areas at elevations as low as $760 \mathrm{~m}$ as found at Cathedral State Park, Preston County (Beane et al. 2010).

Ecological researchers have shown much interest in species distribution models (SDMs) used for predicting suitable habitat for a given species (e.g., Bollinger et al. 2000; Raxworthy et al. 2003; Phillips et al. 2006; Elith et al. 2006; Baldwin 2009). SDM's are not only useful to generate maps identifying areas of suitable habitat but also in determining which variables are the primary drivers for a species' occurrence on the landscape. SDM's provide a valuable tool for many ecological studies and may also be used to guide future field surveys for species with limited ranges (Phillips et al. 2006). 
The SDM incorporated for this study is Maximum Entropy (Maxent), a presence-only modeling technique used to characterize a species' niche in environmental space, accomplished by relating observed occurrences to a suite of environmental variables (Pearson 2007). An advantage of Maxent over other SDM techniques is that the estimated distribution must agree with all that is known or inferred from environmental conditions, and avoids making assumptions not supported by the data (Jaynes 1957; Jaynes 1990). The objective of the Maxent algorithm is to find the probability distribution of maximum entropy (i.e., closest to uniform), which is subject to constraints of information available with regard to the observed distribution of the species and the environmental variables examined (Pearson 2007).

The observed distribution for a particular species is often referred to as the occupied or realized niche. It is important to distinguish between a species fundamental and occupied niche, although they may be similar. Hutchinson (1957) identified the fundamental niche as an $n$ dimensional _hyper-space‘ encapsulating the range of environmental conditions in which a species can survive and reproduce successfully (Parolo et al. 2008). In nature, the fundamental niche of a species is unlikely to occur due primarily to spatial constraints such as limited dispersal ability for a given species, geographic barriers, and intra- and inter-specific competition. The occupied niche may be defined as the portions of the fundamental niche in which a species is not excluded from due to biotic competition and/or geographical and historical constraints (Peason 2007). Therefore, habitat suitability modeling approaches (i.e., niche modeling), such as Maxent are often employed to inductively interpolate or extrapolate the fundamental niche of a given species outside the locations where the species presence has been identified (i.e., realized niche) (Parolo et al. 2008). 
$\mathrm{SDM}^{\text {'s }}$ are able to identify areas of suitable habitat outside of the realized niche by relating the environmental predictors examined to species' ${ }^{\text {}}$ presence identified from fieldcollected data (i.e, known presences) (Pearson 2007; Parolo et al. 2008). Therefore, if the whole range of variation in which a species occurs is captured by the known presences sampled, the more accurate assessment of a species fundamental niche is likely to be modeled, assuming that the environmental and site-specific variables chosen are useful in identifying suitable habitat for the species examined.

For my model analysis, 32 environmental and site-specific variables were incorporated that were believed to be important for the detection of red spruce habitat in West Virginia. The purpose of this research effort was to identify areas on the landscape, at a 30m resolution, which possessed the environmental and site-specific parameters necessary for red spruce habitat. Furthermore, I wished to identify the unique values or range of values for each environmental and site-specific variable in which suitable red spruce habitat is likely to be found. The results of this research should be of great utility to the restoration and conservation efforts currently underway to protect and extend red spruce forest communities which offer unique habitat for so many species of conservation concern.

\section{Methods}

Study Area

The upland forests of West Virginia (i.e., elevations exceeding $915 \mathrm{~m}$ ) comprise two distinct physiographic regions that possess red spruce forest communities; the Allegheny Mountain section and the Ridge and Valley section (Strausbaugh and Core 1964; Stephenson 1993). These two physiographic regions differ in both geography and climate and therefore vary greatly with respect to forest vegetation. The ridges of the Allegheny Mountain section consist 
primarily of Paleozoic sandstones and conglomerates, with underlying rocks of the valleys composed primarily of shale and limestone (Stephenson 1993; Stephenson and Clovis 1983). The Ridge and Valley region, as its name suggests, consists of lowland areas surrounded by many longitudinal ridges. This region is characterized by extensively folded and thrust-faulted Paleozoic strata composed of resistant quartzite, conglomerates, and sandstone on ridges. However, the valleys are composed mostly of less resistant shale and limestone which have eroded over time creating the intervening valleys throughout this region (Stephenson 1993).

The highest elevation zones within these two regions comprise part of NatureServe's Central and Southern Appalachian Spruce-Fir Forest Ecological System and are the focal point for the distribution of red spruce in West Virginia (Comer et al. 2003; Byers et al. 2010). Within this ecological system red spruce occurs primarily within the Allegheny Mountain section and to a much lesser extent in the Ridge and Valley region. This is due primarily to the climate of the Ridge and Valley region which is much drier than its neighboring Allegheny Mountain section to the west.

The western boundary of the Ridge and Valley section is the Allegheny Front, and is therefore subjected to a rain-shadow" effect in which a marked difference occurs between the amounts of precipitation in these two regions (Clarkson et al. 1980). McCay et al. (1997) reported an average annual precipitation in the Allegheny Mountain section of $107.5 \mathrm{~cm}$ in comparison to $82.5 \mathrm{~cm}$ as identified in the Ridge and Valley region. In addition, maximum and minimum average temperatures for January ranged from $4.44^{\circ} \mathrm{C}$ and $-7.72^{\circ} \mathrm{C}$ for the Allegheny section compared to $5.83^{\circ} \mathrm{C}$ to $-6.56^{\circ} \mathrm{C}$ for the Ridge and Valley Section, with July average daily temperatures ranging from $13.5^{\circ} \mathrm{C}$ to $25.17^{\circ} \mathrm{C}$ and $14.22^{\circ} \mathrm{C}$ to $28.67^{\circ} \mathrm{C}$, respectively (McCay et al. 1997). Across the higher elevation areas of both physiographic regions where red spruce may 
be found, the 30-year average precipitation ranges from 1,220-1,680 $\mathrm{mm}$ per year with 30-year mean annual temperatures ranging from $6.7^{\circ} \mathrm{C}$ to $9.4^{\circ} \mathrm{C}$ (Byers et al. 2010).

\section{Sample Site Selection}

To determine potential areas for identifying red spruce presence, a preliminary red spruce habitat suitability map provided by the West Virginia Division of Natural Resources (WVDNR) was used (Byers et al. 2010). This map was created using Maxent and incorporated 90 points of known red spruce occurrence. This habitat suitability map served as the basis for my sample plot locations. As Maxent is a presence-only modeling approach, 250 random Universal Transverse Mercator (UTM) coordinates were generated using a geographic information system (GIS) in areas identified possessing greater than 33 percent likelihood for suitable red spruce habitat. Although 250 random plots were originally generated, some plots were not accessible when conducting our field study. The most common hindrance was private property where access could not be granted, or in a few instances, no feasible access was available. When access nearby was possible, replacement plots were established in areas possessing red spruce with coordinates and plot data recorded. Additionally, if red spruce was found in areas not identified by the WVDNR habitat suitability map, supplemental plots were established to improve model accuracy by providing evidence of red spruce habitat occurring in areas predicted otherwise.

\section{Red Spruce Sampling}

In summers 2008 and 2009 a total of 168 variable-radius plots, using a 10-BAF (i.e., basal area factor) prism, were established throughout the Appalachian Mountain Region (AMR) of West Virginia (Figure 2.1). The UTM coordinates for each plot is provided in Appendix I. Sampling with a prism is a relatively quick way to measure stand diversity and is a density- and distance-dependant measurement, relative to the BAF prism used (Avery and Burkhart 2002). 
At each plot location, trees considered for tally (i.e., in" trees) were measured and recorded by $\mathrm{DBH}$ and species to assess overstory and understory tree composition at each plot location. Therefore, at each plot location, trees per hectare $(\mathrm{TPH})$ and basal area per hectare (BA) were calculated. Finally, geographic coordinates were recorded for all plots created as replacement or supplemental plots for implementation into a GIS.

\section{Model Variables}

A total of 32 environmental and site-specific variables were used as independent variables for the model and included climatic, topographic, and edaphic variables. Nineteen bioclimatic variables were calculated using original climatic datasets (i.e., minimum, maximum, and average monthly temperature and average monthly precipitation) provided by WVDNR. The original climatic datasets were obtained at 400m resolution and were resampled using bilinear interpolation within a GIS to a $30 \mathrm{~m}$ resolution to match other variables considered in the model. Bioclimatic variables are important for ecological applications because they calculate the average climatic values during unique times where biological limitations are likely to or could occur (e.g., mean temperature of the driest quarter of the year). The use of bioclimatic variables also allowed for a drastic reduction in the number of climatic variables examined. Due to the uncertainty of which bioclimatic variables would be considered of importance in identifying red spruce habitat, all 19 variables were considered in the analysis. The 19 bioclimatic variables were calculated using the AML-script provided by the WorldClim database (see Hijmans et al. 2005). A description of each bioclimatic variable, how it was derived, and the range of values across all red spruce presence localities is provided (Table 2.1).

Additional variables considered in the model included elevation, slope, aspect, topographic relative moisture index (TRMI), TRMI-landform, geologic series, solar radiation, 
and soil derived variables including soil type (map unit name), soil $\mathrm{pH}$, percent clay, percent organic matter, percent sand, and percent silt. These topographic and site-specific variables were used because they were presumed to potentially be of importance in defining red spruce habitat within the model. A description of how these non-bioclimatic variables were derived as well as their range of values for the red spruce presence localities is provided (Table 2.2).

\section{Model Building}

Maximum entropy (Maxent), version 3.3.2, is a general purpose machine learning method and was incorporated for our modeling effort (Phillips et al. 2006). Maxent software may be freely downloaded (http://www.cs.princeton.edu/ schapire/maxent/) (Phillips et al. 2004; Phillips et al. 2006). Maxent is a novel modeling method with many advantages: 1) characterizes probability distributions from incomplete information, 2) does not require absence data, 3) utilizes continuous and categorical variables, and 4) the resulting output is a continuous prediction ranging from zero to one, with higher values indicating higher suitability for a given species. Although there are many techniques now available for modeling species distributions, Maxent has been identified in many studies to be a strongly competitive or superior modeling method, particularly for species with limited distribution such as red spruce forests in West Virginia (e.g., Elith et al. 2006; Hernandez et al. 2006; Hijmans and Graham 2006; Phillips et al. 2006; Pearson 2007).

In comparison with traditional regression-based techniques, Maxent does not violate a model assumption if variables which possess multicollinearity or spatial autocorrelation are incorporated. Spatial autocorrelation may be defined as the properties of random variables at a certain distance apart, possessing values that are more or less similar (i.e., possessing a positive or negative autocorrelation, respectively), and is often a problem when ecological modeling is 
performed (Legendre 1993). Although multicollinearity or spatial autocorrelation are not desirable when modeling, most ecological studies must appropriately address this problem. Thus, Maxent models are of great utility compared to regression-based approaches because variables which do exhibit multicollinearity may be used without violating model assumptions. It is still necessary that the user understands the risk associated with including variables which are known to possess multicollinearity or spatial autocorrelation (e.g., a strongly correlated variable may not be considered important if another similar variable is also used in the model) as this will impact model interpretation.

This ability of Maxent to assess complex non-linear variable interactions as well as incorporate correlated variables without violating model assumptions is a positive attribute of newer machine learning techniques over many regression-based techniques (Michael Dougherty, Elkins, WV, personal communication). When using a Maxent modeling approach, features are incorporated as independent variables that the user believes are important drivers for a given species" occurrence on the landscape. Each feature serves as a constraint for the model, and the maximum entropy model selected is the one which best satisfies the constraints of each feature examined (Manning and Schutze 1999). Maxent performs similarly to logistic regression by weighting each feature (i.e., environmental or site-specific variable) by a constant, with the estimated probability distribution divided by a scaling constant to ensure the probabilities range from 0-1 and also sum to 1 (Hernandez et al. 2006).

Although methodologies employing presence/absence data are often prioritized, presence-only modeling approaches should be employed when the objective is to identify suitable habitat of a given species; particularly when the current distribution of the species is unknown or has been dramatically altered (e.g., historical anthropogenic disturbances) (Brotons 
et al. 2004). Presence-only modeling methods are also preferred when ambiguous absences occur due to geographic barriers, local extinction, small patch sizes, species generalization, and biotic interactions (e.g., succession stage, competition) (Hirzel and LeLay 2008). Because Maxent does not utilize absence data, background“ points with their associated environmental variable values are used. These background points serve as pseudo-absences for model assessment and are used to determine the logistic output which ranges from 0 (low suitability) to 1 (high suitability) for habitat prediction.

When using background data within Maxent it is important for the user to understand that this model makes no assumptions of where a particular species does not occur. Rather, the assumption is that a model based on occurrence and background data (i.e., pseudo-absences) will not focus on sampling bias. Therefore, the primary focus of a Maxent model is to distinguish the differences between the distribution of occurrences and that of the background points examined (Phillips et al. 2009; Yates et al. 2010).

The 5,000 background points used for my model were randomly generated using GIS within the six county study area from which the red spruce plots were collected (Figure 2.2). Much of the necessary data preparation required for this analysis was performed within a GIS using ESRI® ArcMap ${ }^{\mathrm{TM}}$ 9.3.1 under an ArcEditor license. Within ArcMap, a shapefile was created for the 168 red spruce presence localities as well as the 5,000 randomly generated (using Hawth's Tools within ArcMap) background points, with UTM coordinates listed for each data point in the attribute table. Next, the 32 independent variables were added as raster grids (.img format) and used to construct attribute tables which identified each variables value for all presence and background localities. These attribute tables were constructed for both shapefiles using the intersect point analysis tool provided by the freely downloaded add-on Hawths 
Analysis Tools', version 3.27 (http://www.spatialecology.com/htools/download.php). The resulting attribute tables provided UTM coordinates for each point locality along with the associated raster grid value for all 32 independent variables considered.

Both attribute tables were then exported from ArcMap and saved in database format (.dbf). Maxent setup typically requires two types of data, the species presence localities in a comma-separated value (CSV) format and the environmental and site-specific data provided in ASCII grid format; with the background points and their associated values calculated within Maxent. However, when large datasets are used for analysis, as in this study, an alternative method should be employed. This alternative method allows the user to input the presence locality data as well as the background points with the environmental and site-specific data already determined for each unique UTM coordinate. This method is referred to as a samples with data' (SWD) format and saves considerable run time when performing multiple replicate runs over a large study area and at a fine resolution (i.e., $30 \mathrm{~m}$ resolution). For my analysis each of the 32 raster grids occupied approximately $1 \mathrm{~GB}$ of file space and at a $30 \mathrm{~m}$ state-wide resolution, represented approximate 70 million pixels for the study area. By assigning the unique value of each independent variable prior to running the model run time was greatly reduced.

Using the SWD file format, a CSV file for the red spruce presence localities and the background points was incorporated into the Maxent model platform. The conversion of the red spruce presence and background points from database format (.dbf) to CSV format was performed using Microsoft Excel 2007. Additionally, all raster grids were converted to ASCII grid (.asc) format for implementation into Maxent. These ASCII grids are necessary to create the state-wide red spruce habitat suitability map. All grid conversions were performed using the =Raster to ASCII' conversion tool within the ArcMap-ArcToolbox. 
Once the data was added to the model all categorical variables were specified accordingly so that they were not considered as a continuous variable in the model (Table 2.2). A description of each categorical variable is available in Appendix II. Next, the check-boxes for Create response curves` and _Do jackknife to measure variable importance` were selected. Within the settings window, a bootstrap replicate run (i.e., sampling with replacement) type was selected for 10 replicates with a random test percentage of $25 \%(\mathrm{n}=42)$ used. In addition, the Random seed check-box was selected so that each replicate run would start with a random seed to ensure that a separate test/train dataset was used for each of the 10 replicate models.

An independent dataset was not available for model assessment and we did not wish to partition the dataset into test and training data, and lose valuable training data. As an alternative, we incorporated a =bootstrap replication' technique which allowed for replicate model runs to be conducted using sampling with replacement (i.e., the same occurrence may be used more than once for individual replicate runs). Bootstrap replication splits the dataset multiple times, and in each case, predictive performance is assessed against the test dataset. This allows for all occurrence data to be used with a random partition performed with each Maxent replicate run.

\section{Results}

A total of 29 species were identified within the red spruce presence plots collected during the field seasons of 2008 and 2009. Using the average BA and relative TPH, importance values (IV's) were calculated by averaging the sum of BA and TPH. Importance Value's provide a unitless assessment of the significance of each species among all plots measured with respect to density and abundance. The species most often encountered were red spruce (IV=40.2), red maple (IV=16.7), yellow birch (IV=11.4), eastern hemlock (IV=10.6), and black cherry (IV=9.2) (Table 2.3). The average stand BA was $44.6 \mathrm{~m}^{2} / \mathrm{ha}$ with $405 \mathrm{TPH}$. The average DBH for all 
species or species group examined was $34.3 \mathrm{~cm}$, with the largest average diameter occurring for eastern white pine and yellow-poplar $(80 \mathrm{~cm}$ and $55 \mathrm{~cm}$, respectively). An examination of the $\mathrm{BA}$ and TPH for these two species reveals they were abnormally large trees occurring only in a few of the sampling plots. Regarding the species group Quercus spp., the most common species sampled was northern red oak (Quercus rubra L.), with white oak (Q. alba L.) and chesnut oak (Q. prinus $\mathrm{L}$.) only identified at a few ridgetop sites. The Other species group included species infrequently identified in the plots and consisted of: pin cherry (Prunus pensylvanica L.), American basswood (Tilia americana L.), hawthorn (Crataegus sp. L.), yellow buckeye (Aesculus flava Aiton), black locust (Robinia pseudoacacia L.), sweet cherry (Prunus avium (L.) L.), shagbark hickory (Carya ovata (Mill.) K. Koch), mockernut hickory (Carya tomentosa (Lam.) Nutt.), and bigtooth aspen (Populus grandidentata Michx.) (Table 2.3).

Using 168 overstory red spruce plots, 5,000 background points, and 32 independent variables, the Maxent model was ran. Model setup included 10 bootstrapped replicate runs (i.e., sampling with replacement) using a random test percentage of $25 \%(\mathrm{n}=42)$ to assess model performance without excluding a portion of the dataset to be used exclusively for model testing. Within the Maxent output an area-under-curve (AUC) value is calculated from the receiver operating characteristic (ROC) plot (Figure 2.3). The AUC value may be interpreted as a single test statistic which assesses model performance with a range of $0-1$. AUC values $<0.5$ indicate the model is no better than random, values $>0.5$ to 0.7 indicate a fair model, values 0.7 to 0.9 indicate a good model, and values $>0.9$ indicate excellent model performance (Baldwin 2009). The mean AUC for all 10 model runs was $0.97(\mathrm{sd}=0.009)$, a value considered to indicate excellent model performance. 
The variables which provided the most information (i.e., gave the largest percent contribution) across all replicate model runs were: maximum temperature of the warmest month (bio_5) (40.6\%), minimum temperature of the coldest month (bio_6) (13.7\%), slope percent (slope30) (6.9\%), mean temperature of the coldest quarter (bio_11) (6.5\%), mean annual temperature (bio_1) (4.6\%), soil type (c_soil) (4\%), and elevation (ned30m) (3\%) (Table 2.4). It is important to note that although the calculated variable percent contributions may be useful for identifying variables important to the overall model performance, spatial autocorrelation must also be considered.

The Maxent output provides an omission/commission graph that may be used to assess whether significant spatial autocorrelations exist in the model which could alter model interpretability (Figure 2.4). This graph shows the omission rate and predicted area as a function of the cumulative threshold. By definition of the cumulative threshold the training omission rate should be close to the predicted omission (i.e., the Maxent distribution should be a close approximation of the probability distribution that represents reality). Therefore, any deviations falling below this line are indicative of spatially autocorrelated data used in the model, resulting in a higher cumulative prediction in relation to the fractional area examined.

Two options are available when spatial autocorrelated data is identified. One option is to attempt to remove the spatial dependency among observations and the second option is to modify the statistical method in order to take the spatial autocorrelation into account; with the latter being preferred when such methods are available (Legendre 1993). Maxent was the modeling approach selected because of its robustness and ability to analyze complex ecological data even when highly correlated topographic and climatic data are used. Hu and Jiang (2010), in a comparison of three competing Maxent models (i.e., full, uncorrelated, and pruned model), stated 
the accuracy of the full model on the testing data indicated its predictive ability outside the training data, and regularization in Maxent appears to prevent overfitting better than variableselection methods in regression-based models." Their findings, among others, reveal the robustness of Maxent for ecological modeling where spatially autocorrelated data is often encountered.

Maxent also provides a jackknife analysis which examines each variable independently. The jackknife analysis assesses model performance by removing a select variable, one at a time, for all variables examined as well as examining the performance of each variable used alone in the model. Baldwin (2009) identified the jackknife analysis important for assessing whether the percent variable contribution for each variable in the Maxent model is skewed because of variable collinearity. This analysis is performed to assess the training gain, test gain, and AUC values for each model, and allows for an assessment of how much unique information is provided by each variable (Figure 2.5). Using the jackknife analysis results we graphed, for ease of comparison, the individual variable results of test gain, training gain, and AUC values for all variables examined (Figure 2.6). Comparisons of the AUC and the gain from the test and training data allows an assessment of how much unique information occurs for each variable in predicting red spruce habitat.

Considering the variables with a test and/or training gain greater than one and an AUC statistic greater than 0.8 , several additional variables may also be identified that were not considered important (i.e., $\leq 3 \%$ variable contribution) to the overall model using all variables across 10 replicate model runs. These included: temperature annual range (bio_07), mean temperature of the wettest quarter of the year (bio_08), mean temperature of the driest quarter of the year (bio_09), (bio_10), and the soil derived variable-percent sand. These variables are 
likely important environmental variables in indentifying red spruce habitat but were not chosen because of strong correlation with other variables considered more important in the model.

We also wished to identify the threshold values associated with each variable considered important to the overall model. To do this we examined each variable independently by creating a Maxent model using only the corresponding variable. This allowed us to examine the individual behavior of each variable graphically and to assess its range of values for indicating the presence of red spruce habitat.

Maximum temperature of the warmest month (bio_05) was the most important variable in the model (i.e., variable contribution of $40.6 \%$ ) and possessed a temperature threshold of $25.0^{\circ} \mathrm{C}$ (Figure 2.7). All areas which possessed a maximum temperature less than $25.0^{\circ} \mathrm{C}$ during the warmest month of the year resulted in an increased probability of possessing suitable red spruce habitat. Minimum temperature of the coldest month (bio_06) possessed the second highest variable contribution percentage (i.e., 13.7\%) and possessed a threshold value of approximately $8.5^{\circ} \mathrm{C}$ (Figure 2.8 ). All values less than $-8.5^{\circ} \mathrm{C}$ resulted in an increased probability of possessing suitable habitat for red spruce to a peak of approximately $-10.5^{\circ} \mathrm{C}$. For this variable (bio_06), the reader should note the range of values in which the red spruce presence localities were sampled was between $-10.5^{\circ} \mathrm{C}$ and $-8.2^{\circ} \mathrm{C}$ (Table 2.1 ). This is likely the cause for the noticeable decline in probability of presence below $-10.5^{\circ} \mathrm{C}$ and above $-8.2^{\circ} \mathrm{C}$. However, this range of temperatures does allow us to examine the potential habitat for red spruce where favorable growing conditions with respect to winter minimum temperatures occur.

Slope percentage (slope30) was also considered important for the model with a $6.9 \%$ variable contribution and was likely considered important because this variable decreased the regularized training gain the most when omitted (Figure 2.5). Therefore, slope percentage 
appears to offer the most information that is not present in the other variables. The threshold value for slope percentage ranged from $0-35 \%$ for which suitable red spruce habitat was predicted most likely to occur (Figure 2.9). It is important to note that the significant decrease in probability of presence below $1 \%$ slope is likely an artifact of the data (i.e., none of the red spruce plots I collected occurred on sites with a slope percent less than 1\%). Therefore, the decrease shown below $1 \%$ slope is unlikely to be realistic as red spruce is also found at highelevation sites which offer a relatively flat topography (e.g., bench).

The coldest temperature of the coldest quarter (bio_11) was also considered important for the model and possessed a threshold value of approximately $-1.8^{\circ} \mathrm{C}$. Any values lower than $1.8^{\circ} \mathrm{C}$ indicated an increased likelihood of red spruce presence (Figure 2.10). Mean annual temperature was also important and possessed a threshold value of approximately $8.50^{\circ} \mathrm{C}$. Mean annual temperatures less than $8.50^{\circ} \mathrm{C}$ resulted in an increased likelihood of suitable habitat for red spruce (Figure 2.11).

The last two variables considered important in the analysis were soil type (c_soil) and elevation (ned30m). Soil type, as a categorical variable, contributed $4 \%$ to model performance and included 136 categories for West Virginia. In the red spruce plots sampled, only 12 soil categories were identified, with three categories occurring in greater than $75 \%$ of the red spruce plots sampled. These three soil types, in order of importance, were Trussel-Simoda-MandyGauley (soil category 92), Shouns-Cateache-Belmont (soil category 63), and Dekalb-Buchanan (soil category value 109) (see Appendix II). The final variable having a variable contribution $\geq$ $3 \%$ was elevation. A threshold for elevation was identified at $900 \mathrm{~m}$, at which any values greater resulted in increased probability of red spruce habitat (Figure 2.12). 
After analyzing variables important in the model the next step was to create suitability maps which indicated areas suitable for red spruce habitat in West Virginia. When a replicated Maxent model is created using a training and test dataset, a table of cumulative and logistic threshold values is provided in the output (Table 2.5; Note that the results shown in this table are from one model and vary slightly from the threshold values derived from the average model results across replicate model runs). The threshold values given in this table are determined by calculating binomial probabilities with associated one-sided p-values for the null hypothesis. When test samples exceed 25, a normal approximation to the binomial is used. The null hypothesis tested for here is that the test points are predicted no better a random prediction with the same fractional predicted area used.

For my study, the logistic threshold value for the minimum training presence (MTP) averaged across all 10 model runs was selected to indicate areas of suitable and unsuitable red spruce habitat. My assurance of data accuracy was the driver for this threshold level selection, as the MTP threshold value indicated the habitat suitability threshold value of a training point (i.e., a red spruce presence point) which was used in the model. This MTP value is the lowest threshold at which a plot is used for training which possesses red spruce. Therefore, all pixels with threshold values greater than or equal to the MTP logistic threshold, served as areas which possessed red spruce habitat. Any threshold values falling below the MTP were therefore considered unsuitable.

Using average minimum training presence (MTP) for all 10 bootstrapped replicate Maxent model analyses $(\mathrm{MTP}=0.074, \mathrm{sd}=0.039)$, the total area of suitable red spruce habitat was identified at 282,939 ha (Figure 2.13). Furthermore, red spruce habitat was distinguished by identifying areas of low, medium, and high habitat suitability. The suitability index thresholds 
incorporated were: unsuitable $(0-<0.074)$, low $(0.074-0.36)$, medium $(>0.36-<0.65)$, and high (0.65-1). These threshold values were classified in ArcMap using equal-interval splits for all areas identified as possessing suitable red spruce habitat (i.e., MTP $\geq 0.074$ ). Areas of high suitability were then mapped using appropriate thresholds within ArcMap. The areas identified with high suitability were identified for approximately 7,800 ha in West Virginia (Figure 2.14). Mapped areas of medium suitability were estimated to occupy 83,000 ha, while areas of low suitability were identified on approximately 192,000 ha (Figure 2.15; Figure 2.16).

Examination of high, medium, and low habitat suitability was also assessed with a total of 7,800,83,000, and 192,000 ha of suitable red spruce habitat identified for each category, respectively (Table 2.6). Eighteen counties were identified which possessed suitable red spruce habitat, with an example map for Pocahontas County provided to show the utility of this $30 \mathrm{~m}$ model analysis at a county level. Only five counties, however, possessed greater than $85 \%$ of the total area identified to possess suitable red spruce habitat and included Randolph (33\%), Pocahontas (31\%), Tucker (12\%), Grant (8\%), and Greenbrier (6\%) counties. In addition, nine counties were identified which possessed high suitability with Randolph, Pocahontas, Pendleton, Grant, and Tucker counties accounting for more than $99 \%$ of these areas. Furthermore, four of the ten counties identified possessing medium suitability accounted for more than $90 \%$ of these areas. These counties included Randolph, Pocahontas, Grant, and Tucker. Lastly, of the 18 counties identified with low red spruce habitat, only half possessed areas which exceeded 1,000 ha. These counties were Pocahontas (59,096 ha), Randolph (56,118), Tucker $(25,809$ ha), Greenbrier (14,091 ha), Pendleton (10,843 ha), Grant (10,480), Webster (7,556 ha), Preston (5,379 ha), and Mineral (1,388 ha) (Table 2.6). 


\section{Discussion}

The maximum entropy modeling method performed well (AUC $\geq 0.9$ ) for identifying red spruce forest habitat in West Virginia. It is important to note that the maps created from this modeling effort in no way indicate the occurrence of red spruce. Rather, they indicate areas on the landscape most likely to possess red spruce habitat because they share similarities with respect to the environmental and site-specific variables identified in the red spruce presence localities used as inputs for the Maxent model. However, the creation of these suitability maps for red spruce habitat greatly surpasses the range maps that have been previous formulated for identifying red spruce.

The variables considered to contribute significantly to model performance were important to examine because of the particular habitat preference in which red spruce forests occur. By identifying which particular variables and the thresholds at which they define the occurrence of a given species is an excellent tool for ecologists. It is evident from this model analysis the strong association of climate with the detection of red spruce habitat, particularly when assessing the bioclimatic variables individually (Figure 2.6). Although several variables contributed to model performance, the maximum temperature of the warmest month (bio_05) and minimum temperature of the coldest month (bio_06) were the most important, together contributing more that $50 \%$ to overall variable contribution (Table 2.4 ). These findings indicated that temperature rather than precipitation may be considered the most important driver with respect to habitat preference for red spruce in West Virginia. Other studies (e.g., McLaughlin et al. 1987, Johnson et al. 1988, Cook and Johnson 1989) have also identified red spruce to be primarily temperature rather than precipitation sensitive, with the historic distributions of red spruce in the AMR driven primarily by small changes in temperature (Vann et al. 1994). 
The threshold values or range of values identified from the Maxent analyses are useful for identifying the parameters where red spruce habitat exists. The findings of this study suggest that in West Virginia, red spruce habitat is predominantly found at elevations exceeding $900 \mathrm{~m}$. With respect to temperature red spruce is primarily found in areas which possess a maximum temperature of the month $\leq 25^{\circ} \mathrm{C}$, a minimum temperature of the coldest month $\leq-10.5^{\circ} \mathrm{C}$, and a mean annual temperature $<8.5^{\circ} \mathrm{C}$.

Furthermore, the bioclimatic variable maximum temperature of the warmest month (bio_05) was considered the most important variable in the Maxent model. Other research work has also indicated July temperature (i.e., warmest month) to be an important determining factor for identifying red spruce presence and/or the ecotone between spruce-fir and hardwood ecosystems (e.g., Wolfe 1979; Pielke 1981; Cogbill and White 1991). Wolfe (1979) proposed $20^{\circ} \mathrm{C}$ in the warmest month for the boundary between coniferous and broad-leaved vegetation in the Northern Hemisphere and Australasia; however in North America the regions with temperatures below the $20^{\circ} \mathrm{C}$ isotherm were also identified to possess the spruce transition forest where red spruce occurs within areas dominated by northern hardwood species. In addition, Vann et al. (1994) reported a lower elevation limit in New York coinciding with the approximate $27.7^{\circ} \mathrm{C}$ isotherm for average July daily maximum temperature. Federer et al. (1989), among three regions in the Northeast U.S., also identified temperature in the latter part of the previous growing season and temperature in the winter as important.

In West Virginia, Pielke (1981) also indentified a $20^{\circ} \mathrm{C}$ isotherm which included areas which exhibited only a minor red spruce component. This finding coincides well with my assessment and indicates the importance of summer temperatures in identifying red spruce habitat. Pielke (1981) attributed the $20^{\circ} \mathrm{C}$ isotherm as a critical temperature during the hot 
summer months as a temperature threshold at which red spruce seedlings were likely to be permanently damaged by heat. Although the growing conditions of red spruce have been well documented, it is not been well-established what constraints these temperatures have on growth rates and survival of red spruce (e.g., Korstian 1937; Oosting and Billings 1951; Blum 1990). I agree with the assertion made by Pielki (1981) that red spruce seedling are vulnerable to high summer temperatures and coupled with increased competition from northern hardwood species in areas offering these warmer temperatures, seems logical that red spruce does not possess optimal habitat in such areas.

The importance of the minimum temperature of the coldest month (i.e., winter climate) has been recently addressed as an important consideration when determining the drivers of vegetation and ecosystem functioning (e.g., Kreyling 2010). Although uncertain, it seems the minimum temperature threshold during the coldest month of the year identified in my model may prevent many competitive northern hardwood species from dominating such areas because of their relatively lower resistance to frost damage. This ability or red spruce to endure extreme cold temperatures therefore stresses the importance of temperature-based climatic conditions in identifying suitable red spruce habitat.

Elevation has often been used in the description of red spruce habitat in the central and southern AMR and provided the impetus for our inclusion of this variable in the model analysis. Elevation is also considered important in the delineation of boundaries between species and community assemblages. The elevation threshold for red spruce presence, when examined solely, occurred at approximately $900 \mathrm{~m}$ in West Virginia. When used exclusively in a Maxent model the AUC value for this variable is 0.9 and compares similarly in model importance when examined against other important bioclimatic variables (Figure 2.6). This $900 \mathrm{~m}$ threshold 
identified in my study, affirms the other historical and current descriptions of the elevational transition into red spruce forest habitats identified in West Virginia (e.g., Egleston 1884; Pielke 1981; Stephenson 1993).

The identification of 282,939 ha of suitable red spruce habitat in West Virginia provides a baseline for determining areas on the landscape where red spruce forests exist or could potentially inhabit and persist under the current climatic conditions used for these models. This research effort has great utility for the active red spruce restoration activities being implemented to establish connectivity between stands and to connect red spruce at higher elevations with the red spruce occurring in the high-elevation valleys, specifically Canaan Valley (Tucker County). Many red spruce plantings have been conducted in West Virginia in recent years by many federal, state, and local parties to establish connectivity of the red spruce ecosystem.

Regarding restoration, this Maxent analysis using statistically-downscaled bioclimatic data will also allow users of these output maps to examine the local potential for spruce restoration at a $30 \mathrm{~m}$ resolution, and would be highly beneficial when used in combination with high-resolution aerial photographs to identify areas that possess suitable habitat but lack the presence of red spruce. By identifying areas which possess the highest probability of supporting red spruce habitat (i.e., high suitability) and implementing these findings into the current restoration and conservation management strategies being used would be of wise-use so that the labor and money spent in these actions are done so with the greatest potential for success. Planting and managing for red spruce in such areas would greatly increase the likelihood of survival and establishment of a red spruce forest community in the future. 


\section{Conclusion}

This modeling effort provides a necessary means to identify suitable red spruce habitat in West Virginia. Additionally, the incorporation of these suitability maps provides a guide for identifying areas most likely to possess the highest suitability and therefore the best combination of environmental and site-specific conditions. These output maps will be of great utility to the current and future conservation and restoration management activities with regard to red spruce in West Virginia. In the face of climatic uncertainty, ensuring the areas identified to possess a high suitability for red spruce habitat should be of primary concern. These areas represent the core areas with respect to habitat and likely possess the unique habitat required by complex red spruce communities. Once these areas have been prioritized for future restoration efforts, then areas of which possess medium or low suitability may be examined. The restoration of red spruce will not only increase the habitat required by the numerous species which thrive in this

unique forest ecosystem, but will also provide red spruce the greatest resilience to future climatic conditions by establishing connectivity and increasing genetic diversity. 


\section{Literature Cited}

Acciavatti, R.E., T.J. Allen, A.R. Miller, L.L. Pechuman, B.C. Kondratieff, R.F. Kirchner, A.G. Wheeler, S.M. Clark, E. van der Berghe, and W.J. Arnold. 1993. Insects and spiders of the upland forests. Pp. 143-178 in S.L. Stephenson ed., Upland Forests of West Virginia. McClain Printing, Parsons, W.Va.

Audley, D.E., J.M. Skelly, L.H. McCormick, and W.A. Jackson. 1998. Crown condition and nutrient status of red spruce (Picea rubens Sarg.) in West Virginia. Water, Air, and Soil Pollution 102:177-199.

Avery, T.E. and H.E. Burkhart. 2002. Forest Measurements. $5^{\text {th }}$ edition. McGraw-Hill, New York. 456p.

Baldwin, R.A. 2009. Use of maximum entropy modeling in wildlife research. Entropy 11:854 -866 .

Beane, N.R., Heitzman, E., and T.M. Schuler. 2010. Stand dynamics of an old-growth hemlock -hardwood forest in West Virginia. Natural Areas Journal 30(1):64-72.

Bollinger, J., Kienest, F., and N.E. Zimmerman. 2000. Risks of global warming on montane and subalpine forests in Switzerland- a modeling study. Reg. Environ. Change 1:99-111.

Blum, B.M., 1990. Picea rubens Sarg. Red Spruce. In: Burns, R. M. and B. H. Honkala, editors. Silvics of North America, Volume 1, Conifers. U.S. Department of Agriculture, Forest Service, Agriculture Handbook 654, Washington, D.C. p. 250-259.

Brotons, L., W. Thuiller, M.B. Araujo, and A.H. Hirzel. 2004. Presence-absence versus presence-only modeling methods for predicting bird habitat suitability. Ecography 27:437-448.

Byers, E.A., Vanderhorst, J.P., and B.P. Streets. 2010. Classification and conservation assessment of upland red spruce communities in West Virginia. WV Natural Heritage Program, WVDNR, Elkins, WV, 68p.

Clarkson, R.B. 1964. Tumult on the Mountains. McCain Printing Co., Parsons, West Virginia.

Clarkson, R.B., W.H. Duppstadt, and R.L. Guthrie. 1980. Forest wildlife plants of the Monongahela National Forest. Boxwood Press, Pacific Grove, CA. 283 p.

Cogbill, C.V., and P.S. White. 1991. The latitude-elevation relationship for spruce-fir forest and treeline along the Appalachian mountain chain. Vegetatio 94:153-175.

Cook, E.R. and A.H. Johnson. 1989. Climate change and forest decline: a review of the red spruce case. Water, Air, and Soil Pollution 48:127-140. 
Comer, P., Faber-Langendoen, D., Evans, R. Gawler, S., Josse, C., Kittel, G., Menard, S., Payne, M., Reid, M., Schulz, K., Snow, K., and J. Teague. 2003. Ecological systems of the United States: A working classification of U.S. terrestrial systems. NatureServe, Arlington, VA.

Egleston, N.H. 1884. Report on forestry, Vol. 4, Government Printing Office, Washington, D.C., $421 \mathrm{pp}$.

Elith, J., C.H. Graham, R.P. Anderson, M. Dudik, S. Ferrier, A. Guisan, R.J. Hijmans, F. Huetmann, J.R. Leathwick, A. Lehmann, J. Li, G. Lohmann, B.A. Loiselle, G. Manion, G. Moritz, M. Nakamura, Y. Nakazawa, J.McC. Overton, A.T. Peterson, S.J. Phillips, K. Richardson, R. Scachetti-Periera, R.E. Schapire, J. Soberon, S. Williams, M.S. Wisz, and N.E. Zimmerman. 2006. Novel methods improve prediction of species' distributions from occurrence data. Ecography 29:129-151.

Federer, C.A., L.M. Tritton, J.W. Hornbeck, and R.B. Smith. 1989. Physiologically based dendroclimate models for effects of weather on red spruce basal-area growth. Agricultural and Forest Meteorology 46:159-172.

Ford, W.M., Stephenson, S.L., Menzel, J.M., Black, D.R., and J.W. Edwards. 2004. Habitat characteristics of the endangered Virginia Northern Flying Squirrel (Glaucomys sabrinus fuscus) in the Central Appalachian Mountains.

Hernandez, P.A., C.H. Graham, L.L. Master, and D.L. Albert. 2006. The effect of sample size and species characteristics on performance of different species distribution modeling methods. Ecography 29:773-785.

Hijmans, R.J., and C.H. Graham. 2006. The ability of climate envelope models to predict the effect of climate change on species distributions. Global Change Biology 12:2272-2281.

Hijmans, R.J., S.E. Cameron, J.L. Parra, P.G. Jones, and A. Jarvis. 2005. Very high resolution interpolated climate surfaces for global land areas. International Journal of Climatology 25:1965-1978.

Hirzel, A.H. and G. Le Lay. 2008. Habitat suitability modeling and niche theory. Journal of Applied Ecology 45:1372-1381.

Hopkins, A.D. 1891. Black Spruce: Preliminary report. West Virginia Agricultural Experiment Station Bulletin 17:93-102.

Hornbeck, J.W. and J.N. Kochenderfer. 1998. Growth trends and management implications for West Virginia's red spruce forests. North J. Appl. For. 15(4):197-202.

$\mathrm{Hu}, \mathrm{J}$. and Z. Jiang. 2010. Predicting the potential distribution of the endangered Przewalski 's gazelle. Journal of Zoology 282:54-63. 
Hutchinson, G.E. 1957. Concluding remarks. Cold Spring Harbor Symposium on Quantitative Biology 22: 415-457.

Jaynes, E.T. 1957. Information theory and statistical mechanics. Physical Review 106(4):620 -630 .

Jaynes, E.T. 1990. Notes on present status and future prospects. In: Grandy Jr., W.T., and L.H. Schick (eds). Maximum entropy and Bayesian methods. Kluwer, Dordrecht, The Netherlands, 1-13.

Johnson, A.H., E.R. Cook, and T.G. Siccama. 1988. Climate and red spruce growth and decline in the northern Appalachians. Proceedings National Academy Sciences 85:5369-5373.

Korstian, C.F. 1937. Perpetuation of spruce on cut-over and burned lands in the higher southern Appalachian Mountains. Ecological Monographs 7:125-167.

Kreyling, J. 2010. Winter climate change: a critical factor for temperate vegetation performance. Ecology 91(7): 1939-1948.

Legendre, P. 1993. Spatial Autocorrelation: Trouble or New Paradigm? Ecology 74(6):1659 $-1673$.

Manning, C. and H. Schutze. 1999. Foundations of statistical natural language processing. MIT Press, Cambridge, MA. 680 pp.

McCay, D.H., M.D. Abrams, and T.E. DeMeo. 1997. Gradient analysis of secondary forests of eastern West Virginia. Journal of the Torrey Botanical Society 124(2):160-173.

McDonald, B.R. 1993. Rare plants of the upland forests. Pp. 67-85. In Upland forests of West Virginia. Stephenson, S.L., (ed.). McClain Printing Co., Parsons, West Virginia.

McLaughlin, S.B., D.J. Downing, T.J. Blasing, E.R. Cook, and H.S. Adams. 1987. An analysis of climate and competition as contributors to decline of red spruce in high elevation Appalachian forests of the eastern United States. Oecologia 72:487-501.

Menzel, J.M., W.M. Ford, J.W. Edwards, and L.J. Ceperly. 2006a. A habitat model for the Virginia northern flying squirrel (Glaucomys sabrinus fuscus) in the Central Appalachian Mountains. USDA Department of Agriculture, Forest Service, Northeastern Research Station, Newtown Square, PA. Research Paper NE 729. 10p.

Menzel, J.M., W.M. Ford, J.W. Edwards, and T.M. Terry. 2006b. Home range and habitat use of the vulnerable Virginia northern flying squirrel Glaucomys sabrinus fuscus in the Central Appalachian Mountains, USA. Oryx 40(2):204-210.

Millspaugh, C.F. 1891. Forest and shade tree insects. Part II. Black spruce, (Picea mariana (Mill.)). West Virginia University. Agricultural Experiment Station Report 3:171-180. 
Minckler, L.S. 1945. Reforestation in the spruce type in the Southern Appalachians. Journal of Forestry 43(5): 349-356.

Odom, R.H., W.M. Ford, J.W. Edwards, C.W. Stihler, and J.M. Menzel. 2001. Developing a habitat model for the endangered Virginia northern flying squirrel (Glaucomys sabrinus fuscus) in the Allegheny Mountains of West Virginia. Biological Conservation 99:245252.

Oosting H.J. and W.D. Billings. 1951. A comparison of virgin spruce-fir forest in northern and southern Appalachian system. Ecology 32(1):84-103.

Parolo G., G. Rossi, and A. Ferrarini. 2008. Toward improved species niche modeling: Arnica montana in the Alps as a case study. Journal of Applied Ecology 45:1410-1418.

Pearson, R.G. 2007. Species` distribution modeling for conservation educators and practitioners. Synthesis. American Museum of Natural History. Available at http://ncep.amnh.org. [Accessed 2 February 2009].

Phillips, S.J., M. Dudik, J. Elith, C.H. Graham, A. Lehmann, J. Leathwick, and S. Ferreir. 2009. Sample selection bias and presence-only distribution models: implications for background and pseudo-absence data. Ecological Applications 19(1):181-197.

Phillips, S.J., M. Dudik, and R.E. Schapire. 2004. A maximum entropy approach to species distribution modeling. In: Proceedings of the $21^{\text {st }}$ International Conference on Machine Learning, ACM Press, New York, pp. 655-662.

Phillips, S.J., R.P. Anderson, and R.E. Schapire. 2006. Maximum entropy modeling of species geographic distributions. Ecological Modelling 190:231-259.

Pielki, R.A. 1981. The distribution of spruce in west-central Virginia before lumbering. Castanea 46(3):201-216.

Raxworthy, C.J., Martinez-Meyer, E., Horning, N., Nussbaum, R.A., Schneider, G.E., Ortega -Huerta, M.A., and A.T. Peterson. 2003. Predicting distributions of known and unknown reptile species in Madagascar. Nature 426:837-841.

Schuler, T.M., W.M. Ford, and R.J. Collins. 2002. Successional dynamics and restoration implicataions of a montane coniferous forest in the central Appalachians, USA. Natural Areas Journal 22(2):88-98.

Stephenson, S.L. 1993. Upland Forest Vegetation. Pp.11-34 in S.L. Stephenson ed., Upland forests of West Virginia. McClain Printing Co., Parsons, West Virginia.

Stephenson, S.L., and H.S. Adams. 1993. Threats to the upland forests. Pp.261-273 in S.L. Stephenson ed., Upland Forests of West Virginia. McClain Printing, Parsons, W.Va. 
Stephenson, S.L., and J.F. Clovis. 1983. Spruce forests of the Allegheny Mountains in Central West Virginia. Castanea 48(1):1-12.

Strausbaugh, P.D., and E.L. Core. 1964. Flora of West Virginia. Introductory Section. West Virginia University Bulletin. Series 65. No. 3-1.

[USGS] United States Geological Survey. 1999. Digital representation of Atlas of United States Trees" by Elbert L. Little. (http://esp.cr.usgs.gov/data/atlas/little/, January 20, 2009).

Vann, D.R., A.H. Johnson, and B.B. Casper. 1994. Effect of elevated temperatures on carbon dioxide exchange in Picea rubens. Tree Physiology 14:1339-1349.

White, P.S., E.R. Buckner, J.D. Pittillo, and C.V. Cogbill. 1993. High-elevation forests: sprucefir forests, northern hardwoods forests, and associated communities. Pp 305-337. In W.H. Martin, S.G. Boyce, and A.C. Echternacht, (eds.). Biodiversity of the Southeastern United States: upland terrestrial communities. John Wiley \& Sons, Inc., New York.

Wiegl, P.D. 2007. The northern flying squirrel (Glaucomys sabrinus): A conservation challenge. Journal of Mammology 88:897-907.

Wolfe, J.A. 1979. Temperature parameters of humid mesic forests of eastern Asia and relation to forests of other regions of the Northern Hemisphere and Australasia. USGS, Geological Survey, Professional Paper 1106.

Yates, C.J., McNeill, A., Elith, J., and G.G. Midgley. 2010. Assessing the impacts of climate change and land transformation on Banksia in the South West Australian Floristic Region. Diversity and Distributions 16:187-201. 
Table 2.1. Climatic variables calculated using AML (Arc-Info workstation script) from the Worldclim-Global Climate Data website (www.worldclim.org) for the 168 red spruce presence localities. The bioclimatic variables were calculated from the AML using monthly minimum, mean, and maximum precipitation and temperature data. All precipitation and temperature data was provided by the West Virginia Division of Natural Resources in 2008.

\begin{tabular}{|c|c|c|c|c|c|}
\hline Variable & Description & Geoprocessing & Min & Max & Mean $\pm \mathrm{SE}$ \\
\hline bio_1 & Annual Mean Temperature & AML script ran using precipitation and temperature data. Units: ${ }^{\circ} \mathrm{C}$ & 5.7 & 8.7 & $6.92 \pm 0.66$ \\
\hline bio_2 & $\begin{array}{l}\text { Mean Diurnal Range (Mean of monthly (max } \\
\text { temp - min temp)) }\end{array}$ & AML script ran using precipitation and temperature data. Units: ${ }^{\circ} \mathrm{C}$ & 9.4 & 13.0 & $11.66 \pm 0.91$ \\
\hline bio_3 & Isothermality (bio_2/bio_7) $(* 100)$ & AML script ran using precipitation and temperature data. Units: ${ }^{\circ} \mathrm{C}$ & $\mathrm{N} / \mathrm{A}$ & $\mathrm{N} / \mathrm{A}$ & $\mathrm{N} / \mathrm{A}$ \\
\hline bio 4 & Temperature Seasonality (st.dev. $* 100)$ & AML script ran using precipitation and temperature data. & $\mathrm{N} / \mathrm{A}$ & $\mathrm{N} / \mathrm{A}$ & $\mathrm{N} / \mathrm{A}$ \\
\hline bio_5 & Maximum Temperature of Warmest Month & AML script ran using precipitation and temperature data. Units: ${ }^{\circ} \mathrm{C}$ & 21.4 & 25.3 & $23.37 \pm 0.89$ \\
\hline bio_6 6 & Minimum Temperature of Coldest Month & AML script ran using precipitation and temperature data. Units: ${ }^{\circ} \mathrm{C}$ & -10.5 & -8.2 & $-9.59 \pm 0.46$ \\
\hline bio_ 7 & Temperature Annual Range (bio_5-bio_6) & AML script ran using precipitation and temperature data. Units: ${ }^{\circ} \mathrm{C}$ & 30.7 & 34.1 & $32.96 \pm 0.58$ \\
\hline bio_8 & Mean Temperature of Wettest Quarter & AML script ran using precipitation and temperature data. Units: ${ }^{\circ} \mathrm{C}$ & -3.2 & 18.2 & $14.50 \pm 3.20$ \\
\hline bio_9 & Mean Temperature of Driest Quarter & AML script ran using precipitation and temperature data. Units: ${ }^{\circ} \mathrm{C}$ & -3.8 & 10.1 & $4.15 \pm 3.80$ \\
\hline bio_10 & Mean Temperature of Warmest Quarter & AML script ran using precipitation and temperature data. Units: ${ }^{\circ} \mathrm{C}$ & 14.9 & 18.4 & $16.68 \pm 0.77$ \\
\hline bio_11 & Mean Temperature of Coldest Quarter & AML script ran using precipitation and temperature data. Units: ${ }^{\circ} \mathrm{C}$ & -4.2 & -1.8 & $-3.34 \pm 0.53$ \\
\hline bio_12 & Annual Precipitation & AML script ran using precipitation and temperature data. Units: $\mathrm{mm}$ & 1139 & 1808 & $1446.59 \pm 126.80$ \\
\hline bio_13 & Precipitation of Wettest Month & AML script ran using precipitation and temperature data. Units: $\mathrm{mm}$ & 109 & 174 & $149.16 \pm 13.80$ \\
\hline bio_14 & Precipitation of Driest Month & AML script ran using precipitation and temperature data. Units: $\mathrm{mm}$ & 77 & 110 & $95.74 \pm 7.48$ \\
\hline bio_15 & Precipitation Seasonality (CV) & AML script ran using precipitation and temperature data. & $\mathrm{N} / \mathrm{A}$ & $\mathrm{N} / \mathrm{A}$ & N/A \\
\hline bio_16 & Precipitation of Wettest Quarter & AML script ran using precipitation and temperature data. Units: $\mathrm{mm}$ & 323 & 499 & $419.87 \pm 36.93$ \\
\hline bio_17 & Precipitation of Driest Quarter & AML script ran using precipitation and temperature data. Units: $\mathrm{mm}$ & 255 & 387 & $316.35 \pm 25.91$ \\
\hline bio_18 & Precipitation of Warmest Quarter & AML script ran using precipitation and temperature data. Units: $\mathrm{mm}$ & 307 & 483 & $405.95 \pm 38.33$ \\
\hline bio_19 & Precipitation of Coldest Quarter & AML script ran using precipitation and temperature data. Units: $\mathrm{mm}$ & 255 & 456 & $337.73 \pm 40.73$ \\
\hline
\end{tabular}


Table 2.2. Other variables acquired for model building and the range of values associated with the 168 red spruce presence localities. All data was geoprocessed by West Virginia Division of Natural Resources in 2008. A _ _" prior to variable name indicates a categorical variable.

\begin{tabular}{|c|c|c|c|c|c|c|}
\hline Variable & Description & Source Data & Geoprocessing & Min & Max & Mean $\pm \mathrm{SE}$ \\
\hline slope30 & Slope (percent) & calculated & $\begin{array}{l}\text { ESRI Spatial Analyst Slope tool: using } \\
\text { ned30m DEM. Units: percent slope }\end{array}$ & 1 & 63 & $16.37 \pm 10.98$ \\
\hline c_soil & Soil type, map unit (MU) name & $\begin{array}{l}\text { US General Soil Map, } \\
\text { (STATSGO2, V.33.1) } \\
\text { 1:250k }\end{array}$ & $\begin{array}{l}\text { Polygons converted to a common } 30 \mathrm{~m} \text { grid } \\
\text { using cell center method. See Appendix II } \\
\text { for classes. (soildatamart.nrcs.usda.gov) }\end{array}$ & $\mathrm{N} / \mathrm{A}$ & N/A & $\mathrm{N} / \mathrm{A}$ \\
\hline ned30m & Elevation & $\begin{array}{l}\text { USGS National Elevation } \\
\text { Dataset }\end{array}$ & $\begin{array}{l}\text { Digital Elevation Model (DEM) at } 30 \mathrm{~m} \\
\text { resolution. Resampled to a common grid } \\
\text { using bilinear interpolation. Units: meters }\end{array}$ & 875 & 1462 & $\begin{array}{c}1169.35 \pm \\
137.73\end{array}$ \\
\hline c_geology & Geologic Series & $\begin{array}{l}\text { West Virginia } 1968 \text { State } \\
\text { Geologic Map. 1:250k }\end{array}$ & $\begin{array}{l}\text { Polygons converted to a common } 30 \mathrm{~m} \text { grid } \\
\text { using cell center method. See Appendix II } \\
\text { for classes. (wvgis.wvu.edu) }\end{array}$ & $\mathrm{N} / \mathrm{A}$ & N/A & N/A \\
\hline c_trmimlf & $\begin{array}{l}\text { Topographic Relative Moisture } \\
\text { Index-Modified-Landform }\end{array}$ & calculated & $\begin{array}{l}\text { Utah State University, RS/GIS Lab, John } \\
\text { Lowery's landform.aml implementing the } \\
\text { methods of Manis (2001). See Appendix II } \\
\text { for classes. }\end{array}$ & $\mathrm{N} / \mathrm{A}$ & N/A & N/A \\
\hline sol & $\begin{array}{l}\text { Total Annual Global Solar } \\
\text { Radiation }\end{array}$ & calculated & $\begin{array}{l}\text { ESRI Spatial Analyst Area Solar Radiation } \\
\text { tool: using ned } 30 \mathrm{~m} \text { DEM. Units: } \\
\text { watts } / \mathrm{m}^{2} / \text { day }\end{array}$ & 982,816 & $1,625,158$ & $\begin{array}{l}1,440,098.98 \\
\pm 96,680.80\end{array}$ \\
\hline $\operatorname{aspct} 30$ & Aspect & calculated & $\begin{array}{l}\text { ESRI Spatial Analyst Aspect tool: using } \\
\text { ned30m DEM. Units: degrees (from North } \\
\text { moving clockwise), flat }=-1\end{array}$ & -1 & 353 & $175.54 \pm 6.61$ \\
\hline trmim & $\begin{array}{l}\text { Topographic Relative Moisture } \\
\text { Index-Modified }\end{array}$ & calculated & $\begin{array}{l}\text { Utah State University, John Lowery's } \\
\text { trmim.aml implementing the methods of } \\
\text { Haplin (1999), Parker (1982), Wilds (1996) } \\
\text { and Manis (2001). }\end{array}$ & 1 & 27 & $13.90 \pm 6.12$ \\
\hline clay & $\begin{array}{l}\text { Percent clay, weighted } \\
\text { average, all horizons }\end{array}$ & $\begin{array}{l}\text { STATSGO2, 1:250k, Soil } \\
\text { Data Viewer, Clay }\end{array}$ & $\begin{array}{l}\text { Polygons converted to a common } 30 \mathrm{~m} \text { grid } \\
\text { using cell center method. }\end{array}$ & 13 & 20 & $16.11 \pm 6.61$ \\
\hline silt & $\begin{array}{l}\text { Percent silt, weighted average, } \\
\text { all horizons }\end{array}$ & $\begin{array}{l}\text { STATSGO2, 1:250k, Soil } \\
\text { Data Viewer, Silt }\end{array}$ & $\begin{array}{l}\text { Polygons converted to a common } 30 \mathrm{~m} \text { grid } \\
\text { using cell center method. }\end{array}$ & 27 & 51 & $45.70 \pm 6.61$ \\
\hline om & $\begin{array}{l}\text { Percent organic matter (om), } \\
\text { weighted average, all horizons }\end{array}$ & $\begin{array}{l}\text { STATSGO2, 1:250k, Soil } \\
\text { Data Viewer, OrgMatter }\end{array}$ & $\begin{array}{l}\text { Polygons converted to a common } 30 \mathrm{~m} \text { grid } \\
\text { using cell center method. }\end{array}$ & 1 & 3 & $2.15 \pm 6.61$ \\
\hline sph & $\begin{array}{l}\text { Soil } \mathrm{pH}(\mathrm{sph}), \text { weighted } \\
\text { average, all horizons }\end{array}$ & $\begin{array}{l}\text { STATSGO2, 1:250k, Soil } \\
\text { Data Viewer, pHwater }\end{array}$ & $\begin{array}{l}\text { Polygons converted to a common } 30 \mathrm{~m} \text { grid } \\
\text { using cell center method. }\end{array}$ & 4 & 5 & $4.26 \pm 6.61$ \\
\hline sand & $\begin{array}{l}\text { Percent sand, weighted } \\
\text { average, all horizons }\end{array}$ & $\begin{array}{l}\text { STATSGO2, 1:250k, Soil } \\
\text { Data Viewer, Sand }\end{array}$ & $\begin{array}{l}\text { Polygons converted to a common } 30 \mathrm{~m} \text { grid } \\
\text { using cell center method. }\end{array}$ & 29 & 58 & $36.95 \pm 6.61$ \\
\hline
\end{tabular}


Table 2.3. Importance value (IV), basal area (BA), and trees per hectare (TPH), and average DBH for all species or species groups examined.

\begin{tabular}{|c|c|c|c|c|}
\hline Species & IV $(\%)$ & $\mathrm{BA}\left(\mathrm{m}^{2} / \mathrm{ha}\right)$ & $\mathrm{TPH}$ & Average DBH $(\mathrm{cm})$ \\
\hline Picea rubens Sarg. & 40.21 & 16.94 & 172.09 & 32.97 \\
\hline Acer rubrum $\mathrm{L}$. & 16.75 & 7.55 & 67.22 & 35.04 \\
\hline Betula alleghaniensis Britton & 11.41 & 4.53 & 51.33 & 30.49 \\
\hline Tsuga canadensis (L.) Carr. & 10.59 & 4.99 & 40.60 & 35.44 \\
\hline Prunus serotina Ehrh. & 9.25 & 5.18 & 27.95 & 46.03 \\
\hline Quercus spp.† & 3.27 & 11.34 & 82.37 & 36.83 \\
\hline Fagus grandifolia Ehrh. & 3.02 & 1.17 & 13.83 & 29.02 \\
\hline Betula lenta $\mathrm{L}$. & 1.00 & 0.41 & 4.41 & 31.79 \\
\hline Acer saccharum Marsh. & 0.87 & 0.40 & 3.38 & 35.60 \\
\hline Pinus resinosa Aiton & 0.62 & 0.30 & 2.35 & 39.85 \\
\hline Magnolia acuminata (L.) L. & 0.45 & 0.22 & 1.62 & 38.49 \\
\hline Acer pensylvanicum $\mathrm{L}$. & 0.40 & 0.07 & 2.65 & 16.75 \\
\hline Liriodendron tulipifera $\mathrm{L}$. & 0.35 & 0.22 & 0.88 & 55.20 \\
\hline Amelanchier arborea (Michx. f.) Fernald & 0.33 & 0.06 & 2.06 & 18.85 \\
\hline Magnolia fraseri Walter & 0.33 & 0.12 & 1.62 & 29.74 \\
\hline Fraxinus americana $\mathrm{L}$. & 0.31 & 0.14 & 1.18 & 35.72 \\
\hline Pinus strobus L. & 0.20 & 0.15 & 0.29 & 80.01 \\
\hline Sorbus americana Marsh. & 0.15 & 0.05 & 0.74 & 26.06 \\
\hline Othert & 0.48 & 1.32 & 13.39 & 37.85 \\
\hline TOTAL & 100.00 & 44.65 & 405.08 & 34.32 \\
\hline
\end{tabular}

†Quercus spp. include northern red oak (Q. rubra L.), white oak (Q. alba L.), and chestnut oak (Q. prinus L.).

tOther species include pin cherry (Prunus pensylvanica L.), American basswood (Tilia americana L.), hawthorn species (Crataegus sp. L.), yellow buckeye (Aesculus flava Aiton), black locust (Robinia pseudoacacia L.), sweet cherry (Prunus avium (L.) L.), shagbark hickory (Carya ovata (Mill.) K. Koch), mockernut hickory (Carya tomentosa (Lam.) Nutt.), and bigtooth aspen (Populus grandidentata Michx.). 
Table 2.4. Average variable percent contribution for all 10 replicated Maxent analyses.

\begin{tabular}{lc} 
Variable & Percent Contribution \\
\hline bio_5 & 40.6 \\
bi__6 & 13.7 \\
slope30 & 6.9 \\
bio_11 & 6.5 \\
bio_1 & 4.6 \\
c_soil & 4 \\
ned30m & 3 \\
c_trmimlf & 2 \\
bio_10 & 1.6 \\
bi__16 & 1.6 \\
c_geology & 1.6 \\
sol & 1.5 \\
bio_7 & 1.3 \\
bio_14 & 1.1 \\
bio_18 & 1 \\
bi__2 & 1 \\
aspct30 & 0.9 \\
silt & 0.8 \\
bio_15 & 0.8 \\
bio_12 & 0.8 \\
bio_8 & 0.8 \\
trmim & 0.7 \\
bio_9 & 0.6 \\
bio_4 & 0.5 \\
bio_3 & 0.5 \\
bio_13 & 0.4 \\
bio_19 & 0.4 \\
bio_17 & 0.3 \\
om & 0.2 \\
clay & 0.1 \\
sph & 0.1 \\
sand & 0 \\
\hline &
\end{tabular}


Table 2.5. Cumulative and logistic thresholds provided in the Maxent output. If test data are available, binomial probabilities are calculated exactly if the number of test samples is at most 25, otherwise using a normal approximation to the binomial. These are 1-sided p-values for the null hypothesis that test points are predicted no better than by a random prediction with the same fractional predicted area. The "Balance" threshold minimizes $6 *$ training omission rate $+.04 *$ cumulative threshold $+1.6 *$ fractional predicted area.

\begin{tabular}{|c|c|c|c|c|c|c|}
\hline $\begin{array}{l}\text { Cumulative } \\
\text { threshold }\end{array}$ & $\begin{array}{l}\text { Logistic } \\
\text { threshold }\end{array}$ & Description & $\begin{array}{c}\text { Fractional } \\
\text { predicted area }\end{array}$ & $\begin{array}{l}\text { Training omission } \\
\text { rate }\end{array}$ & $\begin{array}{l}\text { Test omission } \\
\text { rate }\end{array}$ & P-value \\
\hline 5 & 0.087 & Fixed cumulative value 5 & 0.183 & 0.024 & 0 & 4.88E-43 \\
\hline 4.108 & 0.072 & Minimum training presence & 0.197 & 0 & 0 & $2.06 \mathrm{E}-39$ \\
\hline 26.038 & 0.351 & 10 percentile training presence & 0.069 & 0.095 & 0.286 & $1.36 \mathrm{E}-61$ \\
\hline 18.163 & 0.264 & $\begin{array}{l}\text { Maximum training sensitivity plus } \\
\text { specificity }\end{array}$ & 0.094 & 0.048 & 0.214 & $1.17 \mathrm{E}-53$ \\
\hline 10.275 & 0.172 & $\begin{array}{c}\text { Equal test sensitivity and } \\
\text { specificity }\end{array}$ & 0.133 & 0.048 & 0.143 & $8.46 \mathrm{E}-44$ \\
\hline 5.071 & 0.088 & $\begin{array}{l}\text { Maximum test sensitivity plus } \\
\text { specificity }\end{array}$ & 0.182 & 0.024 & 0 & $2.63 \mathrm{E}-43$ \\
\hline
\end{tabular}


Table 2.6. West Virginia area (ha) by county for low, medium, and high suitability for presence of red spruce habitat.

\begin{tabular}{lrrrr}
\hline Counties & Low Suitability & Medium Suitability & High Suitability & Total Suitability \\
\hline Barbour & 7.2 & - & - & 7.2 \\
Fayette & 134.5 & - & - & 134.5 \\
Grant & $10,479.9$ & $10,257.1$ & 396.0 & $21,133.0$ \\
Greenbrier & $14,090.8$ & $1,414.3$ & 18.3 & $15,523.4$ \\
Mercer & 181.1 & - & - & 181.1 \\
Mineral & $1,387.5$ & 316.3 & 5.8 & $1,709.7$ \\
Monongalia & 96.6 & 7.0 & - & 103.6 \\
Monroe & 31.1 & - & - & 31.1 \\
Nicholas & 257.9 & - & - & 257.9 \\
Pendleton & $10,843.3$ & $4,216.9$ & 681.7 & $15,741.9$ \\
Pocahontas & $59,095.7$ & $25,526.3$ & $2,554.9$ & $87,176.9$ \\
Preston & $5,379.2$ & 763.6 & 49.2 & $6,192.1$ \\
Raleigh & 405.6 & - & - & 405.6 \\
Randolph & $56,117.9$ & $32,450.8$ & $3,973.9$ & $92,542.6$ \\
Summers & 129.7 & - & - & 129.7 \\
Tucker & $25,809.0$ & $7,683.0$ & 157.2 & $33,649.2$ \\
Webster & $7,556.0$ & 417.0 & - & $7,973.0$ \\
Wyoming & 35.5 & - & - & 35.5 \\
\hline TOTAL & $192,038.6$ & $83,052.5$ & $7,837.1$ & $282,928.2$ \\
\hline
\end{tabular}




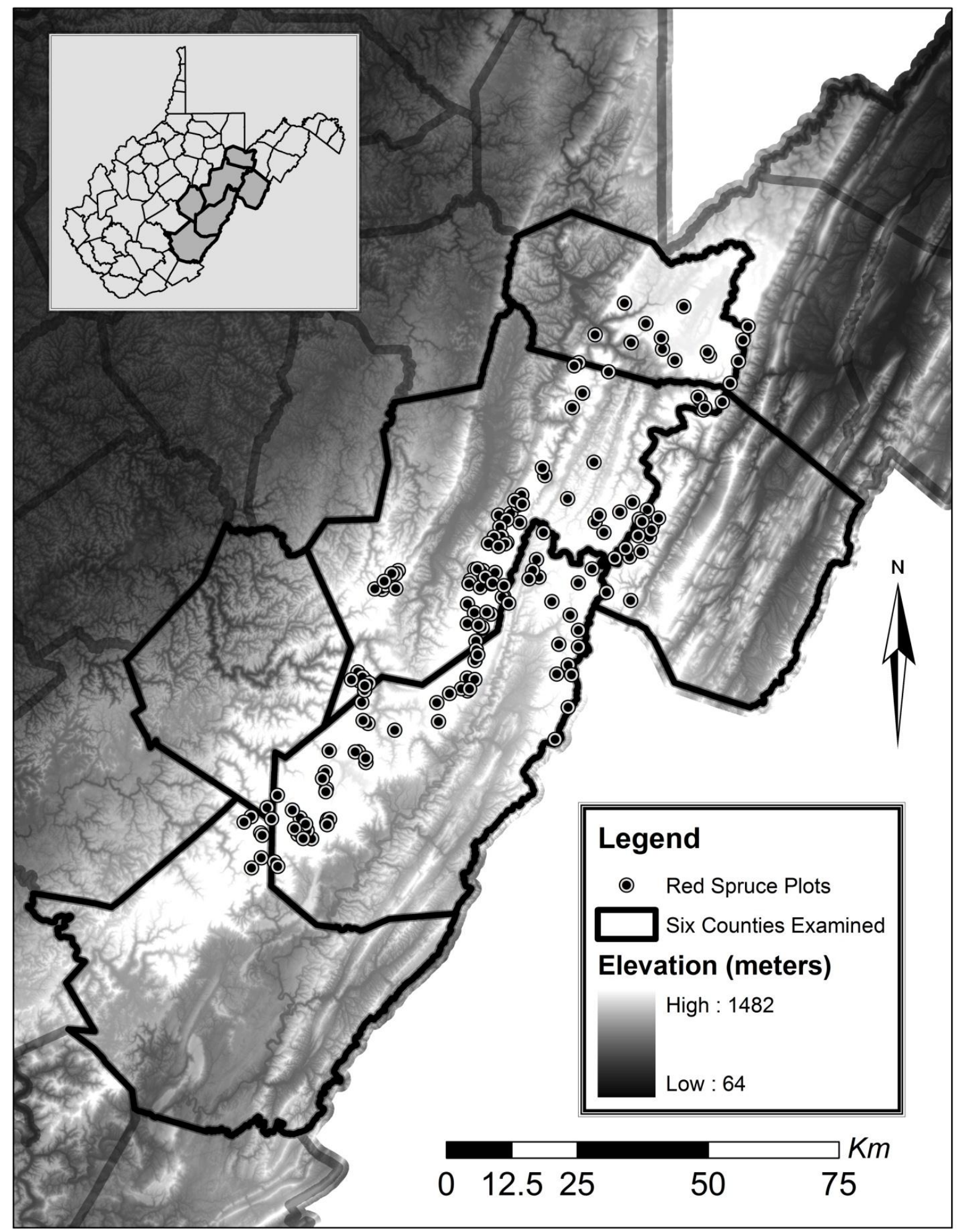

Figure 2.1. Field data collected throughout the Appalachian Mountain Region (AMR) of West Virginia in summers 2008 and 2009. 


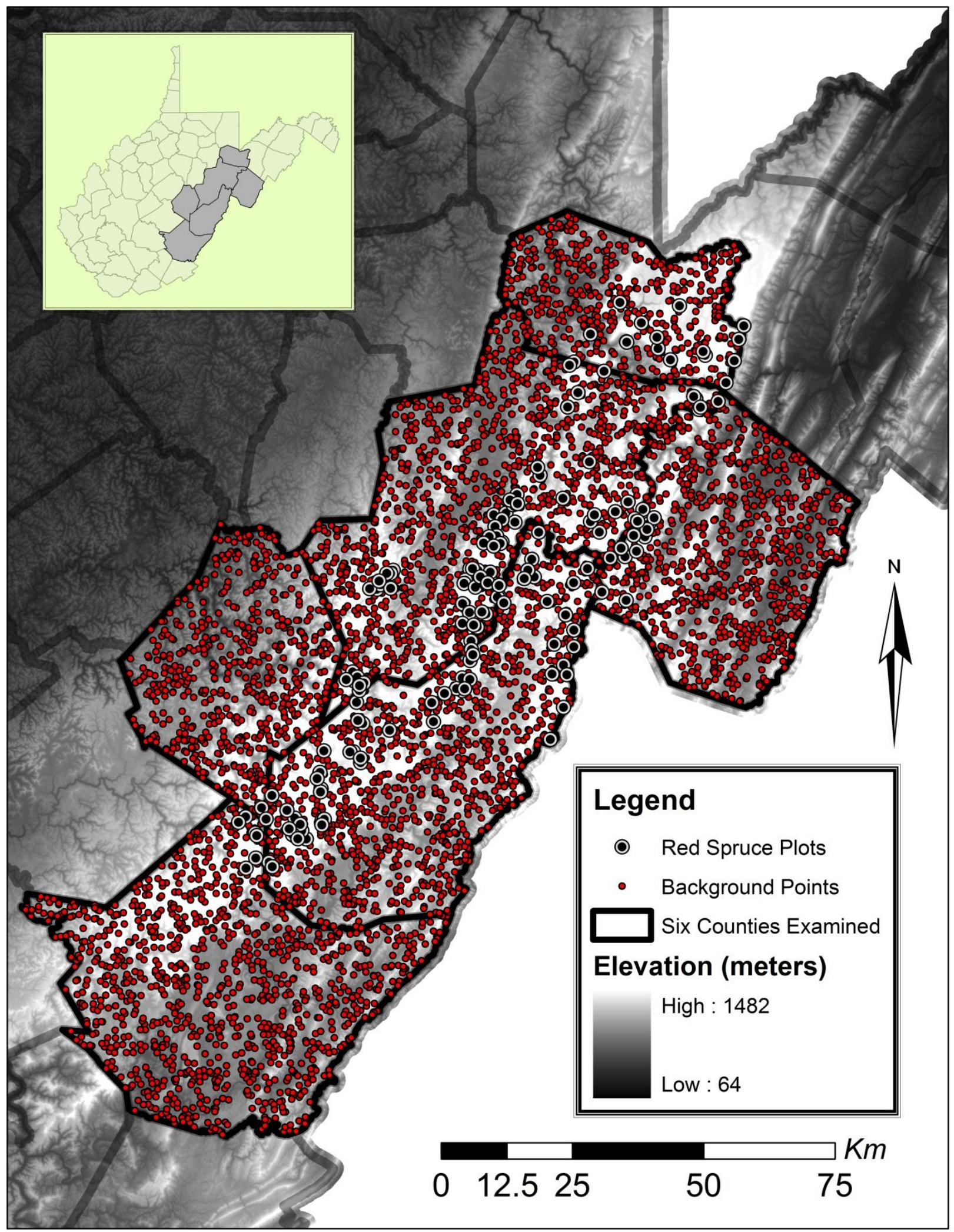

Figure 2.2. Background points generated for our Maxent analysis shown with red spruce plot locations. 


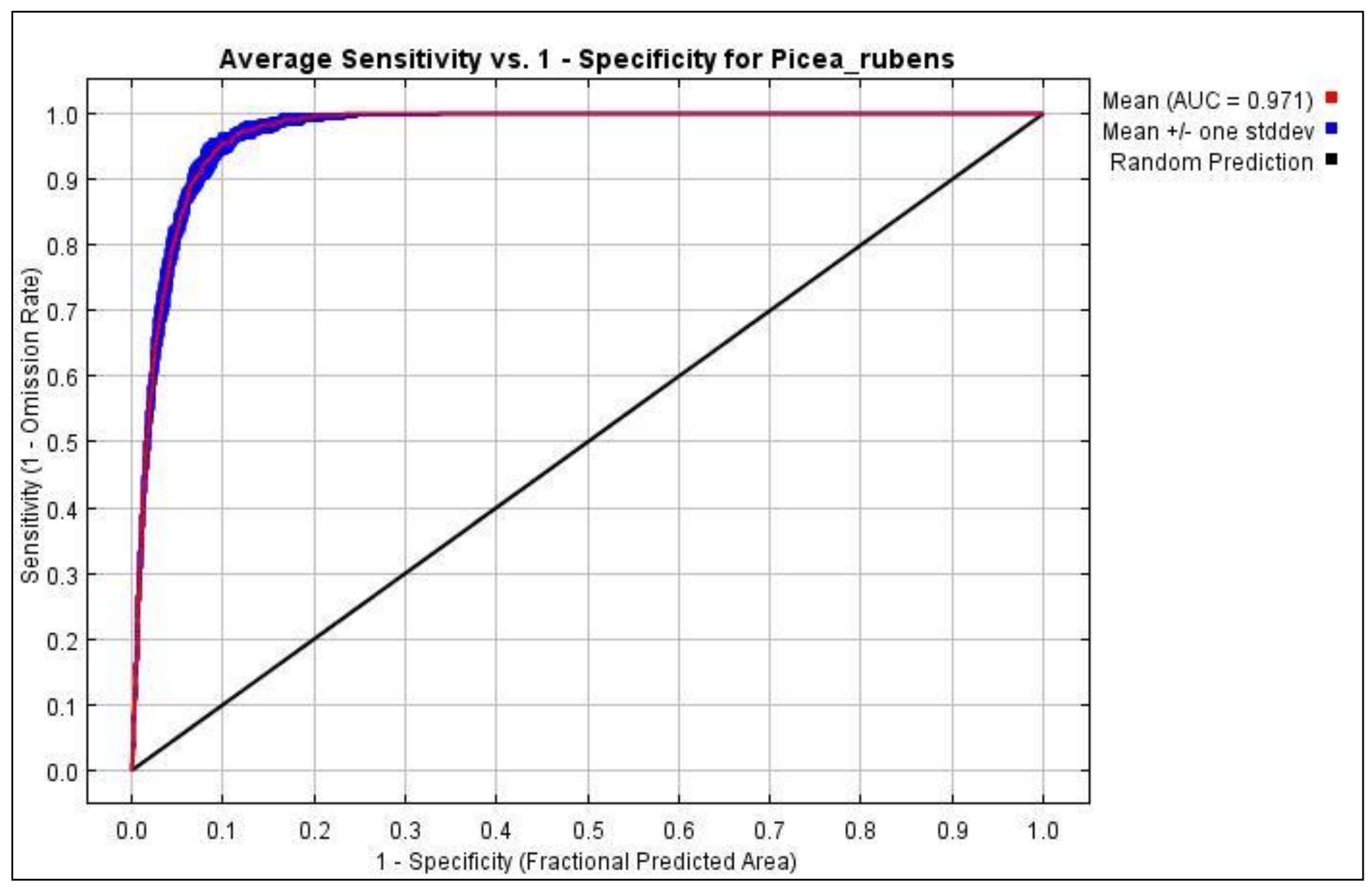

Figure 2.3. Receiver operating characteristic (ROC) curve for current red spruce habitat model, averaged over all ten replicate runs. Specificity is defined here using the predicted area, rather than true commission. The average AUC for all replicate runs was $0.971(\mathrm{sd}=0.008)$. 


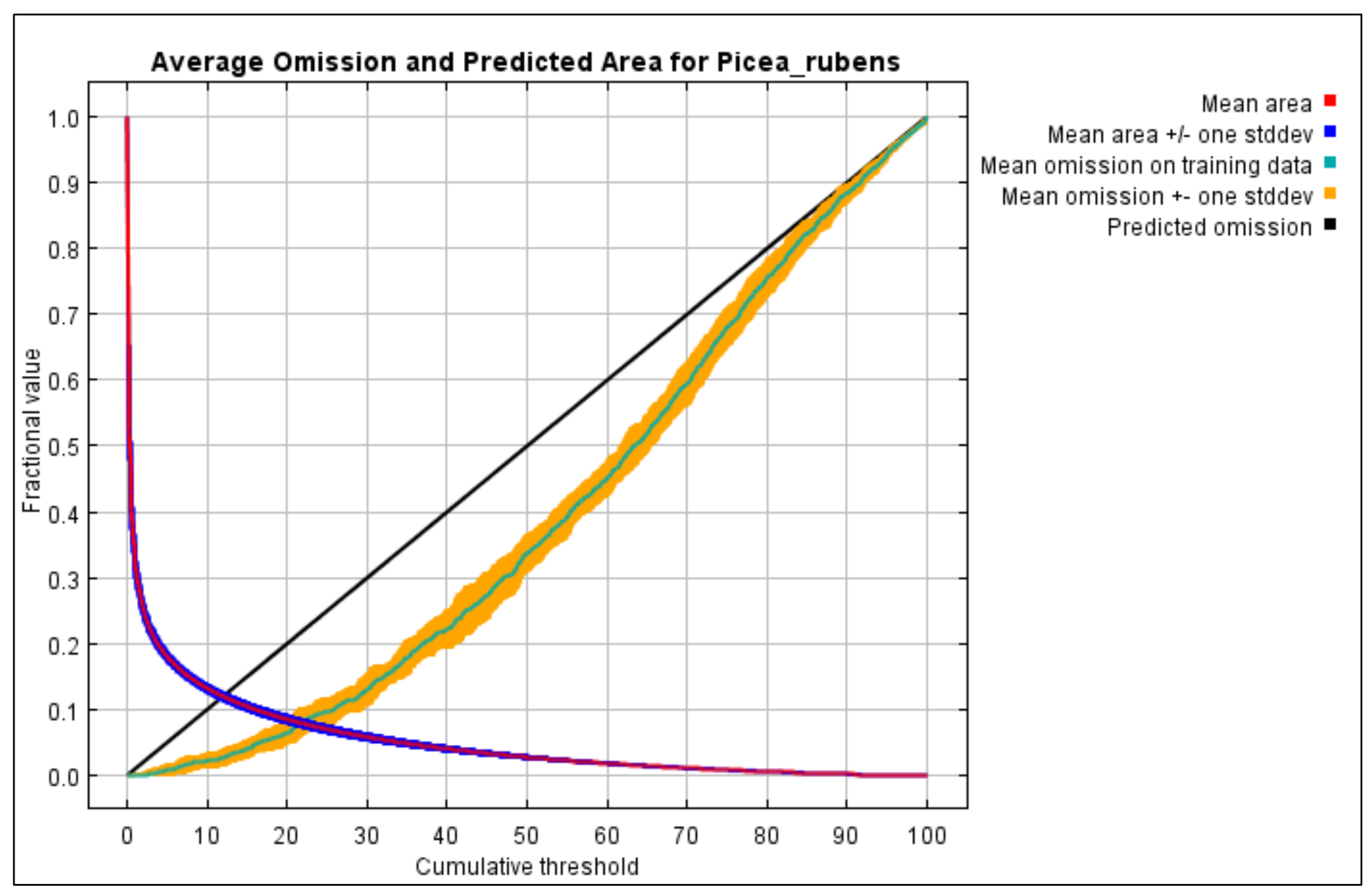

Figure 2.4. Accuracy assessment of Maxent model showing the training omission rate and predicted area as a function of the cumulative threshold, averaged over the ten replicate runs. 


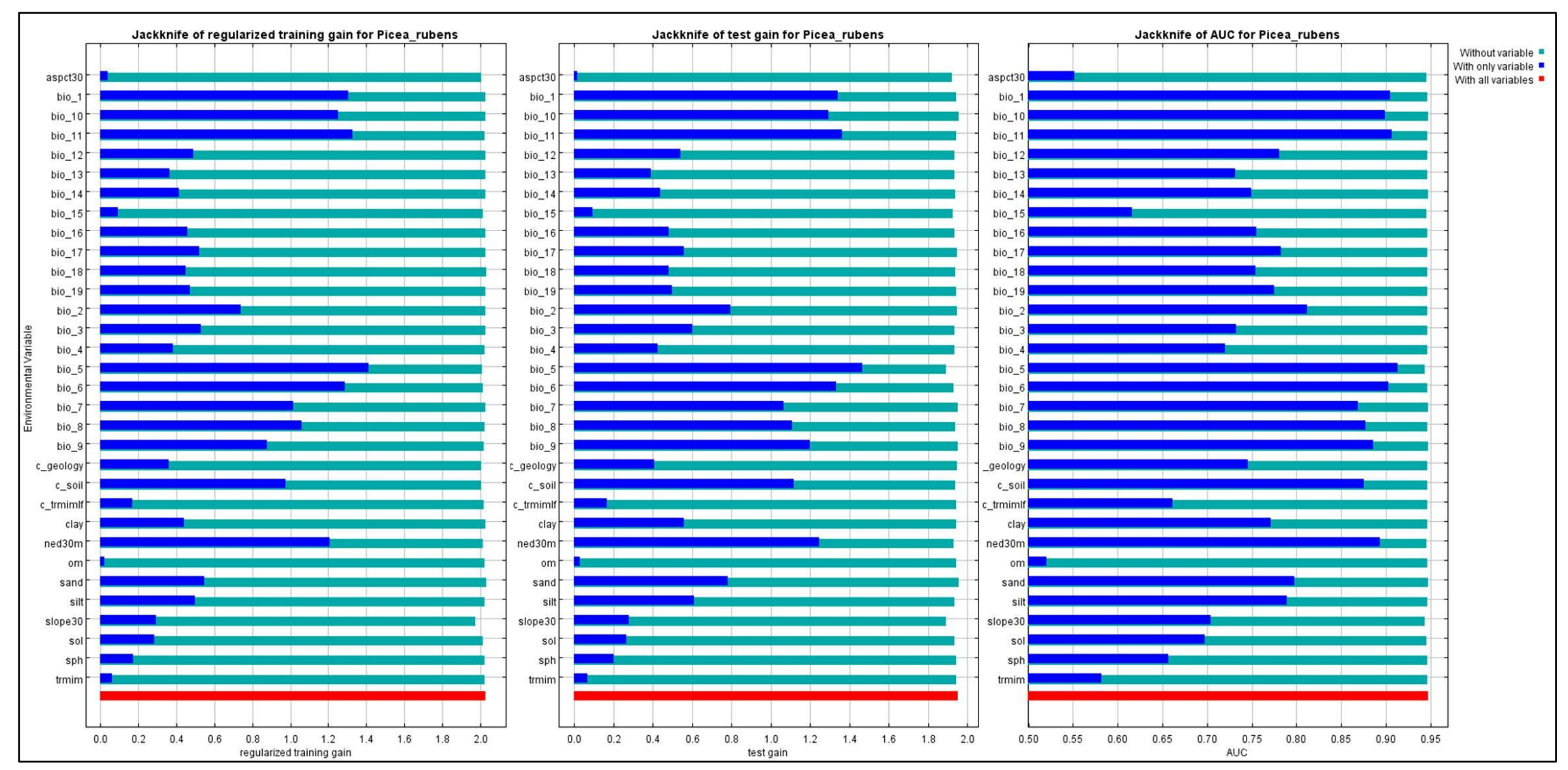

Figure 2.5. Jackknife results provided by Maxent, with and without select variables, with respect to training gain, test gain, and AUC values. 


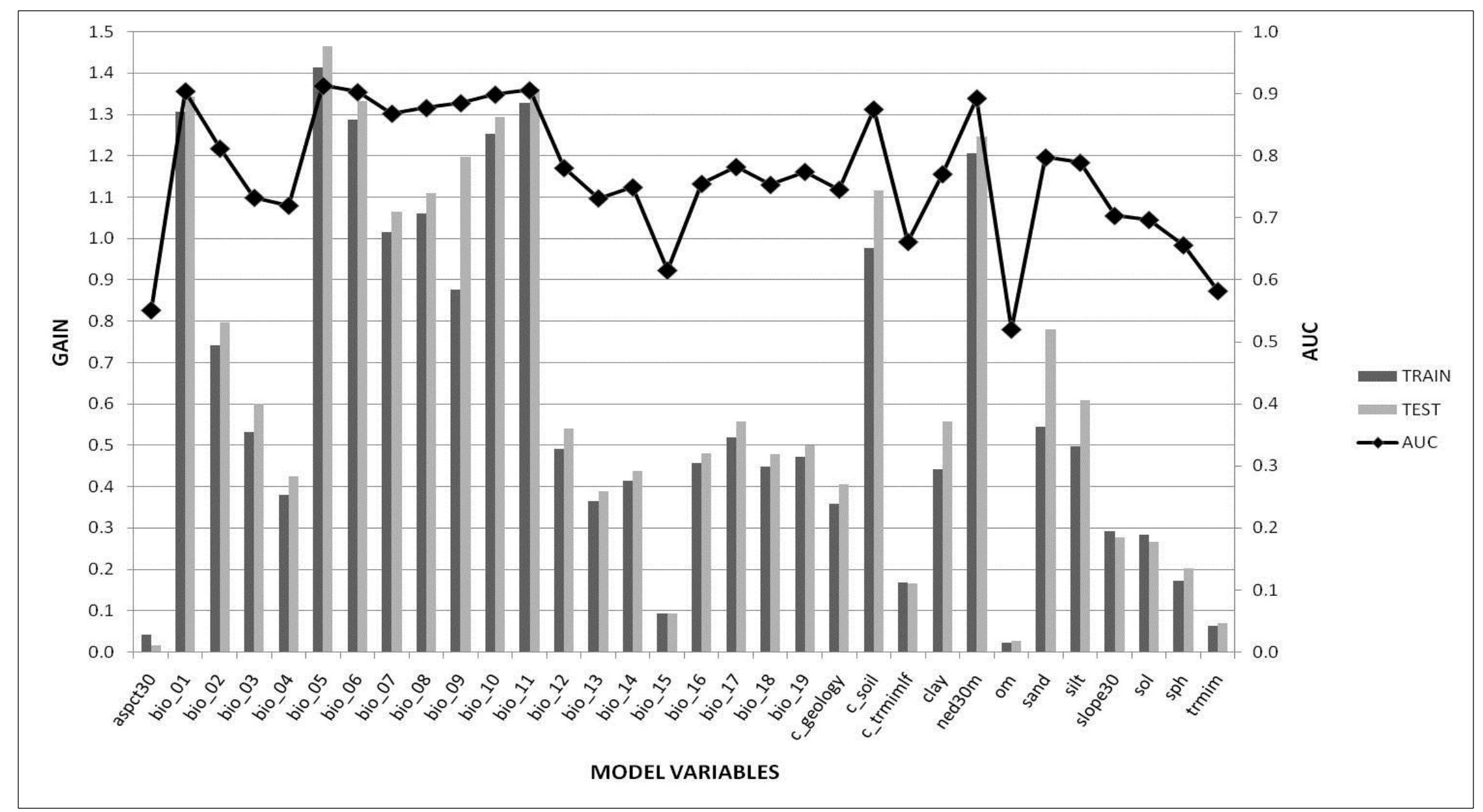

Figure 2.6. Results of training gain, test gain, and AUC values using each variable by itself. This examination is useful when strong variable correlations exist (i.e., climatic data). Additionally, comparison of the training to test gain allows for assessment of how well the model fits the test dataset. 


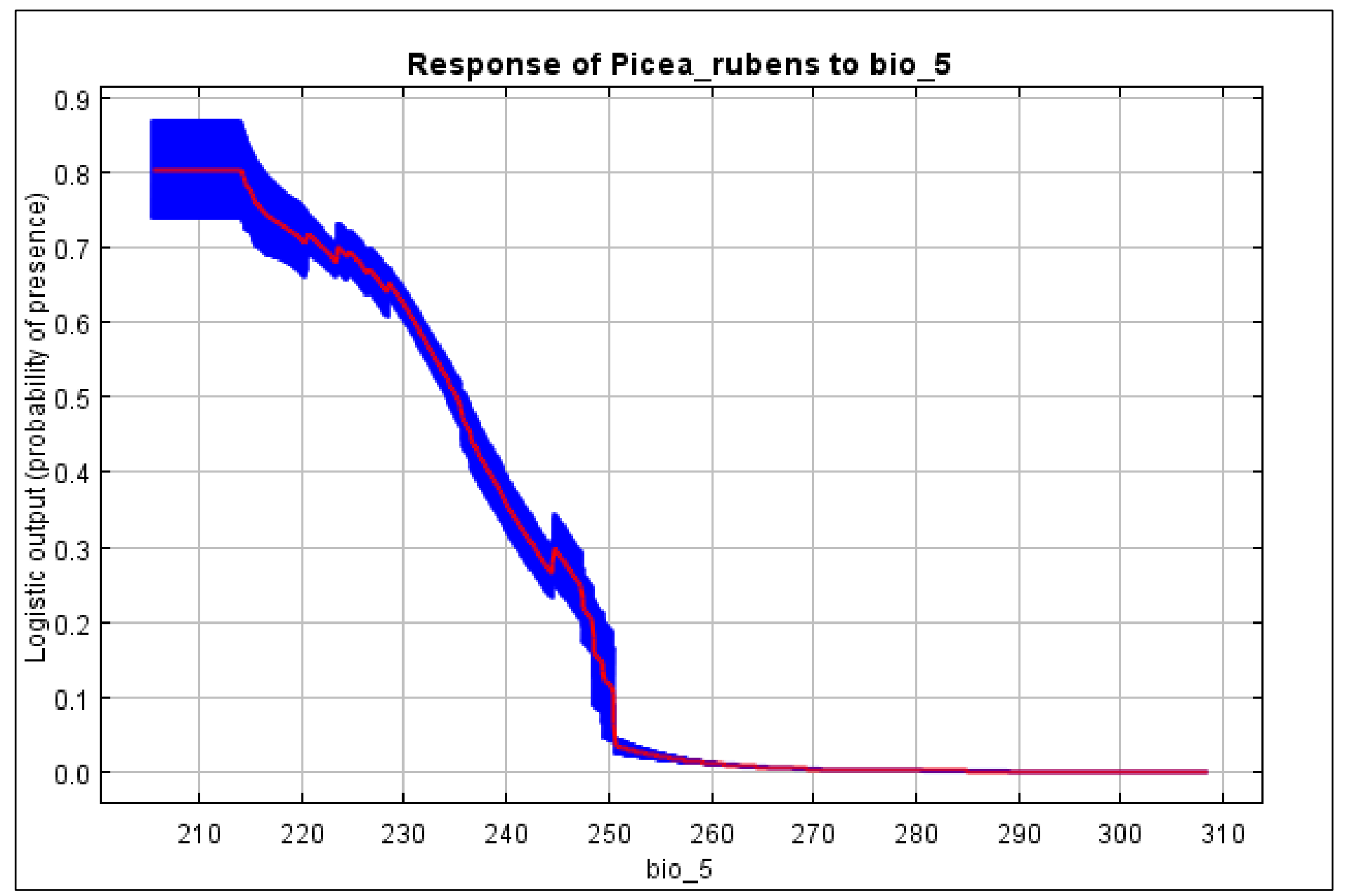

Figure 2.7. Graph of maximum temperature of the warmest month (bio_5). Units are displayed in degrees $\mathrm{C} * 10$. 


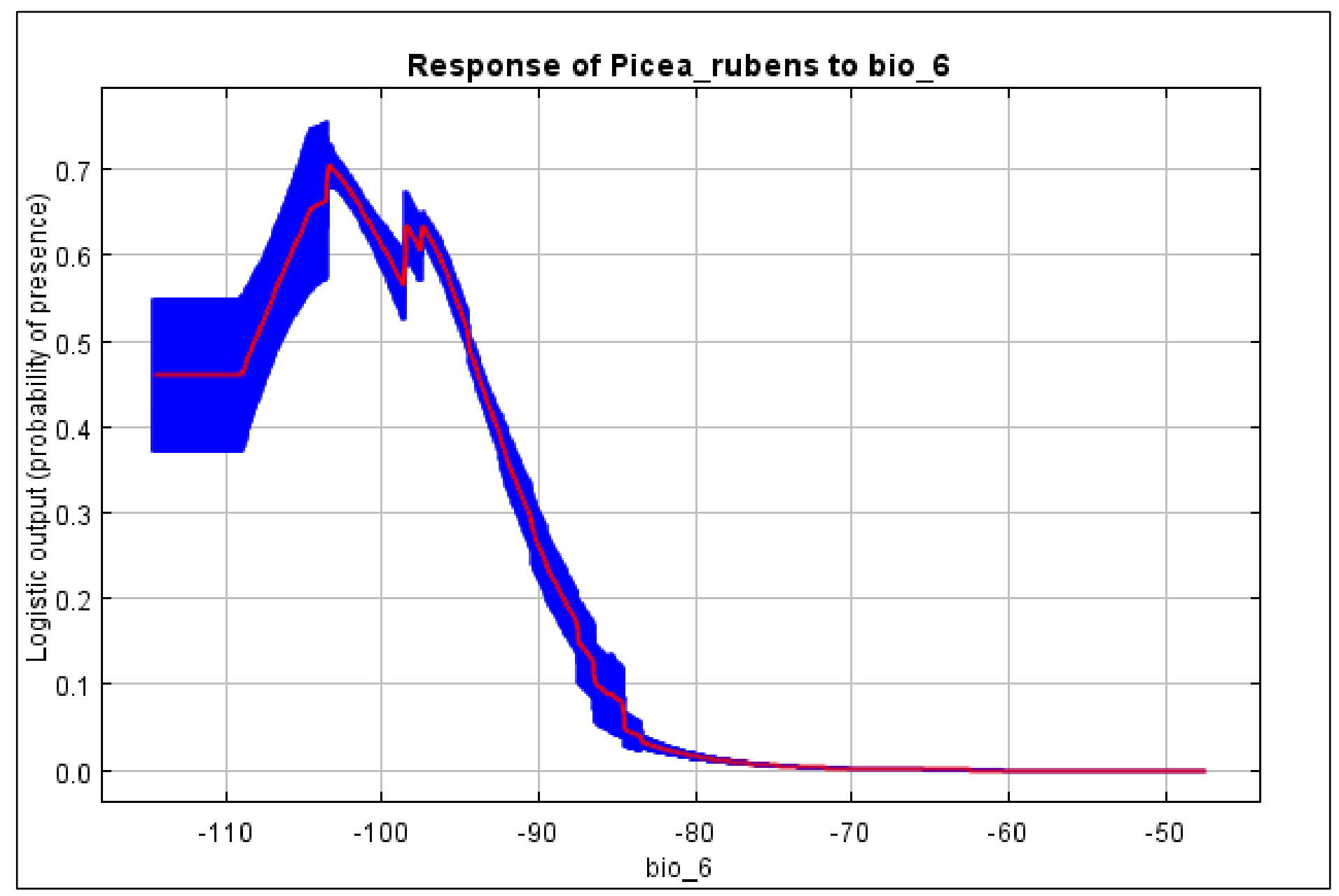

Figure 2.8. Graph of minimum temperature of the coldest month (bio_6). Units are displayed in degrees $\mathrm{C} * 10$. 


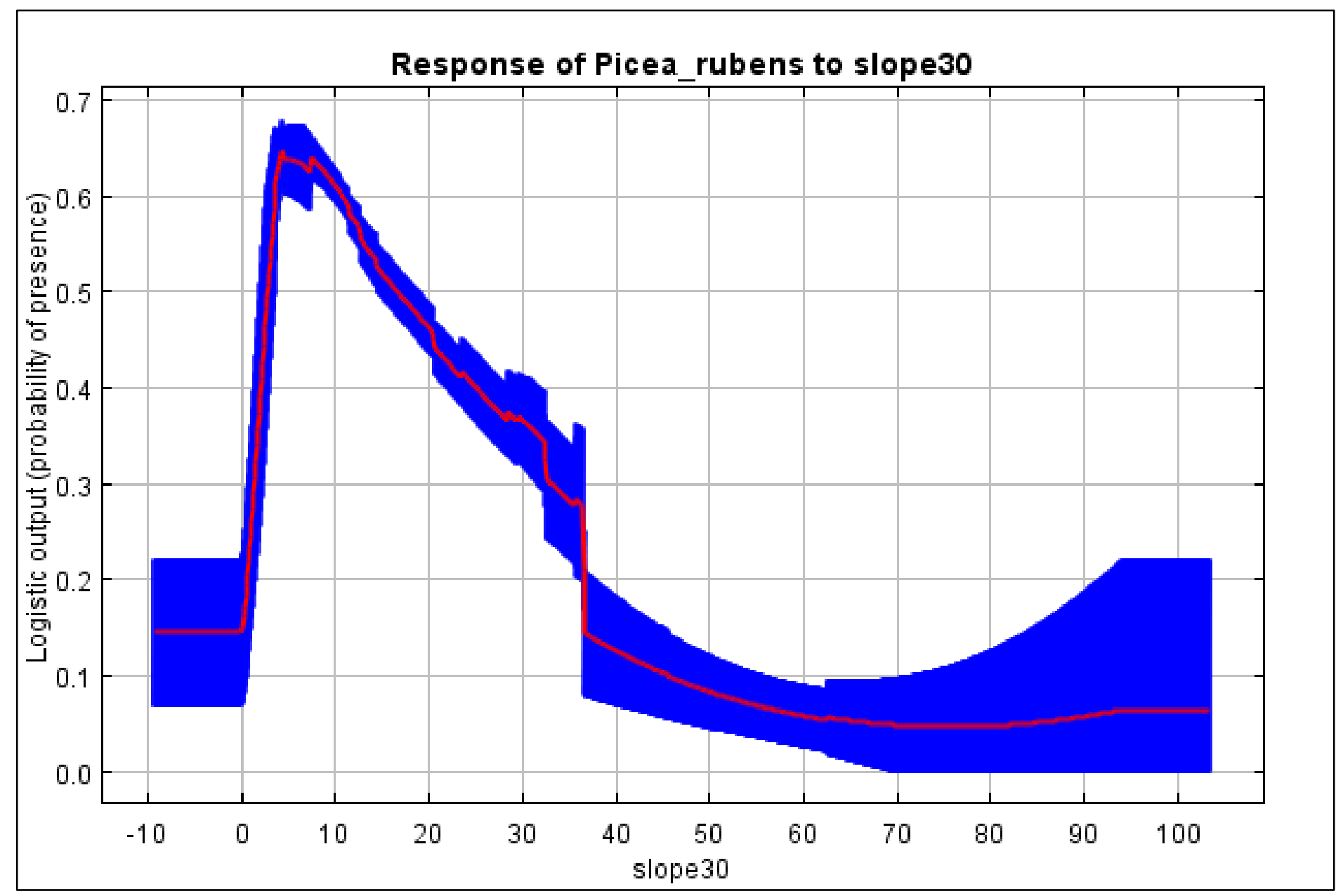

Figure 2.9. Graph of percent slope (slope30). Units are displayed in percent. 


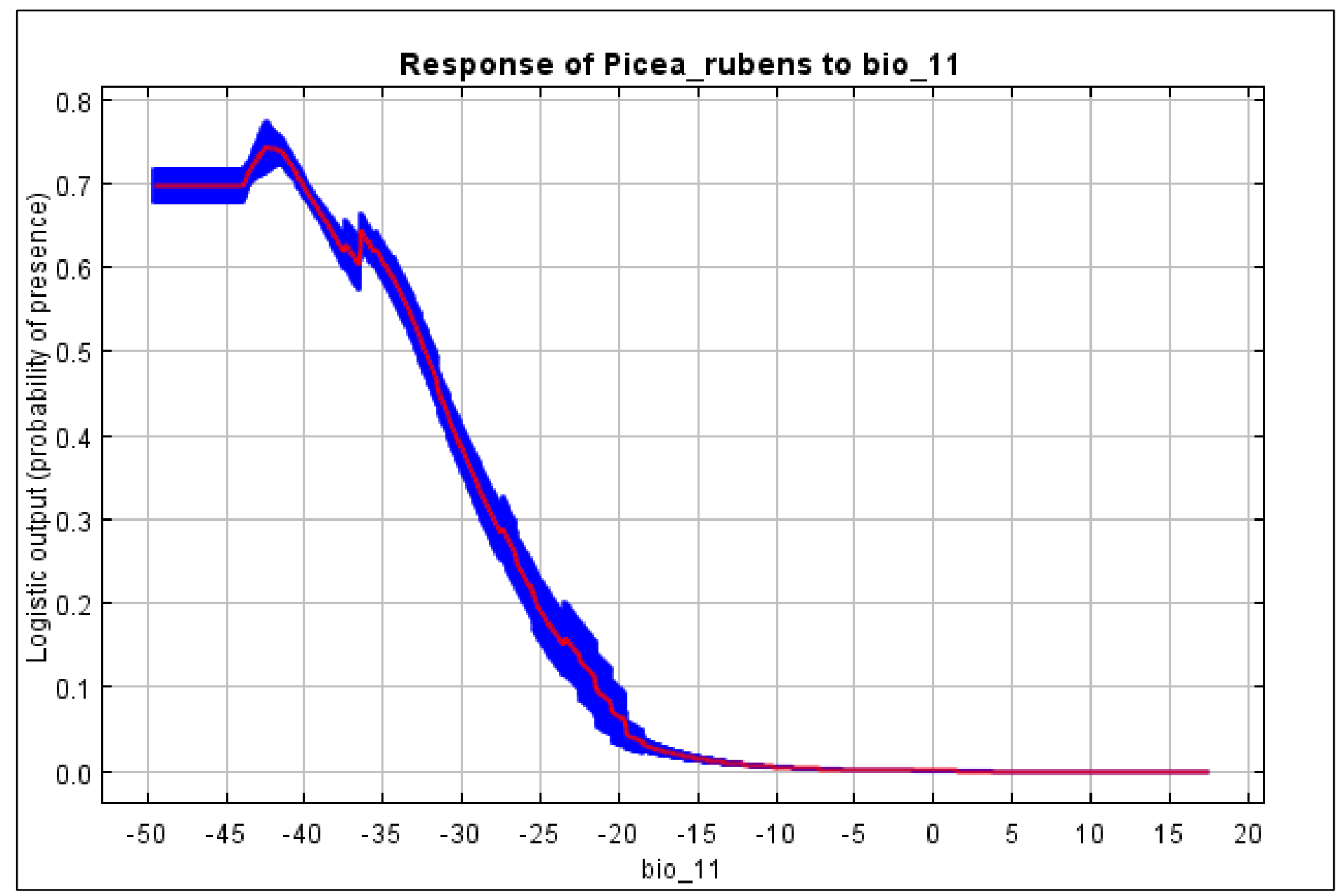

Figure 2.10. Graph of mean temperature of the coldest quarter (bio_11). Units are displayed in degrees $\mathrm{C} * 10$. 


$$
\lambda
$$




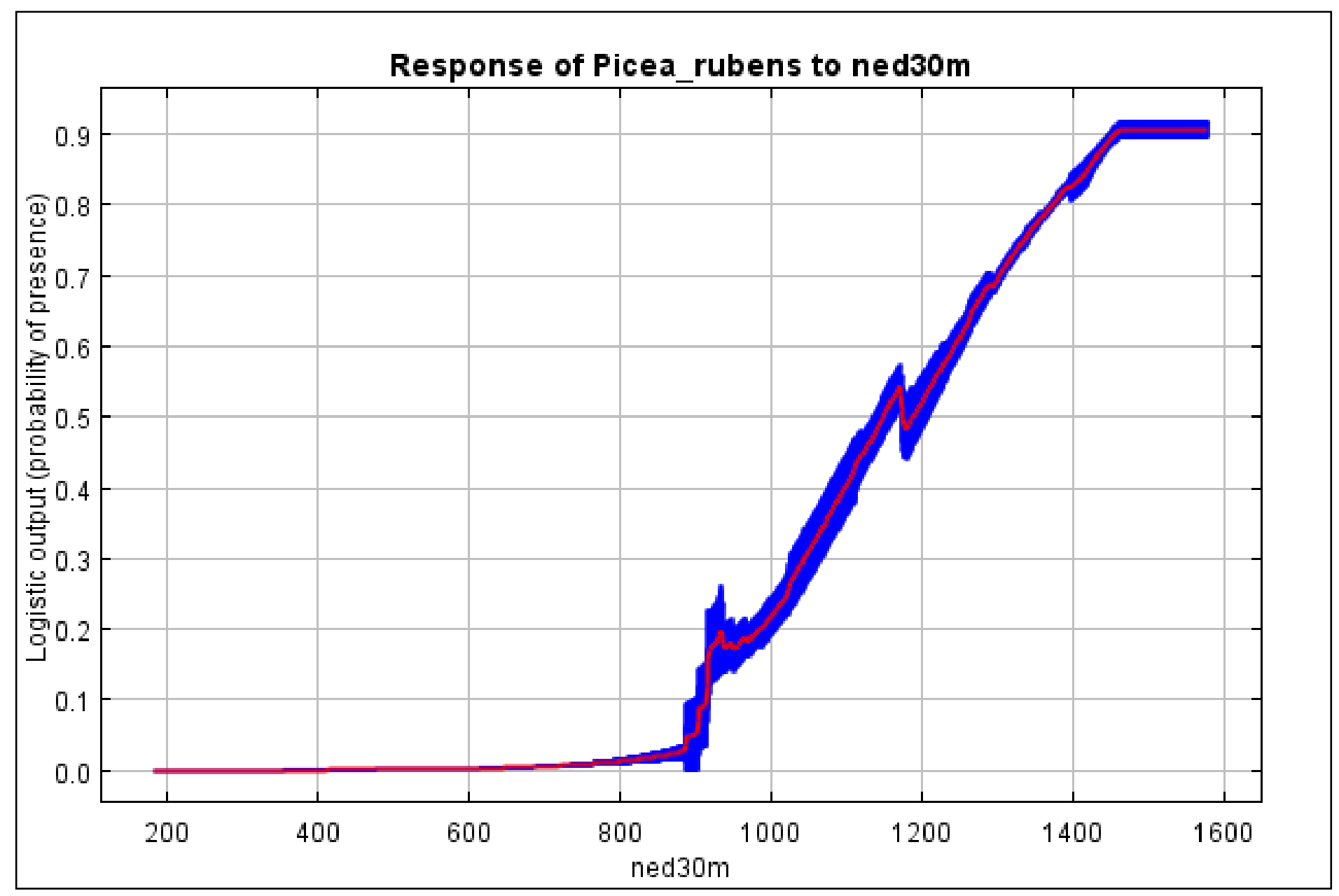

Figure 2.12. Graph of elevation (ned30m). Units are displayed in meters. 


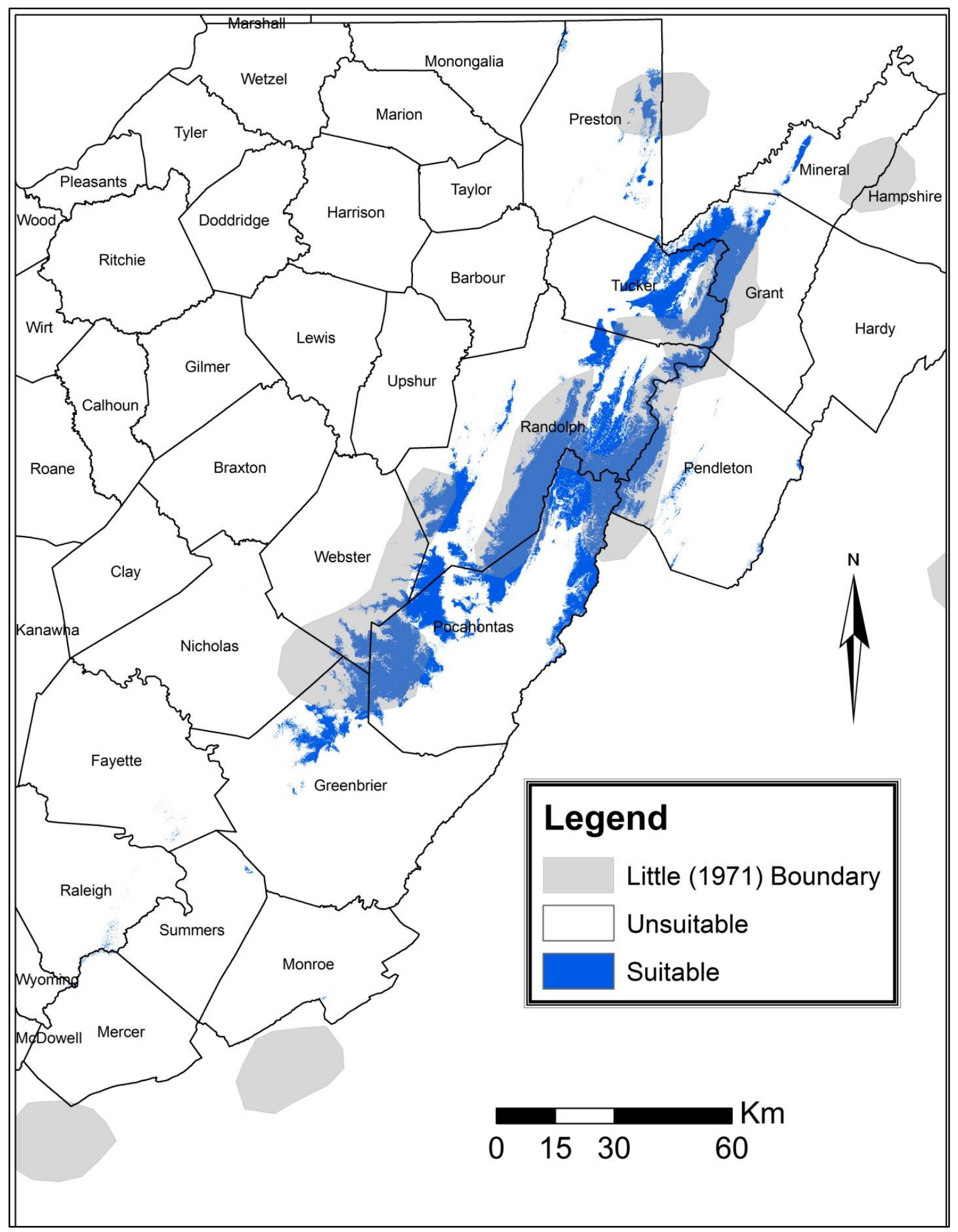

Figure 2.13. Current model results showing suitable and unsuitable habitat for red spruce in West Virginia (MTP threshold=0.07424). Also shown for comparison, the range map for red spruce in North America (USGS 1999). 


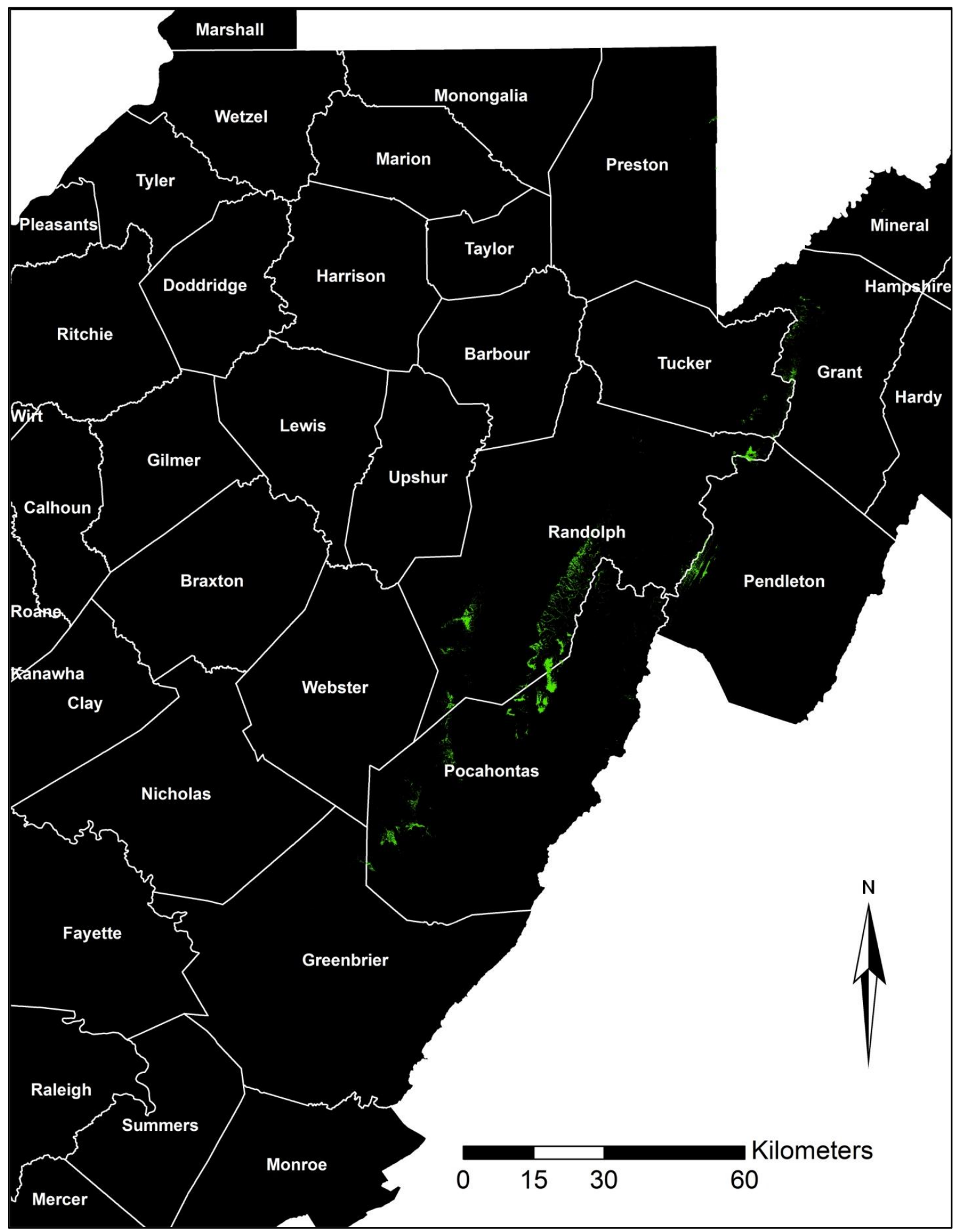

Figure 2.14. Areas modeled having a high probability of suitable red spruce habitat. Counties with high suitability include Grant, Greenbrier, Mineral, Pendleton, Pocahontas, Preston, Randolph, and Tucker.. 


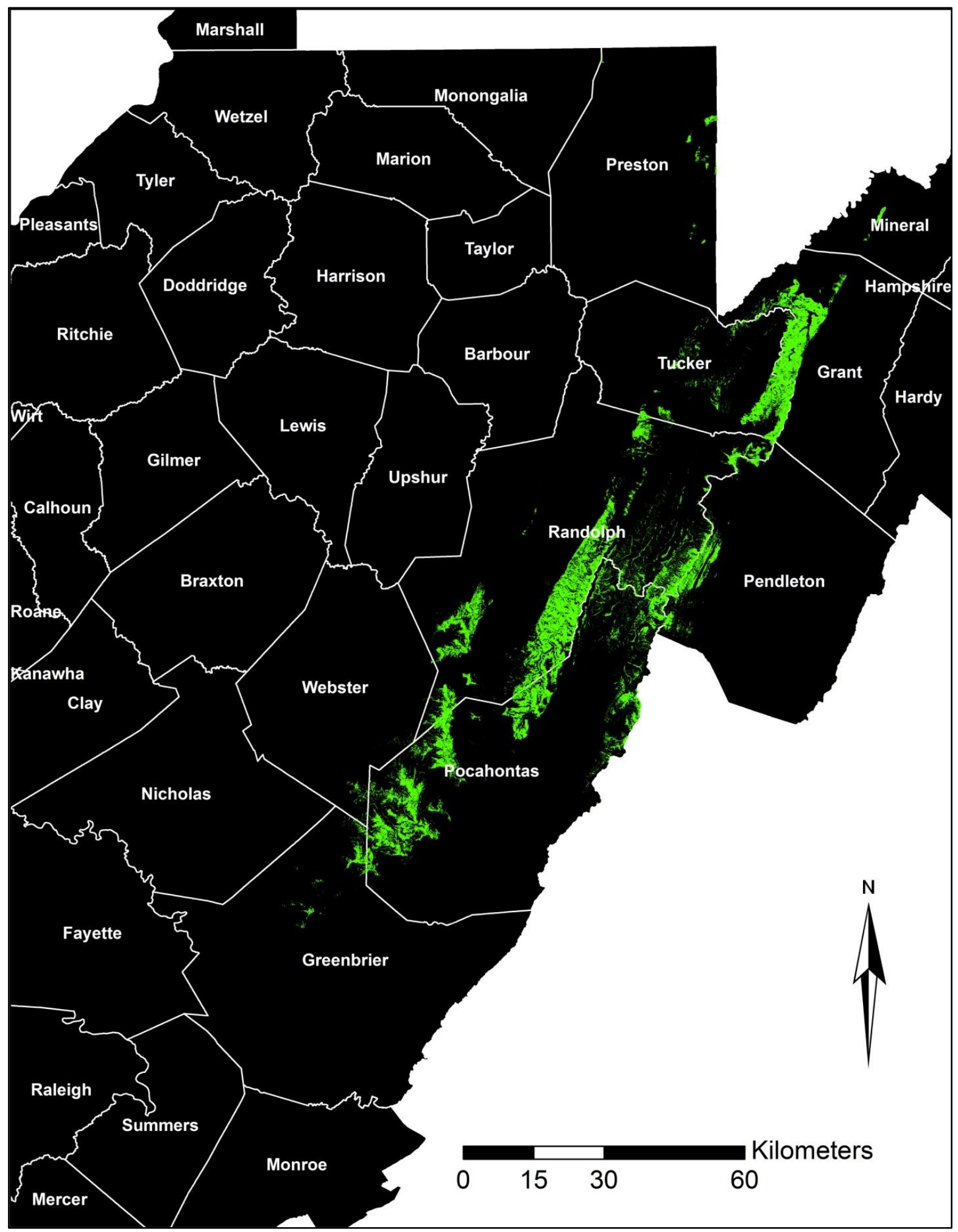

Figure 2.15. Areas modeled having a medium probability of suitable red spruce habitat. Counties which did not possess high suitable habitat but have medium suitability are Monongalia and Webster. 


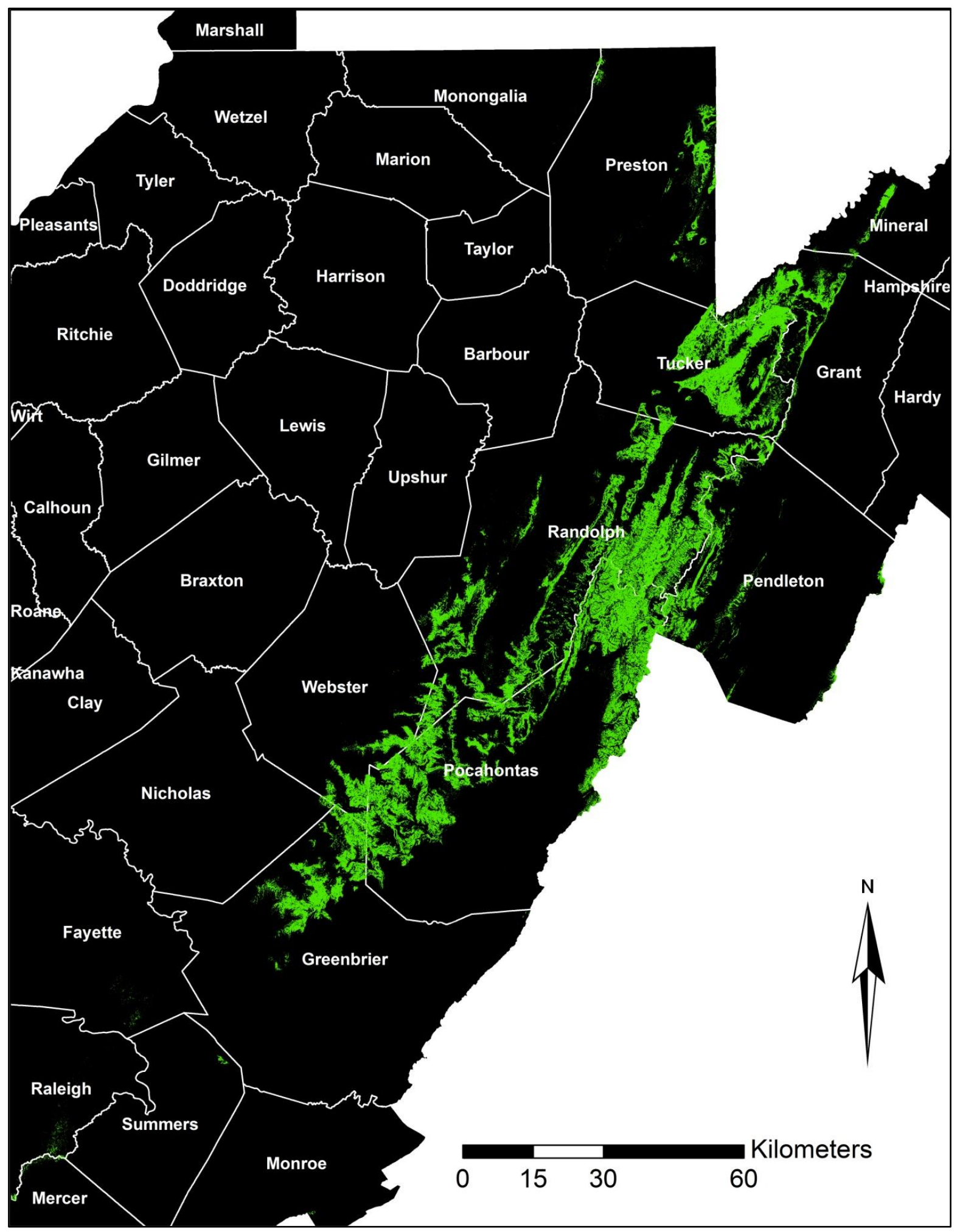

Figure 2.16. Areas modeled having a low probability of suitable red spruce habitat. Counties which did not possess high or medium suitable habitat but have low suitability are Barbour, Fayette, Mercer, Monroe, Nicholas, Raleigh, Summers, and Wyoming.. 


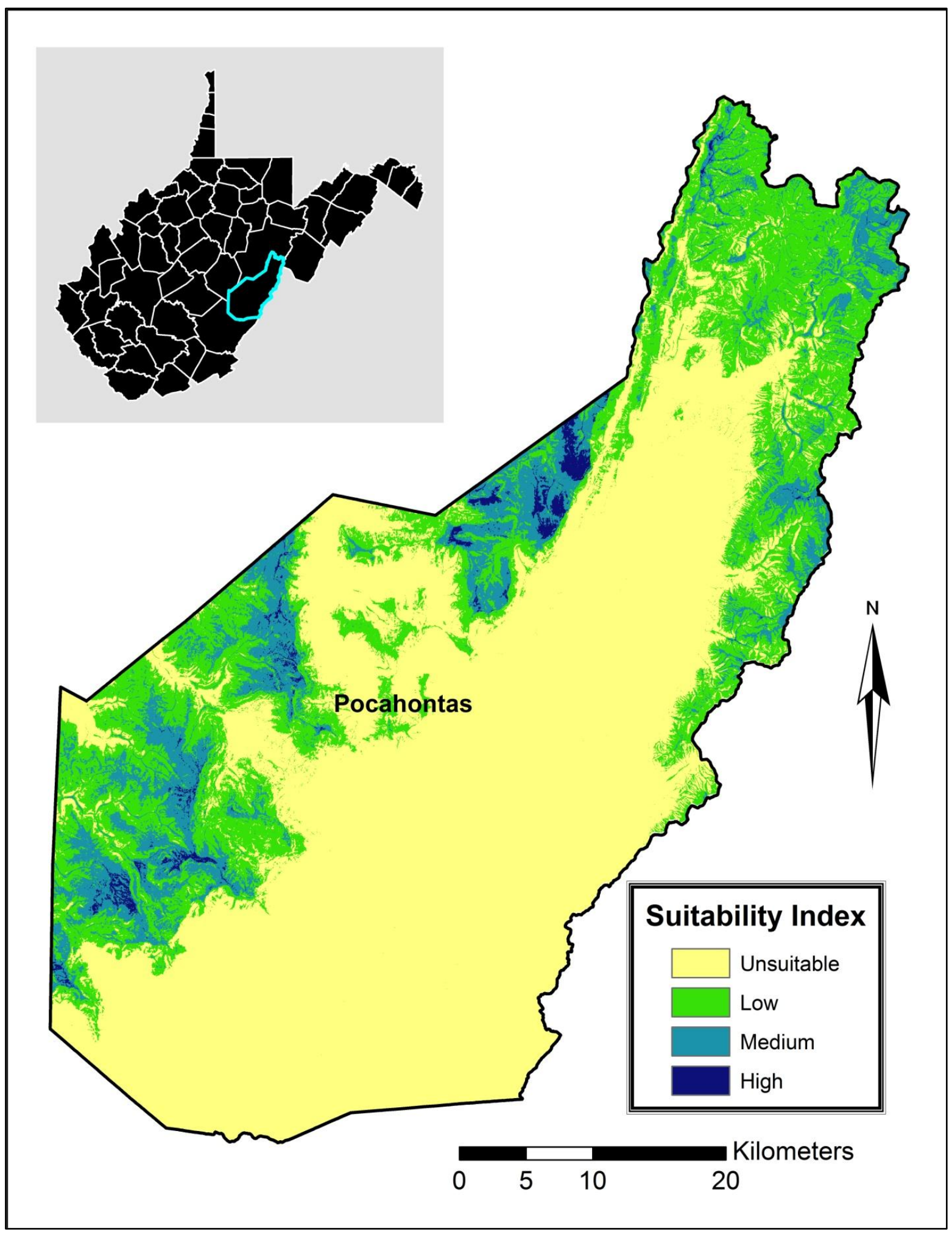

Figure 2.17. Current model results shown at a county level identifying areas of high, medium, and low suitability for red spruce habitat. 
Chapter 3. Using Environmental and Site-specific Variables to Model the Potential Distribution of Red Spruce Forest Habitat in West Virginia under Select Climate Change Scenarios

\begin{abstract}
Many studies now identify the impacts of global climate change as a current and future conservation threat to terrestrial ecosystems. With the changes in climate that have occurred over the last century and that are projected to occur in the $21^{\text {st }}$ century, many plant species are expected to move upwards in elevation or move pole-ward in latitude in response. In West Virginia, red spruce (Picea rubens Sarg.) forests occur in _island-like" distributions among the higher elevations of the state and today are considered a rare forest community, occupying approximately $10 \%$ of its native range. Red spruce has specific habitat requirements, occurring in areas possessing cool temperatures and above average rainfall, and could therefore potentially be greatly affected by climatic warming.

In this study, 168 red spruce presence localities and 24 environmental and site-specific variables were used to model red spruce habitat using select climate change scenarios. Maximum entropy (Maxent) models were created for aggressive and conservative climate change scenarios, with each scenario model performed for three time periods (i.e., 2020, 2050, and 2080). Results for both model analyses indentified three variables which contributed significantly to model performance: mean temperature of the coldest quarter, elevation, and minimum temperature of the coldest month. When combined, these variables contributed more than $40 \%$ to model performance for both scenario models.
\end{abstract}

Changes in suitable habitat area were also assessed for both model scenarios at each time period examined, with dramatic reductions identified. Approximately $6.2 \%$ of the land area in West Virginia was modeled under current conditions. However, by the time period 2020, only $1.3 \%$ and $2.8 \%$ of was identified for the aggressive and conservative climate change models, respectively. By the time period 2080, no suitable red spruce habitat was modeled using the aggressive climate change scenario with 53,866 ha identified using the conservative model, representing less than $1 \%$ of the land area in West Virginia.

Lastly, model results were assessed further to identify areas of low, medium, and high suitability for red spruce habitat at each time period examined and for both scenario models. This analysis was also performed for each county which possessed suitable red spruce habitat to quantify amounts of suitable habitat by county. Eighteen counties were identified to possess current suitable red spruce habitat, with six counties identified possessing high suitability.

These findings indicate the potential impacts of climate change on red spruce forest habitat in West Virginia and should be of great utility to current and future restoration efforts. The utility of this research is that areas are identified which should possess the necessary habitat for red spruce using two diverse climatic change scenarios. If red spruce is restored in the limited areas identified to possess future suitable habitat it should provide this species the greatest resilience to rapid climatic change regardless of which climate change scenario results. 


\section{Introduction}

It is important for forest ecologists to understand the role of climate in defining the spatial patterning of local ecosystems. Climate may be defined as the patterns, means, and extremes of weather (i.e., local atmospheric conditions over a short term) over an extended period of time, typically decades or longer (Barnes et al. 1998; IPCC-AR4 2007). Microclimate (i.e., local variation in climate) influences the spatial patterning of species distributions, with both natural and anthropogenic changes in climate potentially altering the distribution of tree species and their associated productivity (Barnes et al. 1988).

The Earth's climate has warmed over $0.5^{\circ} \mathrm{C}$ in the last century with studies already identifying global climate change as a current and future conservation threat to terrestrial ecosystems (e.g., McCarty 2001). The years 1995-2006 are ranked the twelve warmest years in the instrumental record (i.e., since 1850), with a linear warming trend over the 50 -year period 1956-2005 nearly twice that for the 100 years from 1906-2005 (see IPCC-AR4 2007). In fact, recent greenhouse gas emissions (GHG) have exceeded the latest Intergovernmental Panel on Climate Change (IPCC) Special Report on Emissions Scenarios (SRES) released in 2007, and thus global average temperatures are expected to exceed the $1.5^{\circ} \mathrm{C}$ lower limit cited in the IPCC $4^{\text {th }}$ Assessment Report (Huntley et al. 2010). If this $1.5^{\circ} \mathrm{C}$ lower limit is exceeded, IPCC-AR (2007) project major changes in ecosystem structure and shifts in species' geographical ranges.

With these projected changes in climate, species are expected to move upwards in elevation or move pole-ward in latitude. In West Virginia, red spruce (Picea rubens Sarg.)

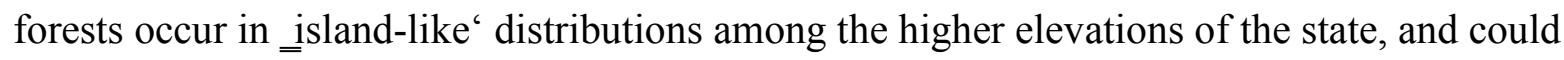
potentially be greatly affected by climatic warming. The extent of red spruce forests in West Virginia prior to exploitative logging from 1880-1920 is estimated at 190,000 ha (Clarkson 1964; 
Millspaugh 1891; Hopkins 1891). Today, these forests are estimated to occupy no more than 24,000 ha, resulting primarily from intense anthropogenic disturbances (Stephenson and Adams 1993). This loss in occupied habitat for red spruce puts this species at an even greater sensitivity to changes in climate as the connectivity which this species possessed prior to anthropogenic disturbances has been dramatically reduced.

As a specialist species, with regard to its habitat requirements, red spruce has a greater potential for habitat modeling than species with more general requirements. In West Virginia, red spruce is found in areas that possess high-elevation, a relatively cool climate, and receive high amounts of rainfall and snow. These areas occur primarily at elevations exceeding 1,000 m; however, red spruce can be found in some areas at elevations as low as $760 \mathrm{~m}$ as found at Cathedral State Park, Preston County (Beane et al. 2010).

Red spruce forests play an important role in watershed protection and boast strong aesthetic values because of the evergreen mountaintop scenery they provide. Red spruce forests are valued on public land particularly because they provide the preferred habitat for the endangered Cheat Mountain salamander (Plethodon nettingi Green) and for the recently delisted Virginia northern flying squirrel (VNFS) (Glaucomys sabrinus fuscus Miller) (Odom et al. 2001; Menzel et al. 2006a; Menzel et al. 2006b). Other high elevation species of conservation concern in West Virginia are the saw-whet owl (Aegolius acadicus Gmelin), snowshoe hare (Lepus americanus Erxleben), northern goshawk (Accipiter gentilis L.), and the fisher (Martes pennanti Erxleben) (Menzel et al. 2006b). The acceleration of red spruce recovery has the potential to enhance or increase habitat availability for these species, and is likely to benefit an array of insects and other invertebrates which have been poorly researched and possibly not yet described (Schuler et al. 2002; Acciavatti et al. 1993). Finally, red spruce, along with eastern hemlock 
(Tsuga canadensis L. Carr.) provides an evergreen canopy critical for maintaining temperatures and water quality of cold water fisheries in high-elevation, headwater streams (Martin and Petty 2009). The recovery and/or expansion of red spruce habitat will benefit numerous wildlife species and further protect those with limited distributions and conservation concern.

With the uncertainty surrounding climatic change and the impacts to red spruce forests in West Virginia, modeling efforts focused on identifying areas best suited for red spruce under select climate change scenarios would be of great importance to conservation and land managers. Ecological researchers have shown much interest in species distribution models (SDMs) used for predicting suitable habitat for a given species (e.g., Bollinger et al. 2000; Raxworthy et al. 2003; Phillips et al. 2006; Elith et al. 2006; Baldwin 2009). SDM`s are not only useful to generate maps identifying areas of suitable habitat but also in determining which variables are the primary drivers for a species' occurrence on the landscape. SDM's may also be used to assess the potential range shifts for a given species under altered climatic conditions and have been proven a valuable tool for many ecological studies (Phillips et al. 2006).

The SDM incorporated for this study is Maximum Entropy (Maxent), a presence-only modeling technique used to characterize a species' niche in environmental space, accomplished by relating observed occurrences to a suite of environmental variables (Pearson 2007). An advantage of Maxent over other SDM techniques is that the estimated distribution must agree with all that is known or inferred from environmental conditions, and thus the technique avoids making assumptions not supported by the data (Jaynes 1957; Jaynes 1990). The objective of the Maxent algorithm is to find the probability distribution of maximum entropy (i.e., closest to uniform), which is subject to constraints of information available with regard to the observed distribution of the species and the environmental variables examined (Pearson 2007). 
The observed distribution for a particular species is often referred to as the occupied or realized niche. It is important to distinguish between a species fundamental and occupied niche, although they may be similar. Hutchinson (1957) identified the fundamental niche as an $n$ dimensional hyper-space‘ encapsulating the range of environmental conditions in which a species can survive and reproduce successfully (Parolo et al. 2008). In nature, the fundamental niche of a species is unlikely to occur due primarily to spatial constraints such as limited dispersal ability for a given species, geographic barriers, and intra- and inter-specific competition. The occupied niche may be defined as the portions of the fundamental niche in which a species is not excluded due to biotic competition and/or geographical and historical constraints (Pearson 2007). Therefore, habitat suitability modeling approaches (i.e., niche modeling), such as Maxent are often employed to inductively interpolate or extrapolate the fundamental niche of a given species outside the locations where the species presence has been identified (i.e., realized niche) (Parolo et al. 2008).

SDM's are able to identify areas of suitable habitat outside of the realized niche by relating the environmental predictors examined to species' presence identified from fieldcollected data (i.e., known presences) (Pearson 2007; Parolo et al. 2008). Therefore, if the whole range of variation in which a species occurs is captured by the known presences sampled, the more accurate assessment of a species fundamental niche is likely to be modeled, assuming that the environmental and site-specific variables chosen are useful in identifying suitable habitat for the species examined.

For my model analysis, 24 environmental and site-specific variables were incorporated that were believed to be important for the detection of red spruce habitat in West Virginia. Climate data derived from statistically-downscaled General Circulation Model (GCM) results 
were used to assess the potential changes in red spruce habitat under two select climate change scenarios assessed at three future time steps using 30-year averages (i.e., 2020 (2010-2039), 2050 (2040-2069), and 2080 (2070-2099)). The purpose of this research effort was to identify areas on the landscape, at a $30 \mathrm{~m}$ resolution, which possessed the environmental and site-specific parameters necessary for red spruce habitat under altered climatic conditions. In addition, we wished to assess areas by county that possessed low, medium, and high suitability for red spruce habitat using appropriate threshold values. The results of this research are expected to be of great utility to conservation managers interested in conserving and restoring red spruce forests in West Virginia.

\section{Methods}

Study Area

The upland forests of West Virginia (i.e., elevations exceeding $915 \mathrm{~m}$ ) comprise two distinct physiographic regions that possess red spruce forest communities; the Allegheny Mountain section and the Ridge and Valley section (Strausbaugh and Core 1964; Stephenson 1993). These two physiographic regions differ in both geography and climate and therefore vary greatly with respect to forest vegetation. The ridges of the Allegheny Mountain section consist primarily of Paleozoic sandstones and conglomerates, with underlying rocks of the valleys composed primarily of shale and limestone (Stephenson 1993; Stephenson and Clovis 1983). The Ridge and Valley region, as its name suggests, consists of lowland areas surrounded by many longitudinal ridges. This region is characterized by extensively folded and thrust-faulted Paleozoic strata composed of resistant quartzite, conglomerates, and sandstone on ridges. However, the valleys are composed mostly of less resistant shale and limestone which have eroded over time creating the intervening valleys throughout this region (Stephenson 1993). 
The highest elevation zones within these two regions comprise part of NatureServe's Central and Southern Appalachian Spruce-Fir Forest Ecological System and are the focal point for the distribution of red spruce in West Virginia (Comer et al. 2003; Byers et al. 2010). Within this ecological system red spruce occurs primarily within the Allegheny Mountain section and to a much lesser extent in the Ridge and Valley region.

The western boundary of the Ridge and Valley section is the Allegheny Front, and is therefore subjected to a rain-shadow" effect in which a marked difference occurs between the amounts of precipitation in these two regions (Clarkson et al. 1980). McCay et al. (1997) reported an average annual precipitation in the Allegheny Mountain section of $107.5 \mathrm{~cm}$ in comparison to $82.5 \mathrm{~cm}$ as identified in the Ridge and Valley region. In addition, maximum and minimum average temperatures for January ranged from $4.44^{\circ} \mathrm{C}$ to $-7.72^{\circ} \mathrm{C}$ for the Allegheny section compared to $5.83^{\circ} \mathrm{C}$ to $-6.56^{\circ} \mathrm{C}$ for the Ridge and Valley Section; with July average daily temperatures ranging from $13.5^{\circ} \mathrm{C}$ to $25.17^{\circ} \mathrm{C}$ and $14.22^{\circ} \mathrm{C}$ to $28.67^{\circ} \mathrm{C}$, respectively (McCay et al. 1997). Across the higher elevation areas of both physiographic regions where red spruce may be found, the 30-year average precipitation ranges from 1,220-1,680 $\mathrm{mm}$ per year with 30-year mean annual temperatures ranging from $6.7^{\circ} \mathrm{C}$ to $9.4^{\circ} \mathrm{C}$ (Byers et al. 2010).

\section{Sample Site Selection}

To determine potential areas for identifying red spruce presence, a preliminary red spruce habitat suitability map provided by the West Virginia Division of Natural Resources (WVDNR) was used (Byers et al. 2010). This map was created using Maxent and incorporated 90 points of known red spruce occurrence. This habitat suitability map served as the basis for my plot determination. As the modeling approach is a presence-only technique, random Universal Transverse Mercator (UTM) coordinates were generated using a geographic information system 
(GIS) in areas identified possessing greater than 33 percent likelihood for suitable red spruce habitat. A total of 250 random plots were originally generated; however, because of random selection some plots were not accessible. The most common hindrance was private property where access could not be granted, or in a few instances, no feasible access was available. When access nearby was possible, replacement plots were established with coordinates and plot data recorded. Additionally, if red spruce was found in areas not identified by the WVDNR habitat suitability map, supplemental plots were established to improve model accuracy by providing evidence of red spruce habitat occurring in areas predicted otherwise.

\section{Red Spruce Sampling}

In summers 2008 and 2009 a total of 168 variable-radius plots, using a 10-BAF (i.e., basal area factor) prism, were established throughout the Appalachian Mountain Region (AMR) of West Virginia (Figure 3.1). The UTM coordinates for each plot is provided in Appendix I. Sampling with a prism is a relatively quick way to measure stand diversity and is a density- and distance-dependant measurement, relative to the BAF prism used (Avery and Burkhart 2002). At each plot location, trees considered for tally (i.e., -in" trees) were measured and recorded by diameter at breast height (DBH) and species to assess overstory and understory tree composition at each plot location. Therefore, at each plot location, trees per hectare (TPH) and basal area per hectare (BA) were calculated. Finally, geographic coordinates were recorded for all plots created as replacement or supplemental plots for implementation into a GIS.

\section{Future Climatic Data}

To assess potential future climatic conditions, a General Circulation Model (GCM) is often used. GCM's are numerical models which use a three-dimensional grid over the globe to represent physical processes in the atmosphere, ocean, cryosphere, and land surface. GCM's are 
considered the most advanced tools currently available for simulating the response of the global climate system to increasing greenhouse gas concentrations (IPCC-DDC 2010).

The Intergovernmental Panel on Climate Change (IPCC) is the leading organization for the assessment of climate change worldwide and is the primary source for obtaining GCM model results and their associated emission scenarios. With regard to the greenhouse gas emission scenarios, the IPCC recognizes four Special Report on Emissions Scenarios (SRES) families. These SRES families explore alternative development pathways, covering a wide range of technological, demographic, and economical driving forces which ultimately alter greenhouse gas (GHG) emissions (IPCC-AR4 2007).

The IPCC SRES families have been widely used to examine the impacts of climate change on terrestrial ecosystems (e.g., Thuiller et al. 2006; Schrag et al. 2008; Yates et al. 2010) and are particularly useful for vulnerability assessments where the potential changes in climate may impact the current range distribution for a particular plant or animal species and/or community (IPCC-DDC 2010). For my modeling effort examining red spruce forest habitat, the latest IPCC $4^{\text {th }}$ assessment data which was released in 2007 was used. The IPCC $4^{\text {th }}$ assessment data is available for several $\mathrm{GCM}^{`}$ 's with their accompanying SRES data and provided the most up-to-date climate data available at the time of my study.

For large-scale climatic research, GCM's provide a powerful tool for assessing potential changes in climatic conditions that are both geographically and physically consistent. However, the disadvantage of using GCM's for region-level studies is that the spatial resolution is often too coarse because these models are constructed at a global scale with a resolution in the order of 3-4 degrees, where 1 degree of longitude represents approximately $111 \mathrm{~km}$. Therefore, this level of 
accuracy for a region-level or statewide assessment is of little utility without further manipulation.

Although the WorldClim database provides statistically downscaled GCM data derived from the IPCC data portal, at the time of my study the $4^{\text {th }}$ assessment IPCC GCM data had not been statistically-downscaled to a $1 \mathrm{~km}$ resolution. As an alternative, we acquired our data from the International Centre for Tropical Agriculture (CIAT). The CIAT had completed portions of the statistical downscaling which were derived from the IPCC $4^{\text {th }}$ assessment GCM's (Ramirez and Jarvis 2008) and were ideal for my study.

The GCM datasets and GIS grids CIAT provided were downloaded from the IPCC data portal and reprocessed (i.e., statistically downscaled) using a spline interpolation algorithm of the anomalies and the current distributions of climates from the WorldClim database. The specific GCM used for my analysis was the United Kingdom Met Office, Hadley Centre for Climate Prediction and Research (UKMO-HADCM3) GCM (IPCC-AR4 2007). The available statistically-downscaled data from CIAT, at the time of our request, was limited to only two of the four scenario families provided by the IPCC SRES (i.e., SRES-A2 and SRES-B2).

For the two scenarios examined in my study, the SRES-A2 storyline describes a very heterogeneous world with high population growth, slow economic development and slow technological change, while the SRES-B2 storyline describes a world with intermediate population and economic growth with an emphasis on local solutions to economic, social, and environmental sustainability. An examination of how these two storylines compare to all other SRES families with respect to GHG emission and projected global average surface temperature change is shown in Figure 3.3 and Table 3.1, respectively. Because of the divergent patterns of the two scenarios examined, SRES-A2 will serve as an _aggressive' change model while SRES- 
B2 will serve as a conservative“ change model. Using both emission scenarios my study will provide insight into the potential impacts of climate change on red spruce forest habitat using a worst- and best-case scenario.

In addition, we wished to incorporate bioclimatic variables as our climatic model inputs. Bioclimatic variables may be defined as parameters derived from mean monthly climate estimates at a given location (Nix 1986). Using our original climate datasets of minimum, maximum, and average monthly temperature and average monthly precipitation, 19 bioclimatic variables were calculated using the AML-script provided by the WorldClim database (see Hijmans et al. 2005). These 19 bioclimatic variables are useful as model inputs because they are considered more biologically important to a species survival on the landscape. Bioclimatic variables are important for ecological applications because they calculate the average climatic values during unique times where biological limitations are likely to or could occur (e.g., mean temperature of the driest quarter of the year). The use of bioclimatic variables also allowed for a drastic reduction in the number of climatic variables examined, leading to a reduced number of climatic variables incorporated into the models.

\section{Environmental and Site-specific Variables}

A total of 24 environmental and site-specific variables were incorporated for the SRESA2 and SRES-B2 scenario models. Due to the uncertainty of which variables would be considered most important in identifying red spruce habitat, all 19 bioclimatic variables were considered in the analyses. Other non-bioclimatic variables examined included aspect, geology type, elevation, solar radiation, and slope percent. These variables were believed to remain constant throughout the 100-year time period modeled and were presumed to potentially be of importance, possibly used as an interaction among climatic variables in defining red spruce 
habitat within the model. Geology type was the only categorical variable used in the future potential distribution models and is described in Appendix II. The bioclimatic variable values averaged for all 168 overstory plots using both model scenarios at each time step examined were also calculated (Table 3.2; Table 3.3).

\section{Model Building}

Maximum entropy (Maxent), version 3.3.2, is a general purpose machine learning method and was used to identify suitable areas of red spruce forest habitat under climatic change. Maxent software may be freely downloaded (http://www.cs.princeton.edu/ schapire/maxent/) (Phillips et al. 2004; Phillips et al. 2006). Maxent uses presence-only occurrence data in conjunction with a suite of environmental variables to predict areas of suitable habitat for a species of interest (Phillips et al. 2006), and has been shown to be a valuable tool for ecological modeling and predicting the effect of climate change on species distributions (e.g., Elith et al. 2006, Hijmans and Graham 2006).

When using a Maxent modeling approach, features are selected as the independent variables that the user believes are important drivers for a given species` occurrence on the landscape. Each feature then serves as a constraint for the model, with the maximum entropy model selected as the one with which the constraints of each feature are satisfied (Manning and Schutze 1999). Thus, Maxent models are the result of empirical evidence available and make no assumption of that which is not known (Jaynes 1957).

In comparison with traditional regression-based techniques, Maxent does not violate a model assumption if variables which possess multicollinearity or spatial autocorrelation are incorporated. Spatial autocorrelation is defined as the property of random variables at a certain distance apart possessing values that are more or less similar (i.e., possessing a positive or 
negative autocorrelation, respectively), and is often a concern when ecological modeling is performed (Legendre 1993). Although multicollinearity or spatial autocorrelation are not desirable when modeling, most ecological studies must appropriately address this problem. When regression-based techniques are used, all variables that exhibit collinearity or spatial autocorrelation typically are removed. Thus, Maxent models are of great utility compared to regression-based approaches because variables which do exhibit multicollinearity may be retained without violating model assumptions. It is still necessary that the user understands the risk associated with including variables which are known to possess multicollinearity or spatial autocorrelation (e.g., a strongly correlated variable may not be considered important if another similar variable is also used in the model) as this will impact model interpretation.

Two options are available when spatial autocorrelated data has been identified. One option is to attempt to remove the spatial dependency among observations and the second option is to modify the statistical method in order to take the spatial autocorrelation into account; the latter is preferred when such methods are available (Legendre 1993). Maxent was the modeling approach selected because of its robustness and ability to analyze complex ecological data even when spatially autocorrelated topographic and climatic data are examined. Hu and Jiang (2010), in a comparison of three competing Maxent models (i.e., full, uncorrelated, and pruned models), stated the accuracy of the full model on the testing data indicated its predictive ability outside the training data, and regularization in Maxent appears to prevent overfitting better than variableselection methods in regression-based models." Their findings, among others, have proven the robustness of Maxent for ecological modeling where spatially autocorrelated data is often encountered. 
This ability of Maxent to assess complex non-linear variable interactions as well as incorporate correlated variables without violating model assumptions is a positive attribute of newer machine learning techniques over many regression-based techniques (Michael Dougherty, Elkins, WV, personal communication). When using a Maxent modeling approach, features are incorporated as independent variables that the user believes are important drivers for a given species' occurrence on the landscape. Each feature serves as a constraint for the model, and the maximum entropy model selected is the one which best satisfies the constraints of each feature examined (Manning and Schutze 1999). Maxent performs similarly to logistic regression by weighting each feature (i.e., environmental or site-specific variable) by a constant, with the estimated probability distribution divided by a scaling constant to ensure the probabilities range from 0-1 and also sum to 1 (Hernandez et al. 2006).

Although methodologies employing presence/absence data are often prioritized, presence-only modeling approaches should be employed when the objective is to identify suitable habitat of a given species; particularly when the current distribution of the species is unknown or has been dramatically altered (e.g., historical anthropogenic disturbances) (Brotons et al. 2004). Presence-only modeling methods are also preferred when ambiguous absences occur due to geographic barriers, local extinction, small patch sizes, species generalization, and biotic interactions (e.g., succession stage, competition) (Hirzel and LeLay 2008). Because Maxent does not utilize absence data, background' points with their associated environmental variable values are used. These background points serve as pseudo-absences for model assessment and are used to determine the logistic output which ranges from 0 (low suitability) to 1 (high suitability) for habitat prediction. 
When using background data within Maxent it is important for the user to understand that this model makes no assumptions of where a particular species of interest does not occur. Rather, the assumption is that a model based on occurrence and background data (i.e., pseudoabsences) will not focus on sampling bias. Therefore, the primary focus of a Maxent model is to distinguish the differences between the distribution of occurrences and that of the background points examined (Phillips et al. 2009; Yates et al. 2010). The 5,000 background points used for my models were randomly generated using a GIS within the six county study area from which the red spruce plots were collected (Figure 3.2). These six counties included Greenbrier, Pendleton, Pocahontas, Randolph, Tucker, and Webster counties.

Much of the necessary data preparation required for this analysis was performed within a GIS using ESRI ${ }^{\circledR}$ ArcMap ${ }^{\mathrm{TM}}$ 9.3.1 under an ArcEditor license. Within ArcMap, a shapefile was created for the 168 red spruce presence localities as well as the 5,000 randomly generated background points, with UTM coordinates listed for each data point in the attribute table. Next, the 24 environmental and site-specific variables for current climatic conditions were added as raster grids (.img format) and used to construct attribute tables which identified each variables value for all presence and background localities as well as the UTM coordinates for all points examined. The attribute tables were constructed for both shapefiles (i.e., red spruce presence points and background points) using the intersect point analysis tool provided by the freely downloaded add-on_Hawths Analysis Tools', version 3.27 (http://www.spatialecology.com/htools/download.php). The resulting attribute tables provided UTM coordinates for each point locality under current climatic conditions along with the associated raster grid values for all 24 environmental and site-specific variables considered at each UTM point examined. 
These attribute tables were then exported from ArcMap and saved in database format (.dbf). Maxent setup typically requires two types of data, the species presence localities in a comma-separated value (CSV) format and the environmental and site-specific data provided in ASCII grid format, with the background points and their associated values calculated within Maxent. However, when large datasets are used for analysis, as in this study, an alternative method should be employed. This alternative method allows the user to input the presence locality data as well as the background points with the environmental and site-specific data already determined for each unique UTM coordinate. This method is referred to as a samples with data' (SWD) format and saves considerable run time when performing multiple replicate runs over a large study area and at a fine resolution (i.e., $30 \mathrm{~m}$ resolution).

Using the SWD file format, a CSV file for the red spruce presence localities and the background points was incorporated into the Maxent model platform. The conversion of the red spruce presence and background points from database format (.dbf) to CSV format was performed using Microsoft Excel 2007. Additionally, all raster grids for all scenarios and time steps examined were converted to ASCII grid (.asc) format for implementation into Maxent. These ASCII grids are necessary to create the state-wide red spruce habitat suitability map for the current and future time periods examined. All grid conversions were performed using the = Raster to ASCII' conversion tool within the ArcMap-ArcToolbox.

Once the data were added to the model all categorical variables were specified accordingly so that they were not considered as a continuous variable in the model (Table 2.2). The file pathnames for all future scenario data (.asc format) were specified in the output directory so that each time step would be modeled using the appropriate future conditions data. Next, the check-boxes for Create response curves ${ }^{\star}$ and _Do jackknife to measure variable 
importance' were selected. Within the settings window, a bootstrap replicate run (i.e., sampling with replacement) type was selected for 10 replicates with a random test percentage of $25 \%$

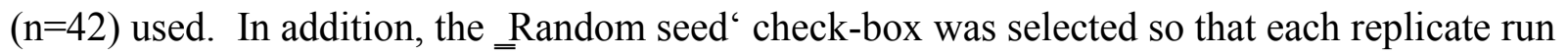
would start with a random seed to ensure that a separate test/train dataset was used for each of the five replicate model runs.

An independent dataset was not available for model assessment. As an alternative, I incorporated a bootstrap replication' technique which allows for replicate model runs to be conducted using sampling with replacement (i.e., the same occurrence may be used more than once for individual replicate runs). Bootstrap replication splits the dataset multiple times, and in each case, predictive performance is assessed against the test dataset. This is an excellent tool for model assessment when an independent dataset is not available or if one wishes to use all sample data collected for model building (e.g., when modeling using a small dataset).

After performing the Maxent analyses, model results were then incorporated into a GIS and the logistic threshold for the minimum training presence (MTP) was selected to identify areas of suitable red spruce habitat. Our assurance of data accuracy was the driver for this threshold level selection, as the MTP value indicated the habitat suitability threshold value of a training point (i.e., a red spruce presence point) which was used in the model. Specifically, the MTP is the lowest logistic threshold value at which a plot was used for training that possessed red spruce occurrence. Therefore, all pixels with threshold values greater than or equal to the MTP logistic threshold served as areas which possessed red spruce habitat. Any threshold values falling below the MTP were considered unsuitable.

Lastly, both model scenarios (i.e., SRES-A2 and SRES-B2) were run independently. Although both model scenarios could have been assessed using one model, the decision to 
separate them out was due primarily to computer limitations. All raster grids used in my model were approximately $1 \mathrm{~GB}$ in file size, and using four projection times (i.e., base, 2020, 2050, and 2080), each model took approximately 24 hours to run using a conventional laptop with a $2 \mathrm{GHz}$ dual-core processor and 2 GB RAM memory.

\section{Results}

A total of 29 species were identified within the 168 plots collected during the field seasons of 2008 and 2009. Using the average basal area per ha $(\mathrm{BA} / \mathrm{ha})$ and relative trees per ha (TPH), importance values (IV‘s) were calculated by averaging the sum of BA/ha and TPH. The species most often encountered were red spruce $(\mathrm{IV}=40.2)$, red maple $(\mathrm{IV}=16.7)$, yellow birch $(I V=11.4)$, eastern hemlock $(I V=10.5)$, and black cherry $(I V=9.2)$ (Table 3.4). The average stand BA was $44.6 \mathrm{~m}^{2} /$ ha with $405 \mathrm{TPH}$.

Using 168 overstory red spruce plots, 5,000 background points, and 24 independent variables, Maxent models were constructed for both model scenarios (i.e., SRES-A2 and SRESB2) examined. Model setup was identical for each scenario model run and included five bootstrapped replicate runs (i.e., sampling with replacement) using a random test percentage of $25 \%(n=42)$. The bootstrap replications were conducted to assess the mean area-under-curve (AUC) for all model runs and allowed me to assess model performance without excluding a portion of the dataset. The AUC value is derived from the receiver operating characteristic (ROC) plot provided in the Maxent output and was calculated for both model scenarios (Figure 3.4; Figure 3.5). The AUC value may be interpreted as a single test statistic which assesses model performance with a range of $0-1$, with AUC values $<0.5$ indicating the model is no better than random, values $>0.5-0.7$ indicating a fair model, values 0.7-0.9 indicating a good model, and values $>0.9$ indicative of an excellent model (Baldwin 2009). The mean AUC for all five 
replicate model runs was $0.959(\mathrm{sd}=0.011)$ and $0.958(\mathrm{sd}=0.011)$ for the SRES-A2 and SRESB2, respectively, and indicated excellent model performance.

Three variables were identified that each contributed more than $10 \%$ to model performance under both scenarios examined (Table 3.5; Table 3.6). These variables were mean temperature of the coldest quarter (bio_11), elevation (ned30m), and minimum temperature of the coldest month (bio_06). When combined these variables contributed more than $40 \%$ to model performance for both scenario models. It is important to note that although variable contributions are useful in identifying which variables were important to overall model performance, spatial autocorrelation must also be considered.

The Maxent output provides an omission/commission graph for each model that may be used to assess whether significant spatial autocorrelations exist in the model which could alter model interpretability (Figure 3.6; Figure 3.7). These omission/commission graphs show the omission rate and predicted area as a function of the cumulative threshold averaged across the five replicate runs that were performed. By definition of the cumulative threshold, the training omission rate plotted in these graphs should be close to the predicted omission line (i.e., the solid black line displayed at a $45^{\circ}$ angle). If the training omission rate follows the predicted omission line, the user may assert that the Maxent distribution is a close approximation of the probability distribution that represents reality. However, any deviations falling below this line defies the definition of the cumulative threshold and results in a higher cumulative prediction in relation to the fractional area examined, and thus, indicates spatial autocorrelated data was used in the modeling process. Therefore, Figure 3.6 and Figure 3.7 for the SRES-A2 and SRES-B2 models, respectively, indicate that spatially autocorrelated data was used in my analyses. 
In addition, jackknife analyses for both scenario models were performed to examine training and test gain as well as the AUC values using each variable independently. The jackknife analyses allow the user to assess how much unique information is provided using each variable and to determine whether the percent variable contribution is likely skewed because of strong variable collinearity (Baldwin 2009). Using the jackknife analyses results we graphed, for ease of comparison, the individual variable results of test gain, training gain, and AUC values for all variables examined for each scenario model (Figure 3.8; Figure 3.9).

Considering the variables of both scenario models with a test and/or training gain greater than one and an AUC statistic greater than 0.8 , several additional variables may also be identified that were not considered important (i.e., $\leq 10 \%$ variable contribution) to overall model results. Other variables considered important using this criterion included: annual mean temperature (bio_01), mean diurnal range (bio_02), isothermality (bio_03), maximum temperature of the warmest month (bio_05), temperature annual range (bio_07), mean temperature of the wettest quarter (bio_08), mean temperature of the driest quarter (bio_09), mean temperature of the warmest quarter (bio_10), and precipitation seasonality (bio_15). These variables may also be considered important environmental variables in identifying red spruce habitat that were not selected in our models, likely due to multicollinearity among variables.

I also wished to identify the threshold values associated with each variable considered important to overall model performance. To do this, I examined each variable independently by creating a Maxent model using only the corresponding variable. This allowed us to examine the individual behavior of each variable graphically and to assess its range of values for indicating the presence of red spruce habitat. 
Assessing the threshold values for the top three variables used in both scenario models, similar threshold values were identified. Mean temperature of the coldest quarter (bio_11), although first in order of importance for the SRES-A2 scenario and third using the SRES-B2 model, had a threshold break point of $-2.0^{\circ} \mathrm{C}$ in both models (Figure 3.10; Figure 3.11). Therefore, mean temperatures of the coldest quarter less than $-2.0^{\circ} \mathrm{C}$ were useful in predicting the presence of red spruce habitat. Elevation (ned $30 \mathrm{~m}$ ) was the second most important variable for both models and shared a $900 \mathrm{~m}$ threshold for presence, with values greater than $900 \mathrm{~m}$ indicative of suitable red spruce habitat (Figure 3.12; Figure 3.13). Lastly, minimum temperature of the coldest month (bio_06) was identified as third in order of importance for the SRES-A2 model and first for the SRES-B2 model. Although they varied in rank among models, they shared a threshold value of $-9.0^{\circ} \mathrm{C}$. Areas possessing a minimum temperature of the coldest month less than $-9.0^{\circ} \mathrm{C}$ were indicative of suitable red spruce habitat (Figure 3.14; Figure 3.15).

After analyzing variable importance among models, the next step was to create suitability maps which indicated areas suitable for red spruce habitat in West Virginia under future climatic conditions. When a replicated Maxent model is created using a training and test dataset, a table of cumulative and logistic threshold values is provided. The threshold values provided in this table are determined by calculating binomial probabilities with associated one-sided p-values for the null hypothesis. When test samples exceed 25, a normal approximation to the binomial is used. The null hypothesis is that the test points are predicted no better than a random prediction with the same fractional predicted area used. For my study, the logistic threshold value for the minimum training presence (MTP) averaged across the five model runs was selected to indicate areas of suitable and unsuitable red spruce habitat. 
My assurance of data accuracy was the driver for the MTP threshold selection. The MTP threshold represents the lowest threshold at which a plot was used for training the model. Thus, this threshold value, because I am confident in my field collection accuracy, represents a point on the landscape where red spruce has been identified. Therefore, all pixels with threshold values greater than or equal to the MTP logistic threshold served as areas which possessed red spruce habitat, with any threshold values falling below the MTP considered unsuitable.

Using the average MTP calculated from the five bootstrapped replicate runs for each scenario model, the MTP threshold values were identified as $0.052(\mathrm{sd}=0.021)$ and 0.0571 $(\mathrm{sd}=0.023)$ for the SRES-A2 and SRES-B2, respectively. Due to the similarity among MTP threshold values, a value of 0.05 was used for both models so that they could be compared. The total area derived for each model scenario and time step (i.e., 2020, 2050, and 2080), using a MTP of 0.05 , was calculated to distinguish suitable versus unsuitable red spruce habitat. Regarding total current red spruce habitat suitability in West Virginia (i.e., all areas possessing an MTP $\geq 0.05$ ), 364,214 ha were identified for the SRES-A2 model, with 362,077 ha identified for the SRES-B2 model (Table 3.7). These areas, considered suitable red spruce habitat, constituted roughly $6.2 \%$ of the total land area in West Virginia. For the time period 2020 (i.e. 2010-2039), dramatic reductions in suitable habitat were identified, with 81,113 ha and 172,541 ha identified for the SRES-A2 and SRES-B2 model, comprising 1.3\% and $2.8 \%$ of the total land area in West Virginia, respectively. For the time period 2050 (i.e., 2040-2069), a dramatic reduction for SRES-A2 model scenario occurred with only 20,015 ha identified as suitable, compared to 159,962 ha identified for the SRES-B2 model. However, by the time period 2080 (i.e., 2070-2099), dramatic reductions for both model scenarios were identified, with a total loss of suitable red spruce habitat in West Virginia modeled using the worst-case model, scenario 
SRES-A2. For the best-case scenario model, SRES-B2, 53,866 ha were identified which possessed suitable red spruce habitat, representing less than $1 \%$ of the total land area in West Virginia and representing an $85 \%$ loss in red spruce habitat compared to current modeled conditions identified for this scenario.

Once areas possessing an MTP $\geq 0.05$ were identified as suitable habitat, both scenario models were assessed further to identify areas of low, medium, and high suitability for red spruce habitat in West Virginia for each time period modeled (Table 3.7). The suitability index thresholds used were: unsuitable $(0-<0.05)$, low $(0.05-0.33)$, medium $(>0.33-<0.66)$, and high (0.66-1). Areas of high suitability were only identified in the SRES-A2 model scenario under current climatic conditions, whereas high suitability areas were identified for the SRES-B2 in current, 2020, and 2050 time periods. Areas of high suitability for current red spruce habitat were identified on 8,951 ha for the SRES-A2 model and 8,062 ha for the SRES-B2 model, representing approximately $2 \%$ of total habitat suitability for both models. For the time period 2020, under the SRES-B2 scenario, 2,187 ha were identified which possessed suitable red spruce habitat with only 21 ha modeled for the time period 2050. Although no suitable habitat was identified at time period 2080 in the SRES-A2 model, a total of 53,866 ha were identified in the SRES-B2 model with none of these areas identified as high suitability and only 227 ha identified to possess medium suitability (Table 3.7).

After calculating area by suitability class, the output raster grids provided by Maxent were reclassified accordingly within a GIS to create maps of habitat suitability for each scenario model. This was done to graphically assess the potential changes in suitable habitat for red spruce for each time period examined and for both model scenarios (Figure 3.16; Figure 3.17). These maps identify areas in West Virginia which possess suitable red spruce habitat, by 
suitability index, as well as how this habitat will likely change based on the two model scenarios examined.

As no areas of suitable habitat were identified for the time period 2080 in the SRES-A2 model, the areas identified in the 2050 time period occupied approximately 20,000 ha and occurred in relatively concentrated areas. These areas included: 1) the boundary between Tucker and Grant Counties, 2) the junction of Randolph, Pendleton, and Pocahontas Counties, and 3) along Cheat Mountain from central Randolph County extending southward into the central portion of Pocahontas County (Figure 3.16). However, for the SRES-B2 model the areas identified for the time period 2080 varied somewhat from the remaining areas identified in the 2050 time period of the SRES-A2 model. Although the junction of Randolph, Pendleton, and Pocahontas Counties and along Cheat Mountain from central Randolph County extending southward into the central portion of Pocahontas County are similar in both models, an expanse of suitable habitat occurring primarily in the southern portion of Pocahontas County and portions of Webster and Greenbrier Counties was identified (Figure 3.17).

Lastly, the statewide assessment identifying red spruce habitat was performed at a county level to quantify red spruce habitat by suitability index for each county that possessed suitable habitat. Appendix III provides the calculated area for each county by suitability index for both model scenarios and across all time periods examined. An example map, at $30 \mathrm{~m}$ resolution is provided for Pocahontas County using both climate change scenarios (Figure 3.18; Figure 3.19). Under the SRES-A2 scenario, drastic reductions occurred in suitable habitat by the time period 2050, with primary areas possessing suitable habitat found in the north-central and northeastern portions of the county. Under the SRES-B2, remaining areas of suitable habitat predicted during the time period 2080, occurred in the same areas identified in the SRES-A2 at time period 2050, 
but with an extended area of suitable habitat identified in the north-west and western portions of the Pocahontas County (Figure 3.19).

\section{Discussion}

The use of Maxent as a species distribution modeling method was successful in identifying suitable red spruce habitat in West Virginia under select climate change scenarios. Model performance was considered excellent (AUC $\geq 0.90$ ), with both scenario models possessing an AUC $>0.95$. It is important to note that the modeled habitat in these analyses do not indicate the occurrence of red spruce. Rather, they identify areas on the landscape most likely to possess suitable red spruce habitat because they share similarities with respect to the environmental and site-specific variables identified within current red spruce presence localities.

The variables found to contribute significantly (i.e., $>10 \%$ contribution to overall model performance) for both scenario models were mean temperature of the coldest quarter (bio_11), elevation (ned30m), and minimum temperature of the coldest month (bio_06). These results reveal the association of red spruce habitat to mean and minimum winter temperatures, as well as, elevation in West Virginia. The importance of the minimum temperature of the coldest month (i.e., winter climate) has been recently addressed as an important consideration when determining the drivers of vegetation and ecosystem functioning (e.g., Kreyling 2010). Indeed, Federer et al. (1989), among three regions in the Northeast U.S., identified temperature in the latter part of the previous growing season and temperature in the winter as important. Although uncertain, it seems the minimum temperature threshold during the coldest month of the year identified in my model may prevent many competitive northern hardwood species from dominating such areas because of their relatively lower resistance to frost damage. This ability 
of red spruce to endure extreme cold temperatures therefore stresses the importance of temperature-based climatic conditions in identifying suitable red spruce habitat.

Elevation (ned30m), the variable identified second in importance for both scenario models, has often been used in the description of red spruce habitat in the central and southern AMR and is often the variable of choice in the delineation of boundaries between species and community assemblages. The $900 \mathrm{~m}$ threshold indentified in this study for both scenario models affirms the other historical and current descriptions of the elevational transition into red spruce forest habitat identified in West Virginia (e.g., Egleston 1884; Pielke 1981; Stephenson 1993). Using these model results, red spruce habitat may be described generally as areas in West Virginia possessing an elevation greater than $900 \mathrm{~m}$, a mean temperature of the coldest quarter (bio_11) of the year less than $-2.0^{\circ} \mathrm{C}$, and a minimum temperature of the coldest month (bio_06) less than $-9.0^{\circ} \mathrm{C}$.

For this study we wanted to determine which of the 19 bioclimatic variables were useful for modeling red spruce habitat. More research is needed to determine which select bioclimatic variables should be incorporated to construct the most parsimonious model. However, Maxent has been shown to perform well using a full or pruned model with respect to number of variables incorporated (Hu and Jiang 2010).

The variables considered important for defining red spruce habitat when used in isolation were also important to examine as some variables were likely not considered due to spatial autocorrelation. Examination of all variables considered important in isolation further reinforced the importance of temperature-based bioclimatic variables for identifying red spruce habitat in West Virginia (Figure 3.8; Figure 3.9). The only bioclimatic variable which was identified to be important when used in isolation that incorporated precipitation data was precipitation 
seasonality (bio_15). This variable, therefore, could potentially play a role in identifying red spruce habitat, although was not considered important in my analyses for either scenario model.

My assessment of the potential impacts of climatic change on red spruce habitat in West Virginia for the SRES-A2 and SRES-B2 models is quite dramatic (Figure 3.16; Figure 3.17). Under the SRES-A2 model, only 81,113 ha was modeled to occur by the time period 2020 (i.e., 30-year average ranging from 2010-2039), indicative of a 78\% loss in suitable habitat compared to current conditions. However, under the SRES-B2 model, 172,541 ha were estimated to exist, a loss of 52\% for red spruce habitat. For the time period 2050 (i.e., 30-year average ranging from 2040-2069), 20,015 ha were modeled to remain under the SRES-A2 scenario compared to 159,962 ha under the SRES-B2 scenario. This was a loss in suitable habitat from current conditions of $95 \%$ and $55 \%$, respectively. Lastly, by the time period 2080 (i.e., 30 -year average ranging from 2070-2099) a total loss of suitable habitat was predicted under the SRES-A2 scenario, with 53,866 ha identified to remain under the SRES-B2 scenario; the latter representing a loss of $85 \%$ suitable habitat compared to current conditions.

The goal of this research effort was not only to predict the amounts of loss in habitat for red spruce under climatic change, but to provide conservation managers suitability maps for both model scenarios examined. Under the SRES-A2 model, it appears the complete loss of suitable habitat for red spruce may occur by the year 2100. This is not a novel find, as Prasad et al. (2007-ongoing) indicated the complete loss of red spruce habitat as well as the majority of the northern hardwood forest community in West Virginia when using GCM's at a $20 \mathrm{~km}$ resolution and Forest Inventory and Analysis (FIA) data. Findings such as this were the impetus of our study as we wished to assess if these results for red spruce would occur if more spatially resolute data was used. 
Under the best-case model scenario, SRES-B2 scenario, approximately 50,000 ha were estimated to occur by the year 2100; however, this still represents a significant loss of suitable habitat. It is also important to reiterate here that areas currently modeled as having red spruce habitat, for the most part, do not possess red spruce. The absence of red spruce in areas possessing suitable habitat, primarily due to intense anthropogenic disturbances, will likely have great impacts on the future distribution of red spruce in West Virginia, regardless of which model scenario our future climatic conditions follows.

Red spruce in West Virginia is a rare species with a drastically reduced historic range size and is likely to be especially vulnerable to climatic change as indicated in this study. These output maps for resource and land managers should be of great utility as they indicate areas on the landscape which possess suitable red spruce habitat under climatic change both at a statewide and county level. Restoring red spruce in areas likely to possess suitable habitat under altered climatic conditions should be of utmost prioritization as these areas are most likely to support red spruce under future climatic conditions.

It has now documented that recent GHG emissions have exceed the highest IPCC SRES scenario identified in the IPCC Fourth Assessment Report which was used for this study (Huntley et al. 2010). If these drastic changes in temperature continue globally, it is only a short time until the impacts will be visible with respect to red spruce habitat in West Virginia. Which climatic scenario will most likely occur in West Virginia is beyond the scope of this research effort, however, the identification of a worst- and best-case scenario for potential habitat loss allows for an assessment of what losses in red spruce habitat could potentially occur.

The Monongahela National Forest (MNF) has, within their Land and Resource Management plan, performed a management prescription specifically focused on spruce and 
spruce-hardwood ecosystem restoration (i.e., MP 4.1) (USDA 2006). The MNF MP 4.1

prescription area comprises a total of 62,000 ha and represents approximately $15 \%$ of the entire MNF lands. In general, this prescription area includes elevations situated above $975 \mathrm{~m}$. The reason for actively restoring red spruce today, specifically on the MNF, is due to the fact that their forest proclamation boundary contains most of the remaining acreage of central Appalachian red spruce and spruce-hardwood forests. In addition, they also possess the majority of land upon which these forest types occurred prior to exploitative logging at the turn of the $20^{\text {th }}$ century (USDA 2006). I believe the model results of this study could be of great use to the restoration activities currently underway by the MNF. Using the suitability maps from my research in conjunction with the designated 62,000 ha prescription area would be of great utility, as areas most likely to succeed under climatic change could be focused on first.

This study models red spruce distribution as a function of climatic and site-specific variables. It is important to note that other factors codetermine species distributions that go beyond the scope of this study which also strongly influence where species occur on the landscape. Examples include dispersal and colonization rates, geographic barriers, landscape fragmentation, and disturbance regimes (Huntley et al. 2010). Other factors such as acid deposition and insect outbreaks (e.g., spruce budworm and bark beetles) which have been reported historically to cause widespread mortality among red spruce stands may also potentially hinder the ability for red spruce to migrate or adapt to climatic change.

In order to minimize the impact of climate change on red spruce forests in West Virginia and the unique biodiversity its ecosystem provides, it is crucial that effective conservation and restoration efforts be actively conducted. These efforts will enhance this species' opportunity to adapt to climatic change (Huntley et al. 2010) and should re-establish the connectivity among 
these high elevation isolated stands. It is without doubt that restoration and recovery of red spruce forests in West Virginia would increase forest diversity and provide habitat for numerous endemic species that are restricted to high elevation forest types (McDonald 1993; White et al. 1993).

\section{Conclusion}

As a specialist species, with regard to its habitat requirements, red spruce will be particularly vulnerable to changes in climate, further exacerbated by the limited distribution this species occupies today compared to its presettlement range. As such, red spruce will likely be one of the first and most heavily affected tree species with respect to losses in suitable habitat in West Virginia. Therefore, identifying areas on the landscape most likely to possess suitable habitat under altered climatic conditions allows for the quantification of potential losses in habitat that may occur. Furthermore, distinguishing areas of low, medium, and high habitat suitability allows for the prioritization of management activities in areas which offer the best chances of success. Regardless of which model scenario future climatic conditions follow, these results provide an interpretation of what potential changes are likely to occur and what areas are likely to possess suitable habitat under future climatic conditions. The results of this research, provided at an unprecedented $30 \mathrm{~m}$ resolution, should be of great interests for future red spruce restoration efforts conducted in West Virginia. 


\section{Literature Cited}

Acciavatti, R.E., T.J. Allen, A.R. Miller, L.L. Pechuman, B.C. Kondratieff, R.F. Kirchner, A.G. Wheeler, S.M. Clark, E. van der Berghe, and W.J. Arnold. 1993. Insects and spiders of the upland forests. Pp. 143-178 in S.L. Stephenson ed., Upland Forests of West Virginia. McClain Printing, Parsons, W.Va.

Avery, T.E. and H.E. Burkhart. 2002. Forest Measurements. $5^{\text {th }}$ edition. McGraw-Hill, New York. 456p.

Baldwin, R.A. 2009. Use of maximum entropy modeling in wildlife research. Entropy 11:854 $-866$.

Barnes, B.V., D.R. Zak, S.R. Denton, and S.H. Spurr. 1998. Forest Ecology. Fourth edition. John Wiley and Sons, Inc. New York. 774p.

Beane, N.R., Heitzman, E., and T.M. Schuler. 2010. Stand dynamics of an old-growth hemlock -hardwood forest in West Virginia. Natural Areas Journal 30(1):64-72.

Bollinger, J., Kienest, F., and N.E. Zimmerman. 2000. Risks of global warming on montane and subalpine forests in Switzerland- a modeling study. Reg. Environ. Change 1:99-111.

Brotons, L., W. Thuiller, M.B. Araujo, and A.H. Hirzel. 2004. Presence-absence versus presence-only modeling methods for predicting bird habitat suitability. Ecography 27:437-448.

Byers, E.A., Vanderhorst, J.P., and B.P. Streets. 2010. Classification and conservation assessment of upland red spruce communities in West Virginia. WV Natural Heritage Program, WVDNR, Elkins, WV, 68p.

Clarkson, R.B. 1964. Tumult on the Mountains. McCain Printing Co., Parsons, West Virginia.

Clarkson, R.B., W.H. Duppstadt, and R.L. Guthrie. 1980. Forest wildlife plants of the Monongahela National Forest. Boxwood Press, Pacific Grove, CA. 283 p.

Comer, P., Faber-Langendoen, D., Evans, R. Gawler, S., Josse, C., Kittel, G., Menard, S., Payne, M., Reid, M., Schulz, K., Snow, K., and J. Teague. 2003. Ecological systems of the United States: A working classification of U.S. terrestrial systems. NatureServe, Arlington, VA.

Egleston, N.H. 1884. Report on forestry, Vol. 4, Government Printing Office, Washington, D.C., $421 \mathrm{pp}$. 
Elith, J., C.H. Graham, R.P. Anderson, M. Dudik, S. Ferrier, A. Guisan, R.J. Hijmans, F. Huetmann, J.R. Leathwick, A. Lehmann, J. Li, G. Lohmann, B.A. Loiselle, G. Manion, G. Moritz, M. Nakamura, Y. Nakazawa, J.McC. Overton, A.T. Peterson, S.J. Phillips, K. Richardson, R. Scachetti-Periera, R.E. Schapire, J. Soberon, S. Williams, M.S. Wisz, and N.E. Zimmerman. 2006. Novel methods improve prediction of species' distributions from occurrence data. Ecography 29:129-151.

Federer, C.A., L.M. Tritton, J.W. Hornbeck, and R.B. Smith. 1989. Physiologically based dendroclimate models for effects of weather on red spruce basal-area growth. Agricultural and Forest Meteorology 46:159-172.

Hernandez, P.A., C.H. Graham, L.L. Master, and D.L. Albert. 2006. The effect of sample size and species characteristics on performance of different species distribution modeling methods. Ecography 29:773-785.

Hijmans, R.J., and C.H. Graham. 2006. The ability of climate envelope models to predict the effect of climate change on species distributions. Global Change Biology 12:2272-2281.

Hijmans, R.J., S.E. Cameron, J.L. Parra, P.G. Jones, and A. Jarvis. 2005. Very high resolution interpolated climate surfaces for global land areas. International Journal of Climatology 25:1965-1978.

Hirzel, A.H. and G. Le Lay. 2008. Habitat suitability modeling and niche theory. Journal of Applied Ecology 45:1372-1381.

Hopkins, A.D. 1891. Black Spruce: Preliminary report. West Virginia Agricultural Experiment Station Bulletin 17:93-102.

Hu, J. and Z. Jiang. 2010. Predicting the potential distribution of the endangered Przewalski`s gazelle. Journal of Zoology 282:54-63.

Huntley, B., B. Phoebe, R. Altwegg, L. Chambers, B.W.T. Coetzee, L. Gibson, P.A.R. Hockey, D.G. Hole, G.F. Midgley, L.G. Underhill, and S.G. Willis. 2010. Beyond bioclimatic envelopes: dynamic species' range and abundance modeling in the context of climatic change. Ecography 33(3):621-626.

Hutchinson, G.E. 1957. Concluding remarks. Cold Spring Harbor Symposium on Quantitative Biology 22: 415-457.

IPCC-AR4. 2007. Climate change 2007: synthesis report. Contribution of working groups I, II, and III to the fourth assessment report of the Intergovernmental Panel on Climate Change. Geneva, Switzerland. Pp 104.

IPCC-DDC. 2010. The IPCC data distribution centre: what is a GCM? Accessed: October 1, 2010. <URL:http://www.ipcc-data.org/ddc_gcm_guide.html> 
Jaynes, E.T. 1957. Information theory and statistical mechanics. Physical Review 106(4):620 -630 .

Jaynes, E.T. 1990. Notes on present status and future prospects. In: Grandy Jr., W.T., and L.H. Schick (eds). Maximum entropy and Bayesian methods. Kluwer, Dordrecht, The Netherlands, 1-13.

Kreyling, J. 2010. Winter climate change: a critical factor for temperate vegetation performance. Ecology 91(7): 1939-1948.

Legendre, P. 1993. Spatial Autocorrelation: Trouble or New Paradigm? Ecology 74(6):1659 $-1673$.

Manning, C. and H. Schutze. 1999. Foundations of statistical natural language processing. MIT Press, Cambridge, MA. 680 pp.

Martin, R.W., and J.T. Petty. 2009. Local temperature and thermal topology interact to influence the distribution of brook trout and smallmouth bass in a central Appalachian watershed. Journal of Freshwater Ecology 23:497-508.

McCarty, J.P. 2001. Ecological consequences of recent climate change. Conservation Biology 15(2):320-331.

McCay, D.H., M.D. Abrams, and T.E. DeMeo. 1997. Gradient analysis of secondary forests of eastern West Virginia. Journal of the Torrey Botanical Society 124(2):160-173.

McDonald, B.R. 1993. Rare plants of the upland forests. Pp. 67-85. In Upland forests of West Virginia. Stephenson, S.L., (ed.). McClain Printing Co., Parsons, West Virginia.

Menzel, J.M., W.M. Ford, J.W. Edwards, and L.J. Ceperly. 2006a. A habitat model for the Virginia northern flying squirrel (Glaucomys sabrinus fuscus) in the Central Appalachian Mountains. USDA Department of Agriculture, Forest Service, Northeastern Research Station, Newtown Square, PA. Research Paper NE 729. 10p.

Menzel, J.M., W.M. Ford, J.W. Edwards, and T.M. Terry. 2006b. Home range and habitat use of the vulnerable Virginia northern flying squirrel Glaucomys sabrinus fuscus in the Central Appalachian Mountains, USA. Oryx 40(2):204-210.

Millspaugh, C.F. 1891. Forest and shade tree insects. Part II. Black spruce, (Picea mariana (Mill.)). West Virginia University. Agricultural Experiment Station Report 3:171-180.

Nix, H.A. 1986. A biogeographic analysis of Australian Elapid Snakes. In: Atlas of Elapid Snakes of Australia. Pp. 4-15. R. Longmore, ed. Australian Flora and Fauna Series Number 7. Australian Government Publishing Service: Canberra. 
Odom, R.H., W.M. Ford, J.W. Edwards, C.W. Stihler, and J.M. Menzel. 2001. Developing a habitat model for the endangered Virginia northern flying squirrel (Glaucomys sabrinus fuscus) in the Allegheny Mountains of West Virginia. Biological Conservation 99:245252.

Parolo G., G. Rossi, and A. Ferrarini. 2008. Toward improved species niche modeling: Arnica montana in the Alps as a case study. Journal of Applied Ecology 45:1410-1418.

Pearson, R.G. 2007. Species' distribution modeling for conservation educators and practitioners. Synthesis. American Museum of Natural History. Available at http://ncep.amnh.org. [Accessed 2 February 2009].

Phillips, S.J., M. Dudik, J. Elith, C.H. Graham, A. Lehmann, J. Leathwick, and S. Ferreir. 2009. Sample selection bias and presence-only distribution models: implications for background and pseudo-absence data. Ecological Applications 19(1):181-197.

Phillips, S.J., M. Dudik, and R.E. Schapire. 2004. A maximum entropy approach to species distribution modeling. In: Proceedings of the $21^{\text {st }}$ International Conference on Machine Learning, ACM Press, New York, pp. 655-662.

Phillips, S.J., R.P. Anderson, and R.E. Schapire. 2006. Maximum entropy modeling of species geographic distributions. Ecological Modelling 190:231-259.

Pielki, R.A. 1981. The distribution of spruce in west-central Virginia before lumbering. Castanea 46(3):201-216.

Prasad, A.M., L.R. Iverson, S. Matthews, and M. Peters. 2007-ongoing. A climate change atlas for 134 forest tree species of the eastern United States [database]. http://www.nrs.fs.fed.us/atlas/tree, Northern Research Station, USDA Forest Service, Delaware, $\mathrm{OH}$.

Raxworthy, C.J., Martinez-Meyer, E., Horning, N., Nussbaum, R.A., Schneider, G.E., Ortega -Huerta, M.A., and A.T. Peterson. 2003. Predicting distributions of known and unknown reptile species in Madagascar. Nature 426:837-841.

Ramirez, J. and A. Jarvis. 2008. High resolution statistically downscaled future climate surfaces. International Centre for Tropical Agriculture, CIAT. Available at: $<$ URL:http://gisweb.ciat.cgiar.org/GCMPage>

Schrag, A.N., Bunn, A.G., and L.J. Graumlich. 2008. Influence of bioclimatic variables on tree -line conifer distribution in the Greater Yellowstone Ecosystem: implications for species of conservation concern. Journal of Biogeography 35:698-710. 
Schuler, T.M., W.M. Ford, and R.J. Collins. 2002. Successional dynamics and restoration implicataions of a montane coniferous forest in the central Appalachians, USA. Natural Areas Journal 22(2):88-98.

Stephenson, S.L. 1993. Upland Forest Vegetation. Pp.11-34 in S.L. Stephenson ed., Upland forests of West Virginia. McClain Printing Co., Parsons, West Virginia.

Stephenson, S.L., and H.S. Adams. 1993. Threats to the upland forests. Pp.261-273 in S.L. Stephenson ed., Upland Forests of West Virginia. McClain Printing, Parsons, W.Va.

Stephenson, S.L., and J.F. Clovis. 1983. Spruce forests of the Allegheny Mountains in Central West Virginia. Castanea 48(1):1-12.

Strausbaugh, P.D., and E.L. Core. 1964. Flora of West Virginia. Introductory Section. West Virginia University Bulletin. Series 65. No. 3-1.

Thuiller, W., Lavorel, S., Sykes, M.T. and M.B. Araujo. 2006. Using niche-bases modeling to assess the impact of climate change on tree functional diversity in Europe. Diversity and Distributions 12:49-60.

USDA 2006. Monongahela National Forest - Land and Resource Management Plan. United States Department of Agriculture-Forest Service. 246p.

White, P.S., E.R. Buckner, J.D. Pittillo, and C.V. Cogbill. 1993. High-elevation forests: sprucefir forests, northern hardwoods forests, and associated communities. Pp 305-337. In W.H. Martin, S.G. Boyce, and A.C. Echternacht, (eds.). Biodiversity of the Southeastern United States: upland terrestrial communities. John Wiley \& Sons, Inc., New York.

Yates, C.J., McNeill, A., Elith, J., and G.G. Midgley. 2010. Assessing the impacts of climate change and land transformation on Banksia in the South West Australian Floristic Region. Diversity and Distributions 16:187-201. 
Table 3.1. Best estimate and likely range of projected global average surface warming at the end of the $21^{\text {st }}$ Century for all Special Report on Emission Scenarios (SRES) families identified in the IPCC $4^{\text {th }}$ Assessment Summary Report (adapted from IPCC-AR4 2007).

\begin{tabular}{lcc}
\hline & Temperature change $\left({ }^{\circ} \mathrm{C}\right.$ at $2090-2099$ relative to 1980-1999) \\
\cline { 2 - 3 } Case & Best estimate & Likely range \\
\hline Constant year 2000 concentrations & 0.6 & $0.3-0.9$ \\
B1 scenario & 1.8 & $1.1-2.9$ \\
A1T scenario & 2.4 & $1.4-3.8$ \\
B2 scenario & 2.4 & $1.4-3.8$ \\
A1B scenario & 2.8 & $1.7-4.4$ \\
A2 scenario & 3.4 & $2.0-5.4$ \\
A1FI scenario & 4.0 & $2.4-6.4$ \\
\hline
\end{tabular}


Table 3.2. Average values for the 19 bioclimatic variables used for the SRES-A2 scenario with the range of values for all four time steps examined (i.e., Current, 2020, 2050, 2080) using the 168 overstory red spruce presence localities.

\begin{tabular}{|c|c|c|c|c|c|}
\hline \multirow[b]{2}{*}{ Variable } & \multirow[b]{2}{*}{ Description } & Current & 2020 & 2050 & 2080 \\
\hline & & \multicolumn{4}{|c|}{ Temperature Variables (Units: ${ }^{\circ} \mathrm{C}$ ) } \\
\hline Bio_1 & Mean Annual Temperature & 7.5 & 8.7 & 10.2 & 12.4 \\
\hline Bio_2 & Mean Diurnal Range & 11.4 & 11.4 & 11.5 & 11.9 \\
\hline Bio_3 & Isothermality & 3.4 & 3.2 & 3.2 & 3.1 \\
\hline Bio_4 & Temperature Seasonality & $\mathrm{N} / \mathrm{A}$ & $\mathrm{N} / \mathrm{A}$ & $\mathrm{N} / \mathrm{A}$ & $\mathrm{N} / \mathrm{A}$ \\
\hline Bio 5 & Maximum Temperature of Warmest Month & 23.7 & 25.6 & 28.3 & 31.8 \\
\hline Bio_6 & Minimum Temperature of Coldest Month & -9.8 & -9.7 & -7.7 & -5.9 \\
\hline Bio_- 7 & Temperature Annual Range (Bio5-Bio6) & 33.4 & 35.3 & 35.9 & 37.8 \\
\hline Bio_- 8 & Mean Temperature of Wettest Quarter & 15.6 & 16.9 & 18.8 & 11.7 \\
\hline Bio_-9 & Mean Temperature of Driest Quarter & -0.1 & 6.9 & 0.3 & 11.9 \\
\hline Bio_10 & Mean Temperature of Warmest Quarter & 17.2 & 18.6 & 20.9 & 23.6 \\
\hline \multirow[t]{2}{*}{ Bio_11 } & Mean Temperature of Coldest Quarter & -3.2 & -2.8 & -1.3 & 0.4 \\
\hline & & \multicolumn{4}{|c|}{ Precipitation Variables (Units: $\mathrm{mm}$ ) } \\
\hline Bio_12 & Annual Precipitation & 1412 & 1468 & 1528 & 1572 \\
\hline Bio_13 & Precipitation of Wettest Month & 140 & 155 & 156 & 169 \\
\hline Bio_14 & Precipitation of Driest Month & 102 & 100 & 107 & 99 \\
\hline Bio_15 & Precipitation Seasonality & $\mathrm{N} / \mathrm{A}$ & N/A & $\mathrm{N} / \mathrm{A}$ & N/A \\
\hline Bio 16 & Precipitation of Wettest Quarter & 394 & 418 & 420 & 489 \\
\hline Bio_17 & Precipitation of Driest Quarter & 321 & 323 & 347 & 341 \\
\hline Bio_18 & Precipitation of Warmest Quarter & 384 & 390 & 389 & 388 \\
\hline Bio_19 & Precipitation of Coldest Quarter & 322 & 353 & 361 & 349 \\
\hline
\end{tabular}


Table 3.3. Average values for the 19 bioclimatic variables used for the SRES-B2 scenario with the range of values for all four time steps examined (i.e., Current, 2020, 2050,2080 ) using the 168 overstory red spruce presence localities.

\begin{tabular}{|c|c|c|c|c|c|}
\hline \multirow[b]{2}{*}{ Variable } & \multirow[b]{2}{*}{ Description } & Current & 2020 & 2050 & 2080 \\
\hline & & \multicolumn{4}{|c|}{ Temperature Variables (Units: ${ }^{\circ} \mathrm{C}$ ) } \\
\hline Bio 1 & Mean Annual Temperature & 7.5 & 8.7 & 9.7 & 10.9 \\
\hline Bio_2 & Mean Diurnal Range & 11.4 & 11.4 & 11.7 & 11.7 \\
\hline Bio_3 & Isothermality & 3.4 & 3.3 & 3.2 & 3.1 \\
\hline Bio_4 4 & Temperature Seasonality & $\mathrm{N} / \mathrm{A}$ & $\mathrm{N} / \mathrm{A}$ & $\mathrm{N} / \mathrm{A}$ & $\mathrm{N} / \mathrm{A}$ \\
\hline Bio_5 & Maximum Temperature of Warmest Month & 23.7 & 25.5 & 27.5 & 28.6 \\
\hline Bio 6 & Minimum Temperature of Coldest Month & -9.8 & -9.0 & -8.2 & -8.3 \\
\hline Bio_7 & Temperature Annual Range (Bio5-Bio6) & 33.4 & 34.6 & 35.7 & 36.9 \\
\hline Bio_8 & Mean Temperature of Wettest Quarter & 15.6 & 16.3 & 16.9 & 15.5 \\
\hline Bio_9 & Mean Temperature of Driest Quarter & -0.1 & 4.5 & 1.7 & 15.4 \\
\hline Bio_- 10 & Mean Temperature of Warmest Quarter & 17.2 & 18.7 & 20.3 & 21.6 \\
\hline \multirow[t]{2}{*}{ Bio_11 } & Mean Temperature of Coldest Quarter & -3.2 & -2.4 & -1.8 & -1.0 \\
\hline & & \multicolumn{4}{|c|}{ Precipitation Variables (Units: $\mathrm{mm}$ ) } \\
\hline Bio_12 & Annual Precipitation & 1412 & 1457 & 1481 & 1551 \\
\hline Bio_- 13 & Precipitation of Wettest Month & 140 & 141 & 168 & 175 \\
\hline Bio_14 & Precipitation of Driest Month & 102 & 96 & 105 & 101 \\
\hline Bio_- 15 & Precipitation Seasonality & $\mathrm{N} / \mathrm{A}$ & $\mathrm{N} / \mathrm{A}$ & $\mathrm{N} / \mathrm{A}$ & $\mathrm{N} / \mathrm{A}$ \\
\hline Bio_- 16 & Precipitation of Wettest Quarter & 394 & 415 & 423 & 460 \\
\hline Bio_17 & Precipitation of Driest Quarter & 321 & 309 & 336 & 345 \\
\hline Bio_18 & Precipitation of Warmest Quarter & 384 & 412 & 371 & 388 \\
\hline Bio 19 & Precipitation of Coldest Quarter & 322 & 334 & 344 & 357 \\
\hline
\end{tabular}


Table 3.4. Importance value (IV), basal area (BA), and trees per hectare (TPH), and average $\mathrm{DBH}$ for all species or species groups examined.

\begin{tabular}{|c|c|c|c|c|}
\hline Species & IV $(\%)$ & $\mathrm{BA}\left(\mathrm{m}^{2} / \mathrm{ha}\right)$ & $\mathrm{TPH}$ & Average DBH $(\mathrm{cm})$ \\
\hline Picea rubens Sarg. & 40.21 & 16.94 & 172.09 & 32.97 \\
\hline Acer rubrum $\mathrm{L}$. & 16.75 & 7.55 & 67.22 & 35.04 \\
\hline Betula alleghaniensis Britton & 11.41 & 4.53 & 51.33 & 30.49 \\
\hline Tsuga canadensis (L.) Carr. & 10.59 & 4.99 & 40.60 & 35.44 \\
\hline Prunus serotina Ehrh. & 9.25 & 5.18 & 27.95 & 46.03 \\
\hline Quercus spp.† & 3.27 & 11.34 & 82.37 & 36.83 \\
\hline Fagus grandifolia Ehrh. & 3.02 & 1.17 & 13.83 & 29.02 \\
\hline Betula lenta $\mathrm{L}$. & 1.00 & 0.41 & 4.41 & 31.79 \\
\hline Acer saccharum Marsh. & 0.87 & 0.40 & 3.38 & 35.60 \\
\hline Pinus resinosa Aiton & 0.62 & 0.30 & 2.35 & 39.85 \\
\hline Magnolia acuminata (L.) L. & 0.45 & 0.22 & 1.62 & 38.49 \\
\hline Acer pensylvanicum $\mathrm{L}$. & 0.40 & 0.07 & 2.65 & 16.75 \\
\hline Liriodendron tulipifera $\mathrm{L}$. & 0.35 & 0.22 & 0.88 & 55.20 \\
\hline Amelanchier arborea (Michx. f.) Fernald & 0.33 & 0.06 & 2.06 & 18.85 \\
\hline Magnolia fraseri Walter & 0.33 & 0.12 & 1.62 & 29.74 \\
\hline Fraxinus americana $\mathrm{L}$. & 0.31 & 0.14 & 1.18 & 35.72 \\
\hline Pinus strobus L. & 0.20 & 0.15 & 0.29 & 80.01 \\
\hline Sorbus americana Marsh. & 0.15 & 0.05 & 0.74 & 26.06 \\
\hline Othert & 0.48 & 1.32 & 13.39 & 37.85 \\
\hline TOTAL & 100.00 & 44.65 & 405.08 & 34.32 \\
\hline
\end{tabular}

$\dagger$ †uercus spp. include northern red oak (Q. rubra L.), white oak (Q. alba L.), and chestnut oak (Q. prinus L.).

+Other species include pin cherry (Prunus pensylvanica L.), American basswood (Tilia americana L.), hawthorn species (Crataegus sp. L.), yellow buckeye (Aesculus flava Aiton), black locust (Robinia pseudoacacia L.), sweet cherry (Prunus avium (L.) L.), shagbark hickory (Carya ovata (Mill.) K. Koch), mockernut hickory (Carya tomentosa (Lam.) Nutt.), and bigtooth aspen (Populus grandidentata Michx.). 
Table 3.5. SRES-A2 Average variable percent contribution for all 10 replicated Maxent analyses.

\begin{tabular}{lc} 
Variable & Percent Contribution \\
\hline bio_11r & 17.8 \\
ned30m & 15.2 \\
bio_06r & 14.5 \\
slope30 & 9.7 \\
bio_07r & 8.5 \\
bio_05r & 5.8 \\
bio_01r & 4.2 \\
c_geology & 3.7 \\
bio_19r & 2.9 \\
bio_02r & 2.6 \\
sol_cal & 2.5 \\
bio_04r & 2.1 \\
bio_14r & 2.0 \\
bio_13r & 1.6 \\
aspct30 & 1.5 \\
bio_12r & 1.4 \\
bio_08r & 1.0 \\
bio_10r & 0.8 \\
bio_09r & 0.8 \\
bio_18r & 0.4 \\
bio_17r & 0.4 \\
bio_03r & 0.3 \\
bio_15r & 0.2 \\
bio_16r & 0.2
\end{tabular}


Table 3.6. SRES-B2 Average variable percent contribution for all 10 replicated Maxent analyses.

\begin{tabular}{cc} 
Variable & Percent Contribution \\
\hline bio_06r & 16.9 \\
ned30m & 13.7 \\
bio_11r & 12.4 \\
bio_08r & 7.3 \\
bio_01r & 6.8 \\
bio_05r & 6.5 \\
bio_02r & 6.5 \\
slope30 & 6.0 \\
bio_07r & 4.6 \\
bio_04r & 3.0 \\
c_geology & 2.4 \\
bio_12r & 1.8 \\
bio_19r & 1.8 \\
bio_13r & 1.7 \\
sol & 1.7 \\
bio_09r & 1.4 \\
aspct30 & 1.4 \\
bio_14r & 1.1 \\
bio_17r & 1.1 \\
bio_16r & 0.9 \\
bio_18r & 0.7 \\
bio_15r & 0.1 \\
bio_10r & 0.1 \\
bio_03r & 0.1
\end{tabular}


Table 3.7. Area (ha) of red spruce habitat suitability modeled using 4 time steps (i.e., Current, 2020, 2050, 2080) under both model scenarios.

\begin{tabular}{|c|c|c|c|c|c|c|}
\hline \multirow[b]{2}{*}{ Scenario } & \multirow{2}{*}{$\begin{array}{l}\text { Model } \\
\text { Period } \\
\end{array}$} & \multicolumn{4}{|c|}{ Suitability Index } & \multirow{2}{*}{$\begin{array}{c}\text { Total } \\
\text { Suitability }\end{array}$} \\
\hline & & Unsuitable & Low & Medium & High & \\
\hline \multirow[t]{4}{*}{$\mathrm{A} 2$} & Current & $5,882,245$ & 269,782 & 85,481 & 8,951 & 364,214 \\
\hline & 2020 & $6,165,346$ & 81,103 & 10 & - & 81,113 \\
\hline & 2050 & $6,226,444$ & 20,015 & - & - & 20,015 \\
\hline & 2080 & $6,246,459$ & - & - & - & - \\
\hline \multirow[t]{4}{*}{ B2 } & Current & $5,884,382$ & 260,369 & 93,646 & 8,062 & 362,077 \\
\hline & 2020 & $6,073,918$ & 156,548 & 13,807 & 2,187 & 172,541 \\
\hline & 2050 & $6,086,497$ & 150,002 & 9,938 & 21 & 159,962 \\
\hline & 2080 & $6,192,593$ & 53,639 & 227 & - & 53,866 \\
\hline
\end{tabular}




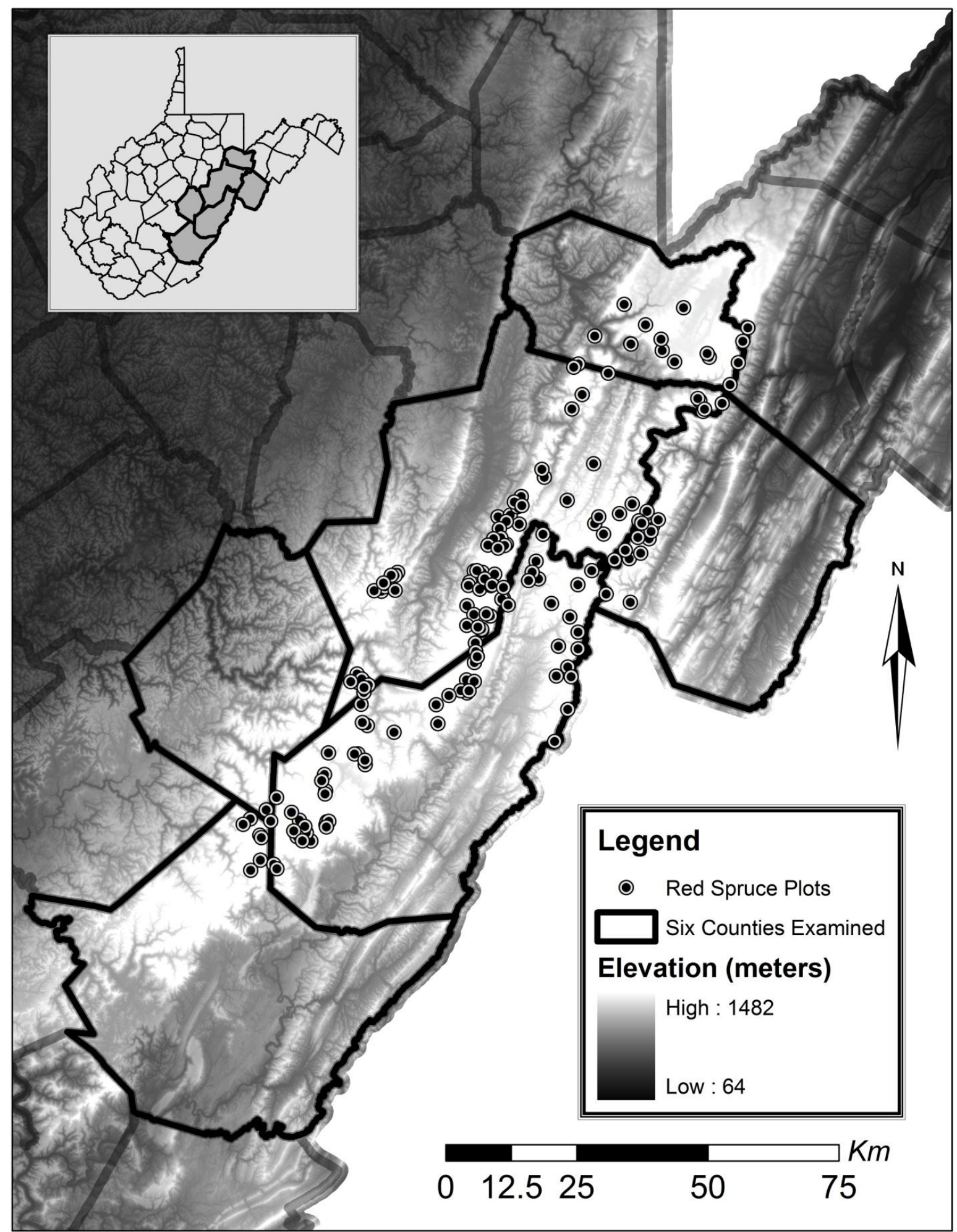

Figure 3.1. Field data collected throughout the Appalachian Mountain Region (AMR) of West Virginia in summers 2008 and 2009. 


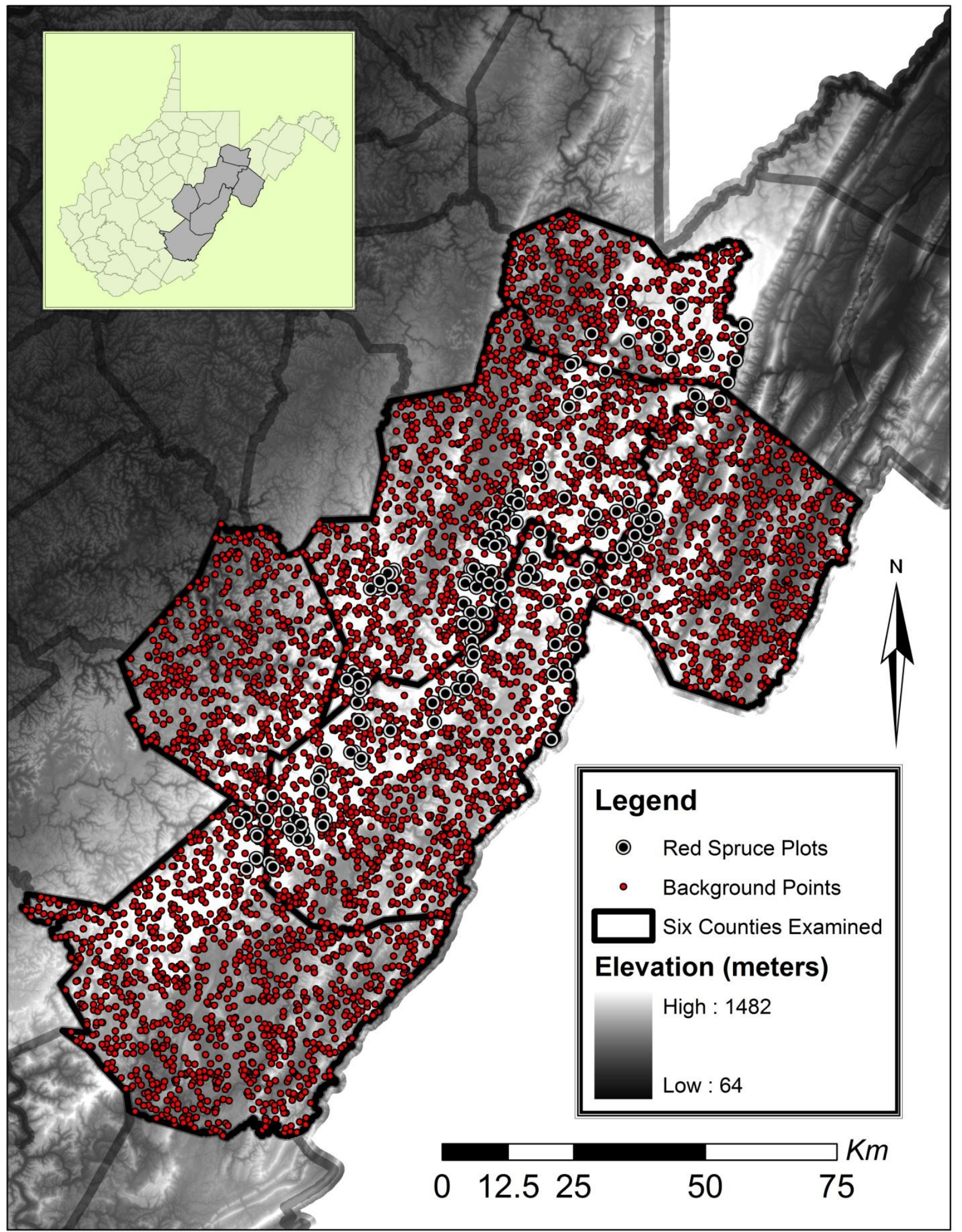

Figure 3.2. Background points generated for our Maxent analysis shown with red spruce presence locations. 


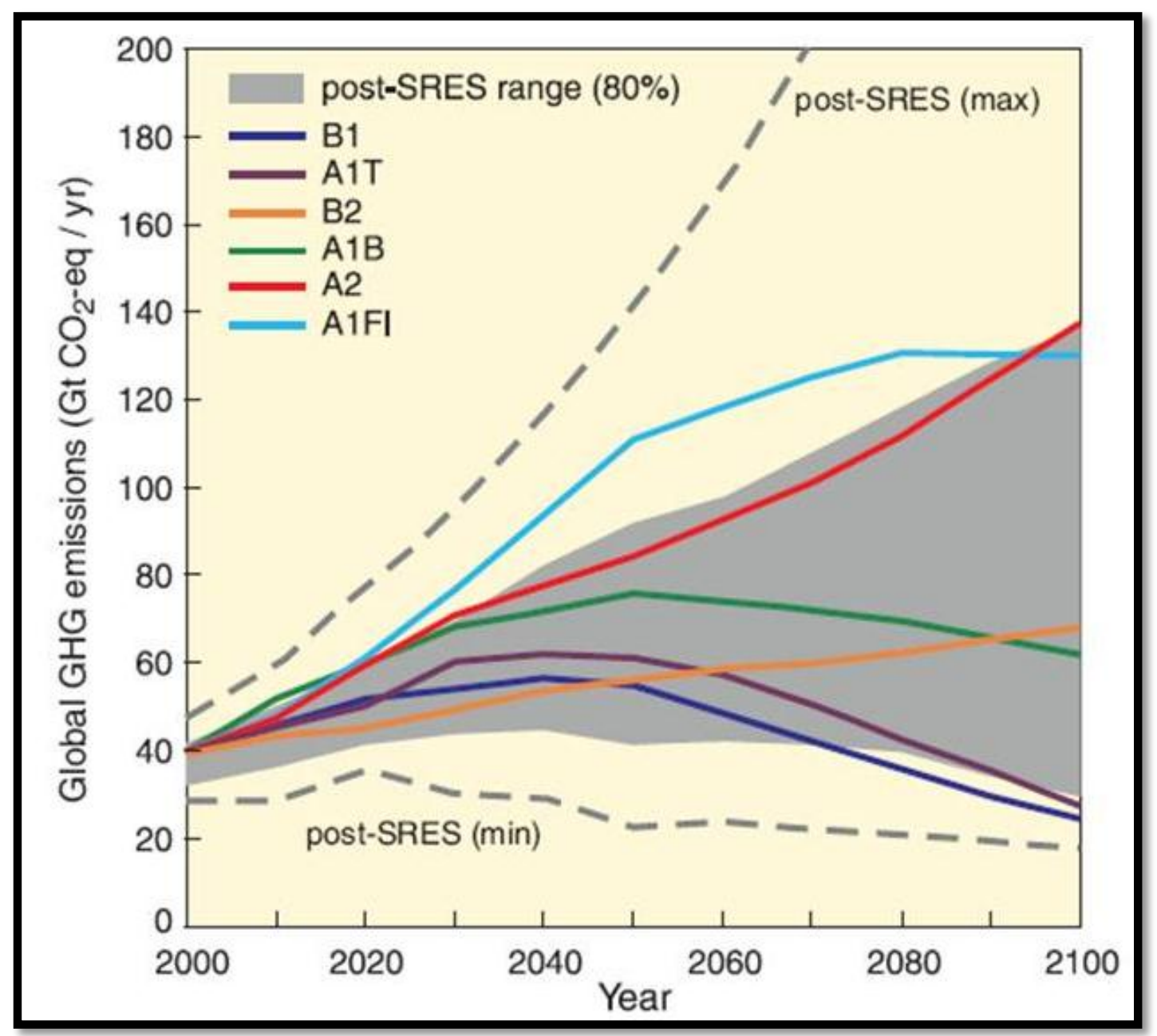

Figure 3.3. Scenarios for greenhouse gas emissions (GHG) from 2000 to 2100 in the absence of additional climate policies (Adapted from IPCC-AR4 2007). 


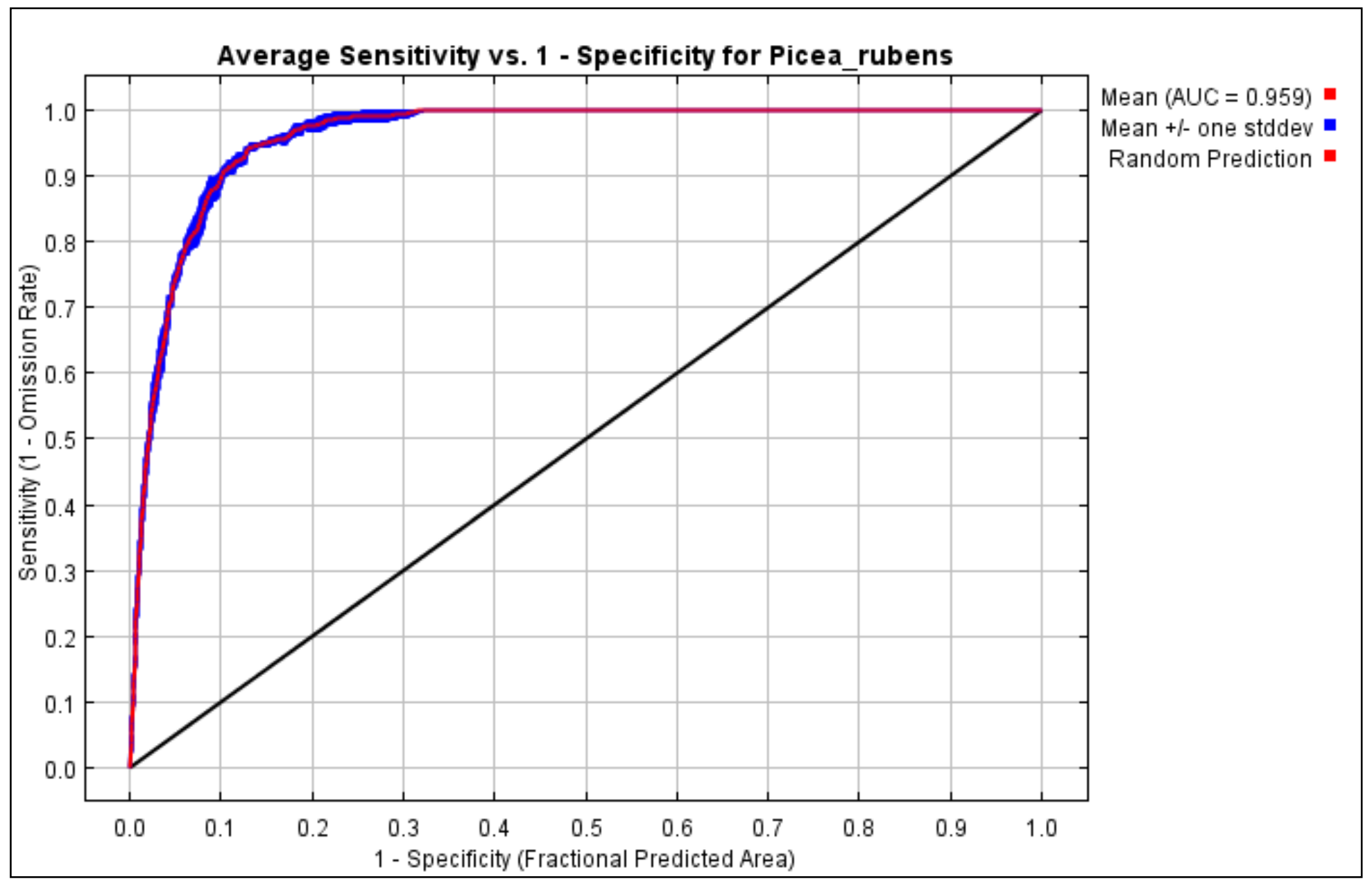

Figure 3.4. Receiver operating characteristic (ROC) curve for the SRES-A2 scenario red spruce habitat model, averaged over all ten replicate runs. Specificity is defined here using the predicted area, rather than true commission. The average AUC for all replicate runs was $0.959(\mathrm{sd}=0.011)$. 


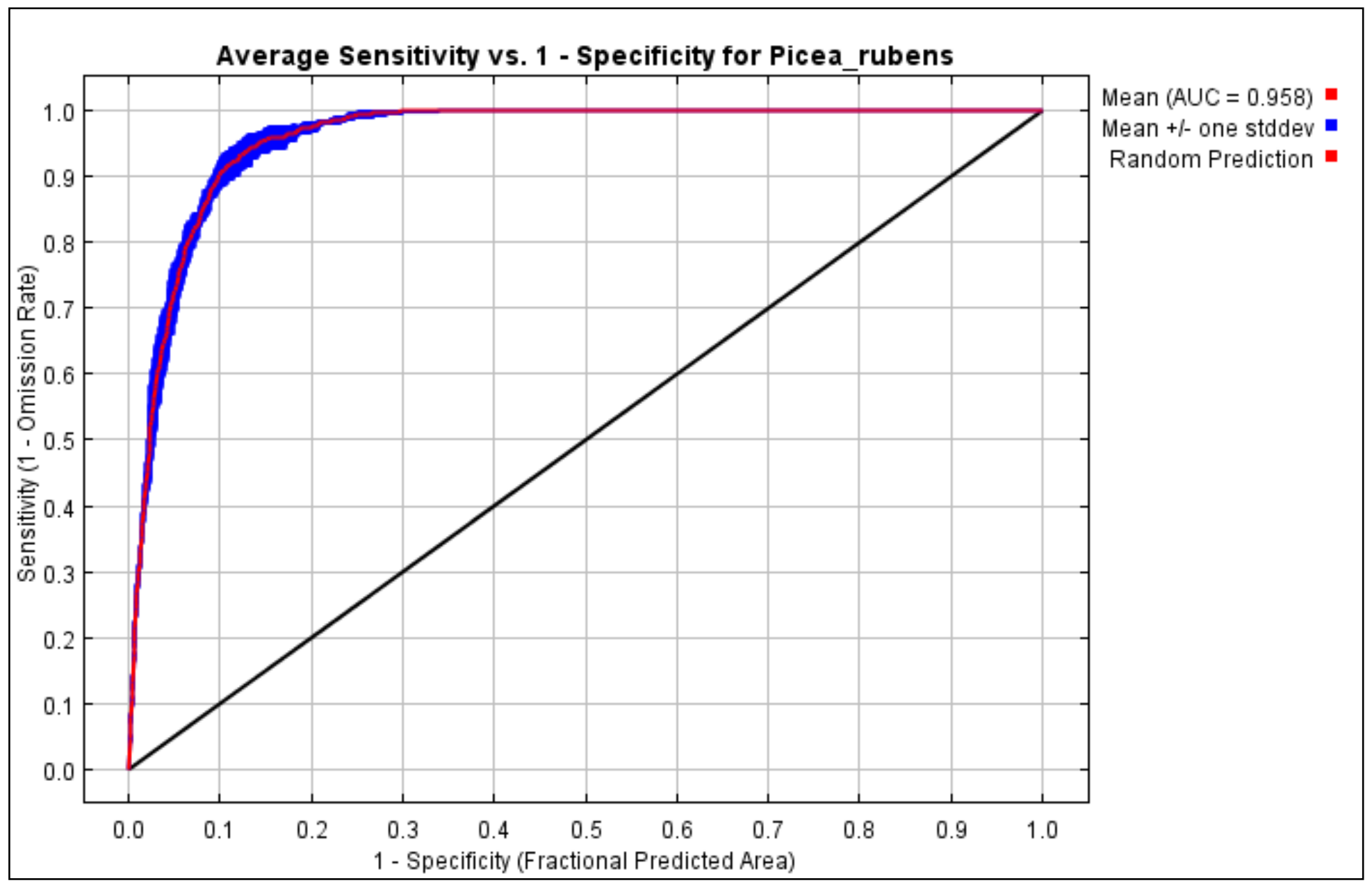

Figure 3.5. Receiver operating characteristic (ROC) curve for the SRES-B2 scenario red spruce habitat model, averaged over all ten replicate runs. Specificity is defined here using the predicted area, rather than true commission. The average AUC for all replicate runs was $0.958(\mathrm{sd}=0.011)$. 


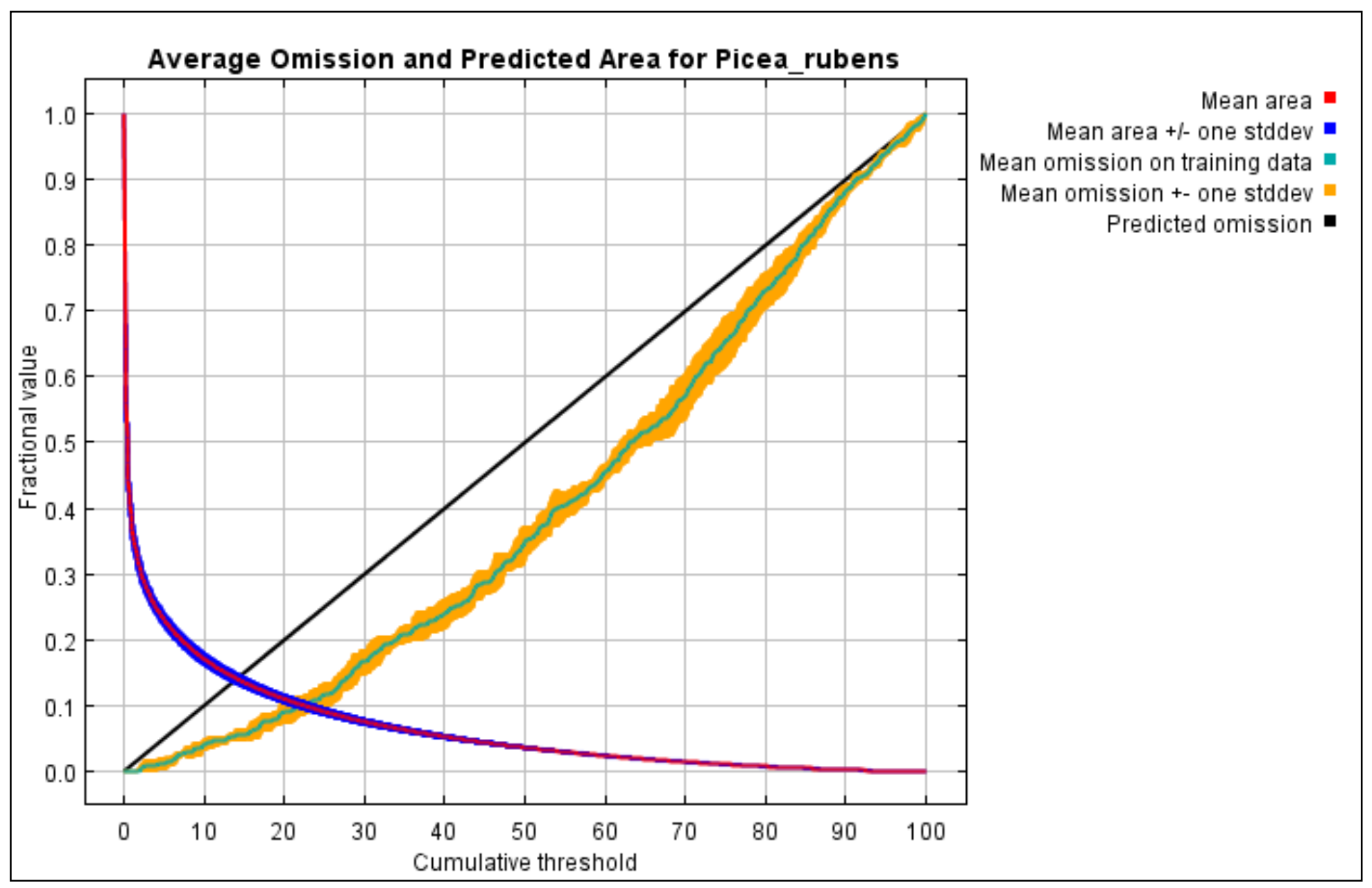

Figure 3.6. Accuracy assessment of the SRES-A2 Maxent model showing the training omission rate and predicted area as a function of the cumulative threshold, averaged over the five replicate runs. 


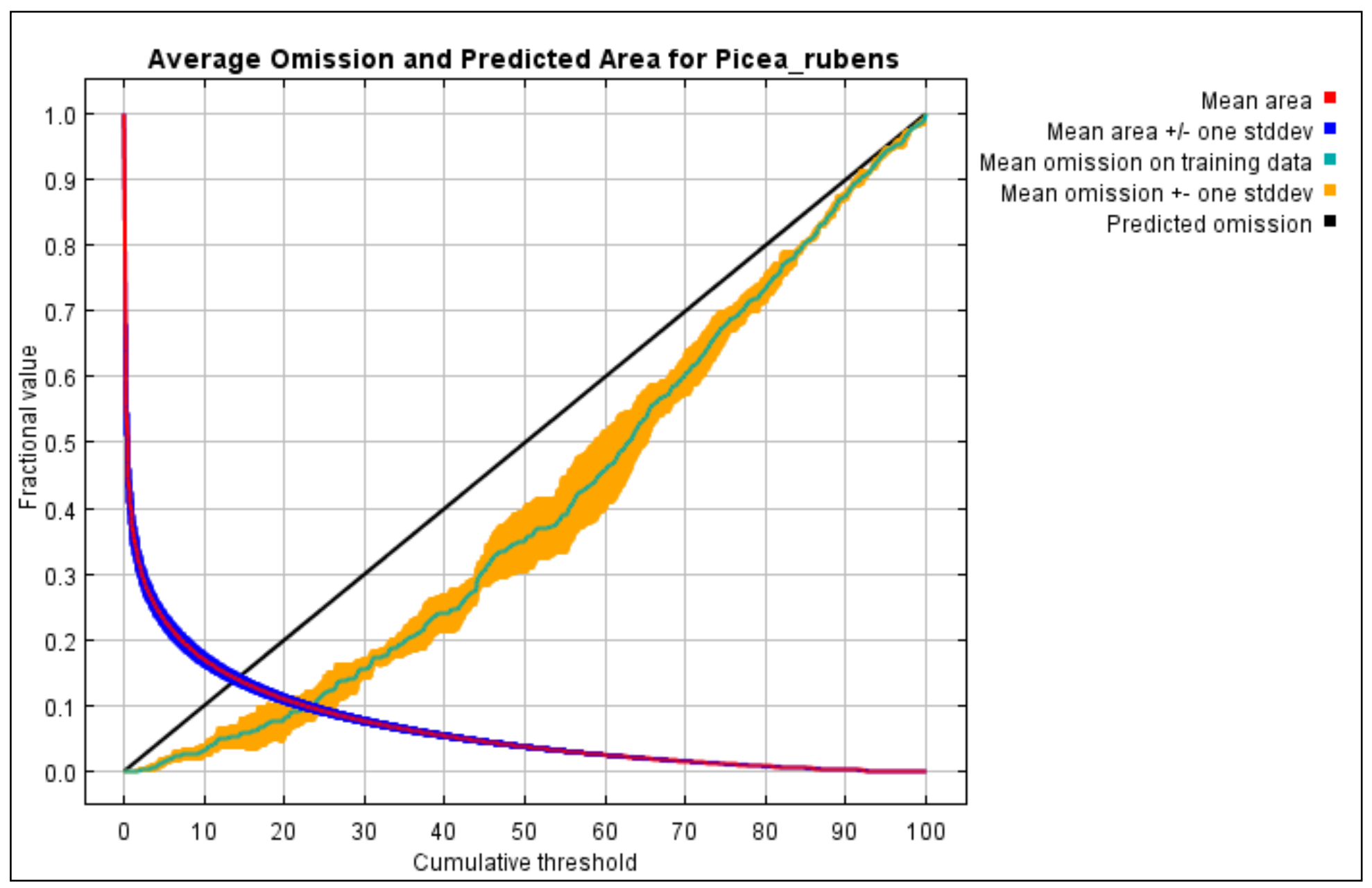

Figure 3.7. Accuracy assessment of the SRES-B2 Maxent model showing the training omission rate and predicted area as a function of the cumulative threshold, averaged over the five replicate runs. 


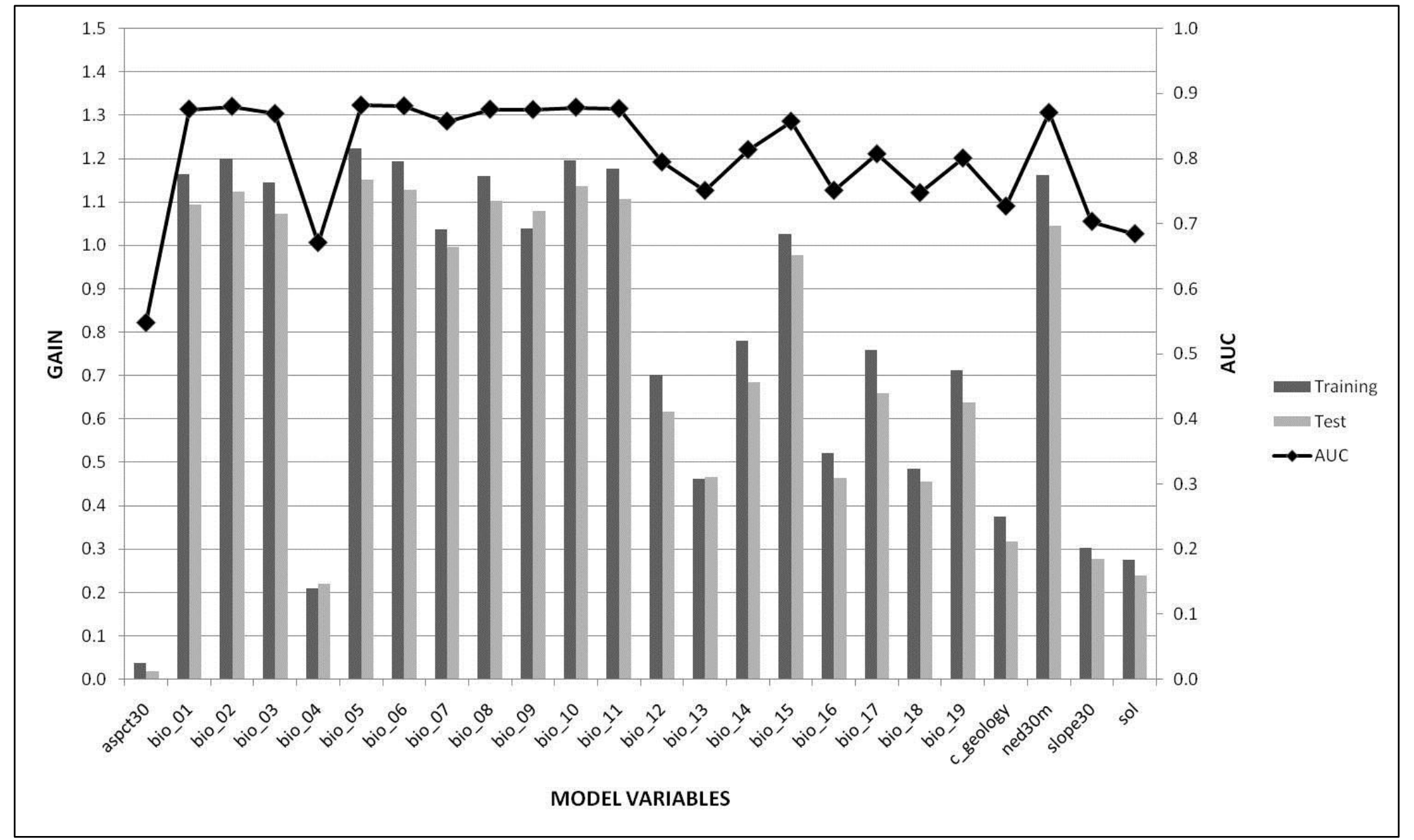

Figure 3.8. Graph of training gain, test gain, and AUC values using each variable by itself for the SRES-A2 model. This examination is useful when strong variable correlations exist (i.e., climatic data). Additionally, comparison of the training to test gain allows for assessment of how well the model fits the test dataset. 


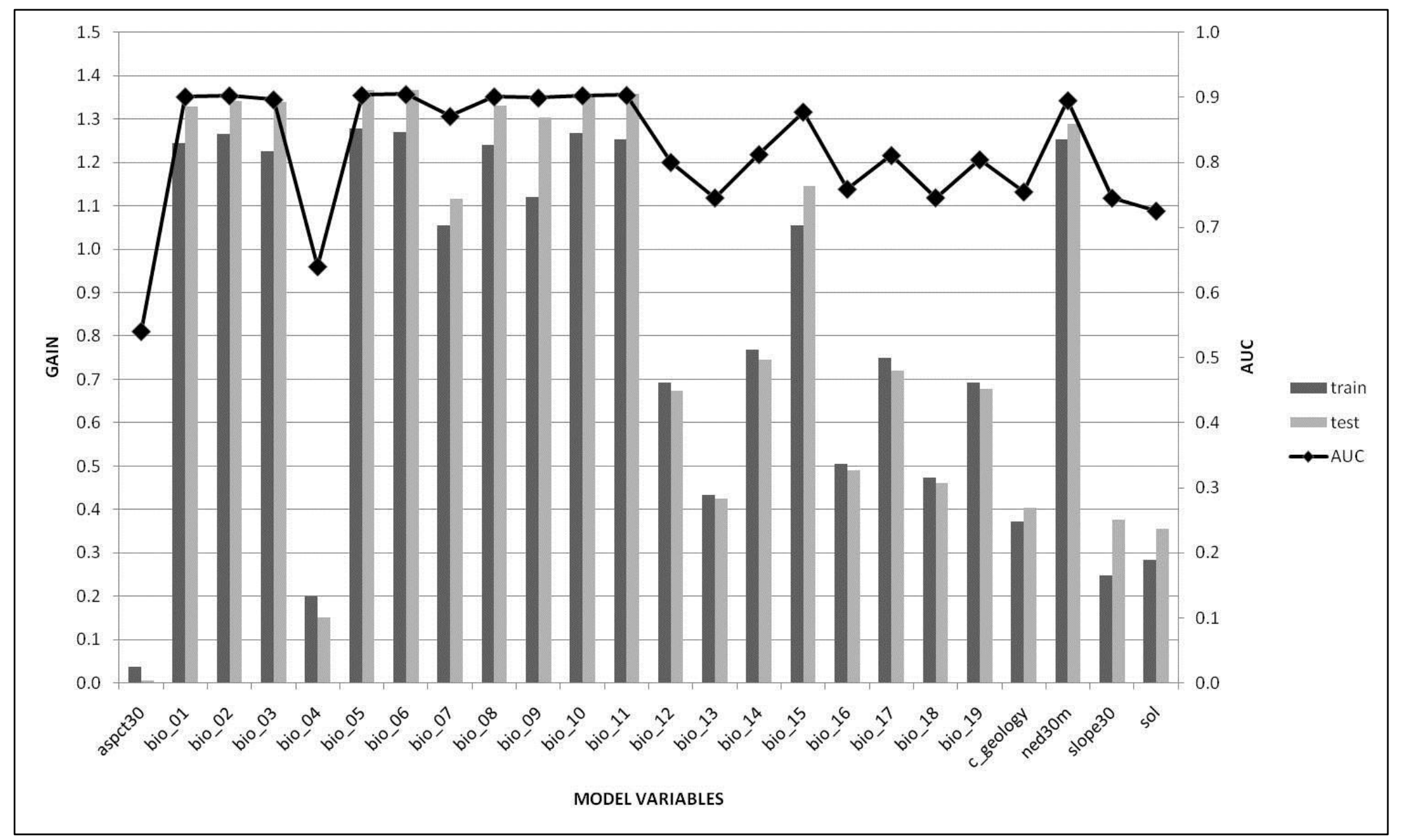

Figure 3.9. Graph of training gain, test gain, and AUC values using each variable by itself for the SRES-B2 model. This examination is useful when strong variable correlations exist (i.e., climatic data). Additionally, comparison of the training to test gain allows for assessment of how well the model fits the test dataset. 


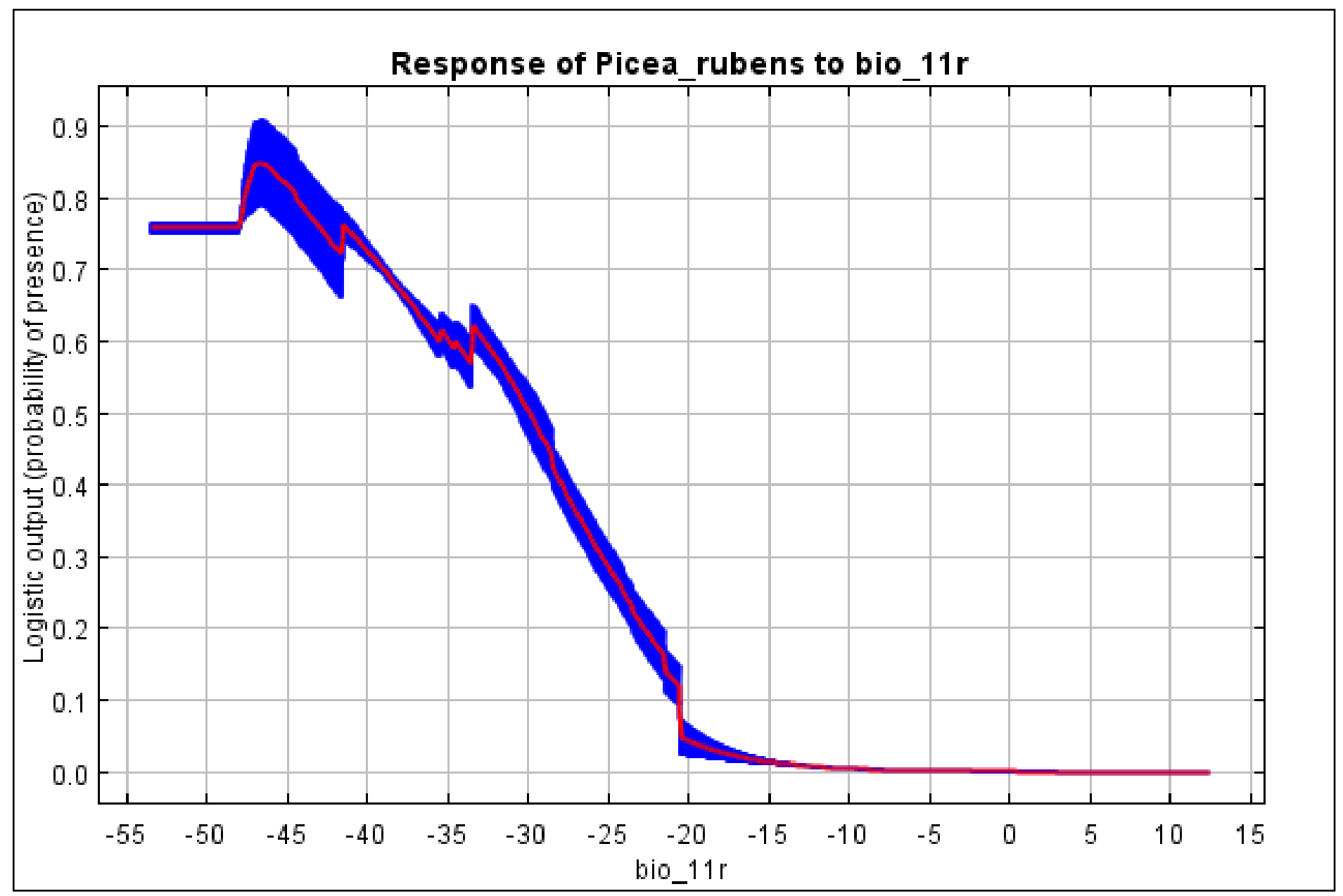

Figure 3.10. Graph of mean temperature of the coldest quarter (bio 11) for the SRES-A2 model. Units are displayed in degrees $\mathrm{C} * 10$. 


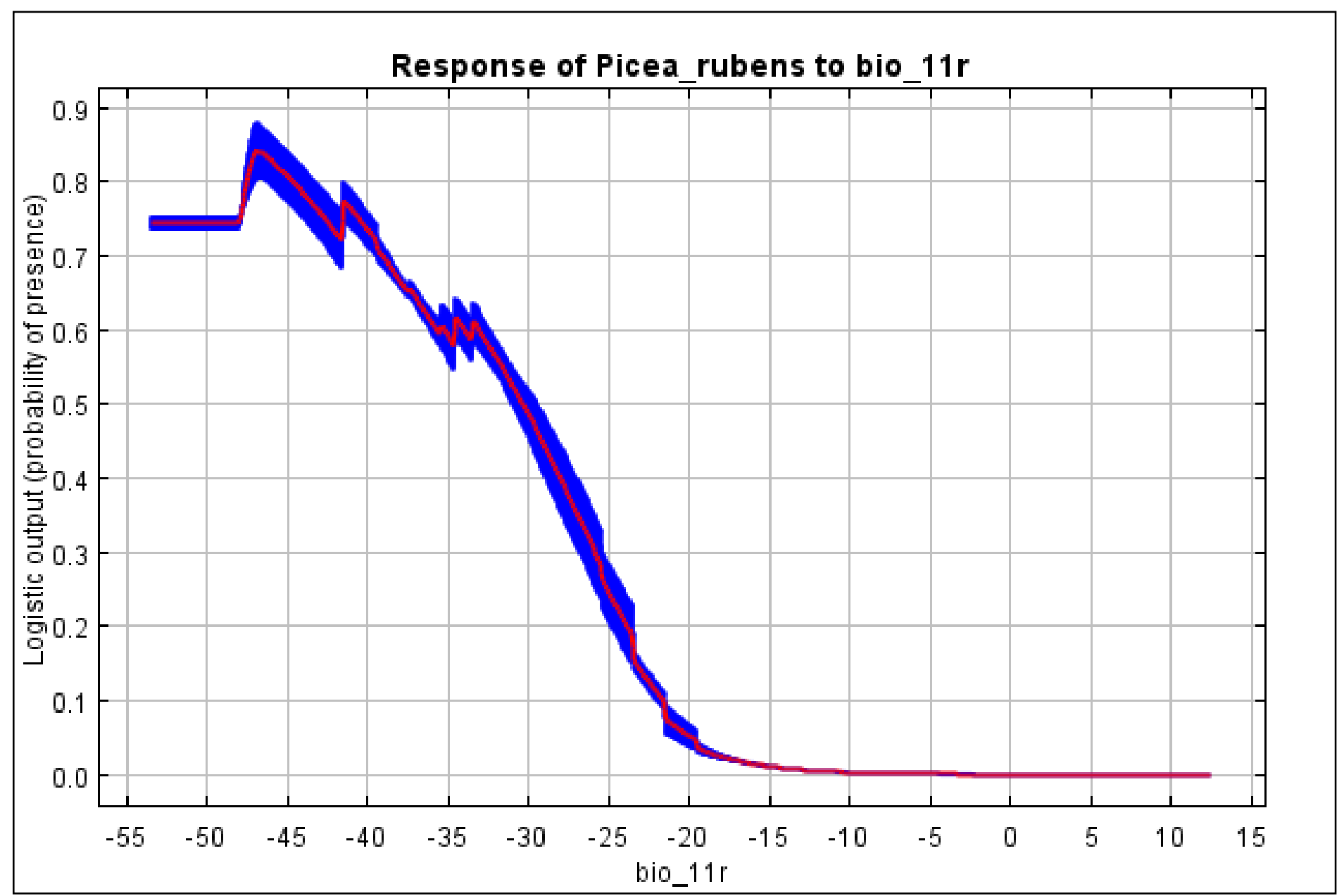

Figure 3.11. Graph of mean temperature of the coldest quarter (bio_11) for the SRES-B2 model. Units are displayed in degrees $\mathrm{C} * 10$. 


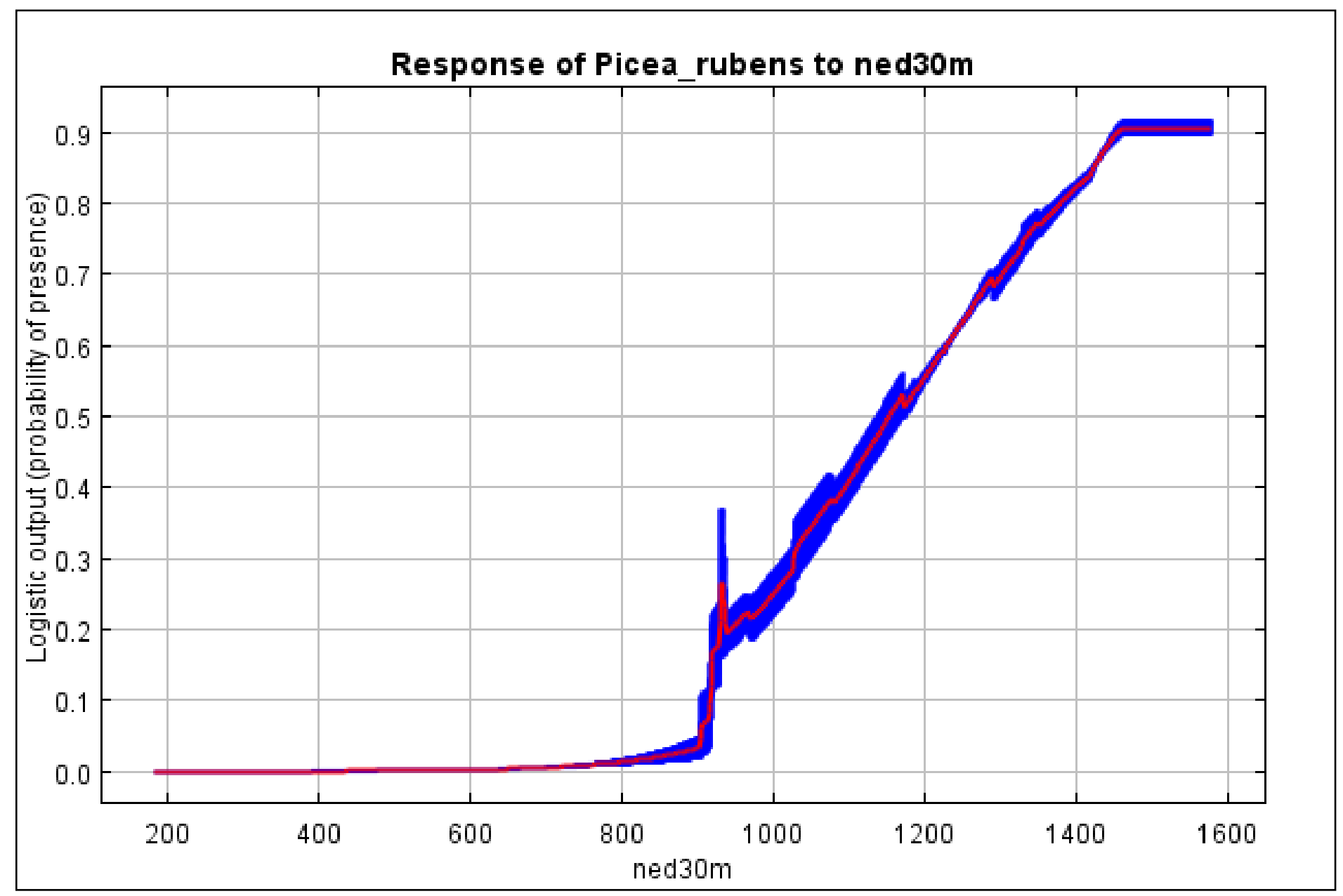

Figure 3.12. Graph of elevation (ned30m) for the SRES-A2 model. Units are displayed in meters. 


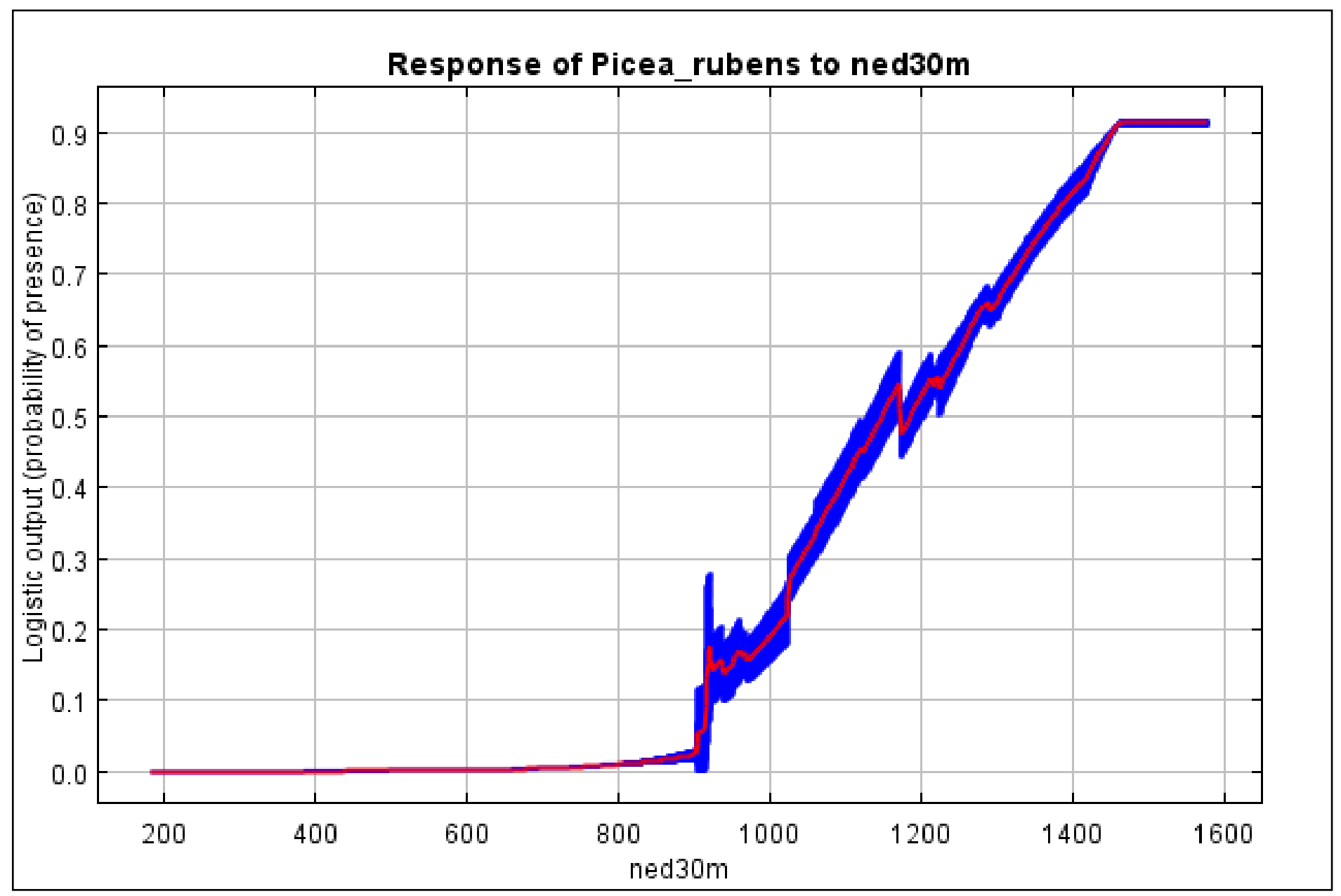

Figure 3.13. Graph of elevation (ned30m) for the SRES-B2 model. Units are displayed in meters. 


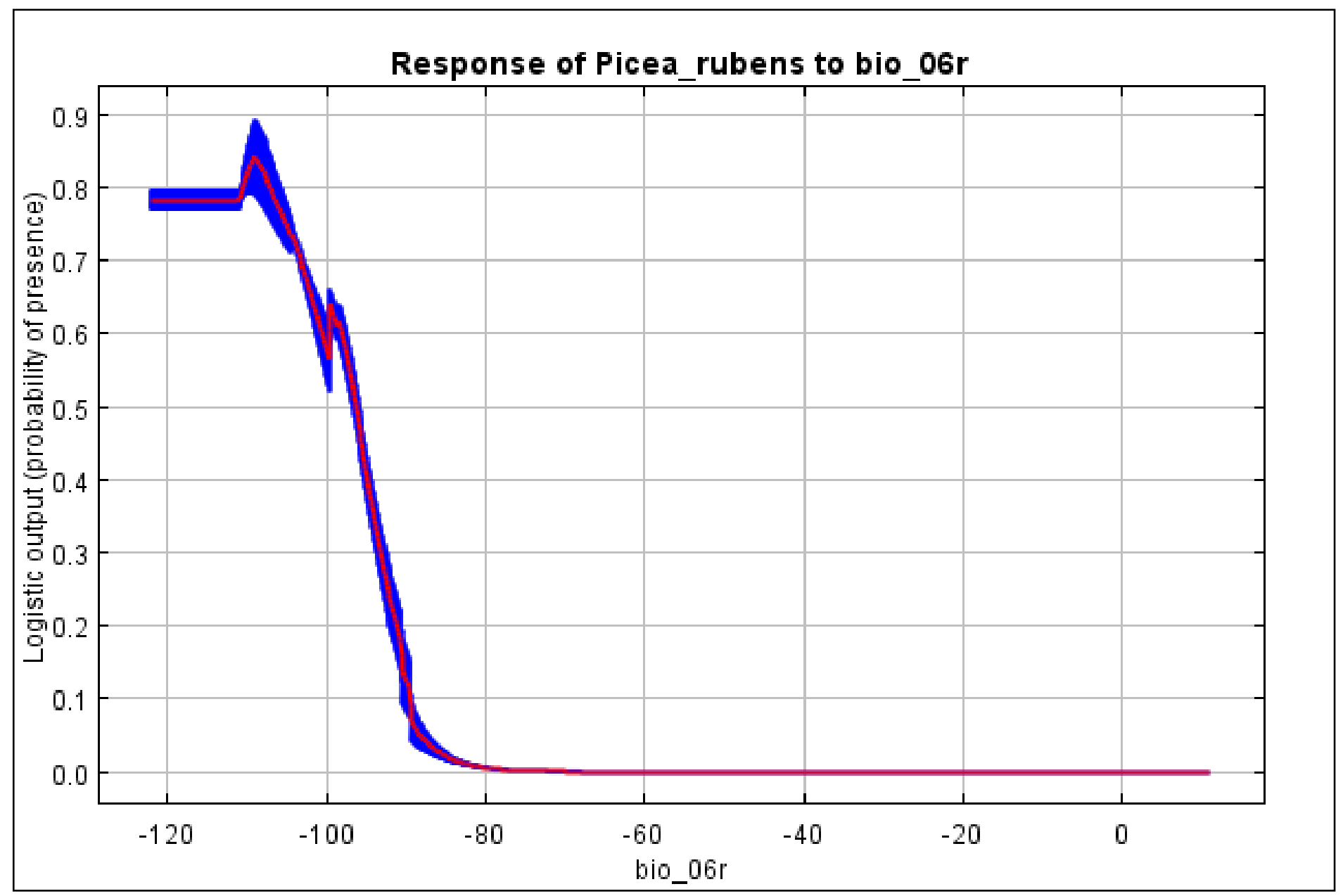

Figure 3.14. Graph of minimum temperature of the coldest month (bio_06) for the SRES-A2 model. Units are displayed in degrees $\mathrm{C} * 10$. 


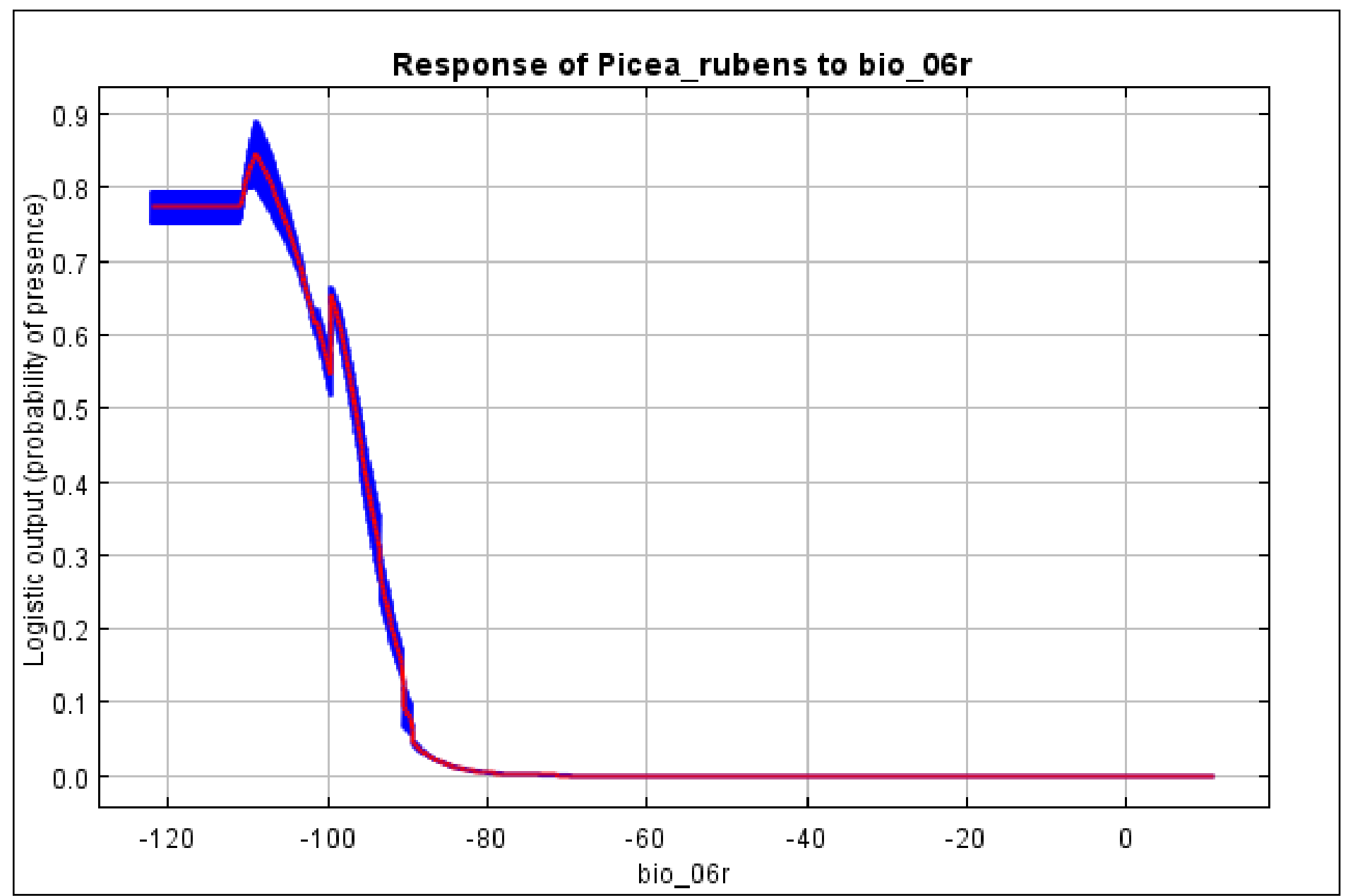

Figure 3.15. Graph of minimum temperature of the coldest month (bio_06) for the SRES-B2 model. Units are displayed in degrees $\mathrm{C} * 10$. 


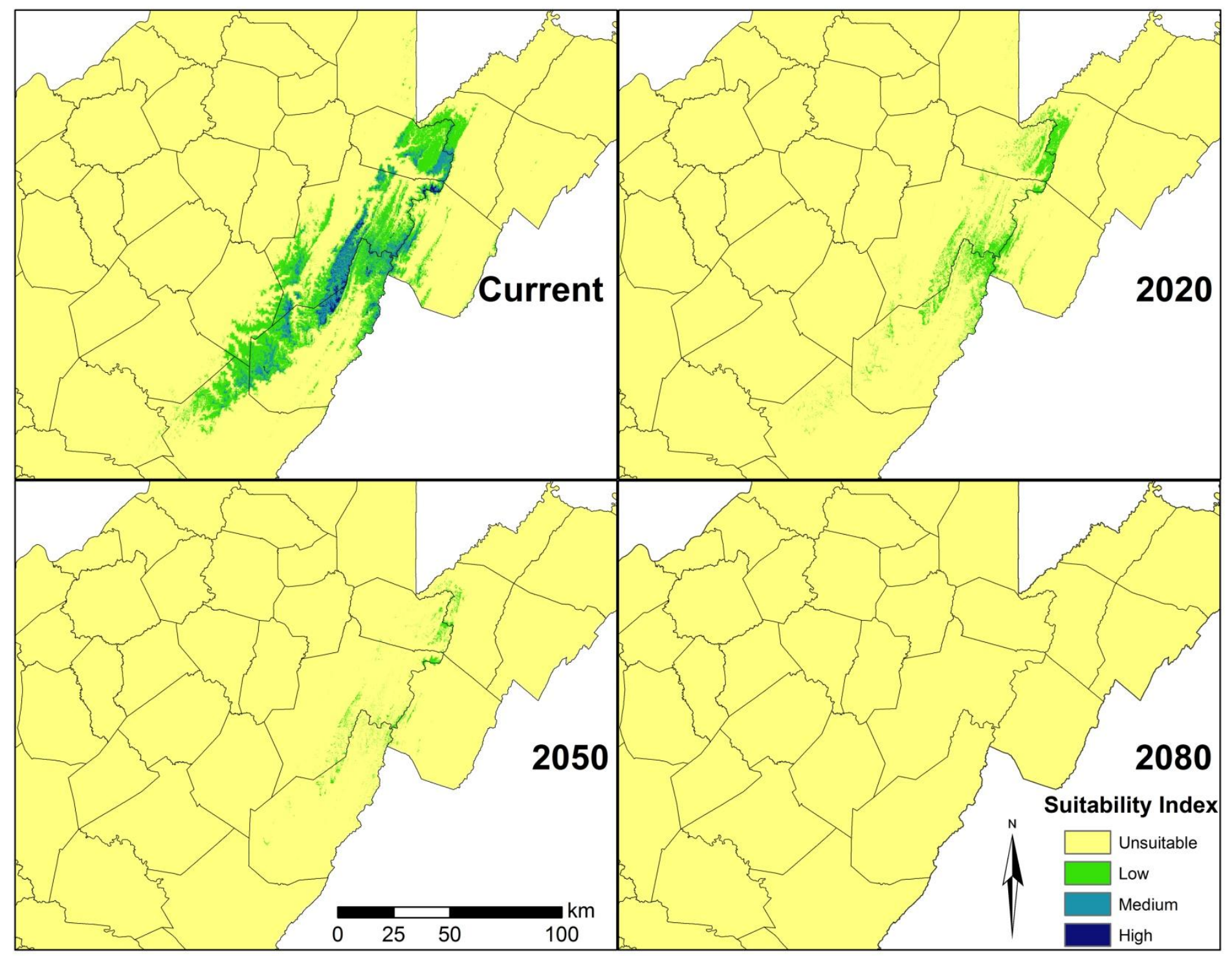

Figure 3.16. Areas modeled to possess red spruce habitat by suitability index in West Virginia for all time steps examined for the SRES-A2 model scenario. 


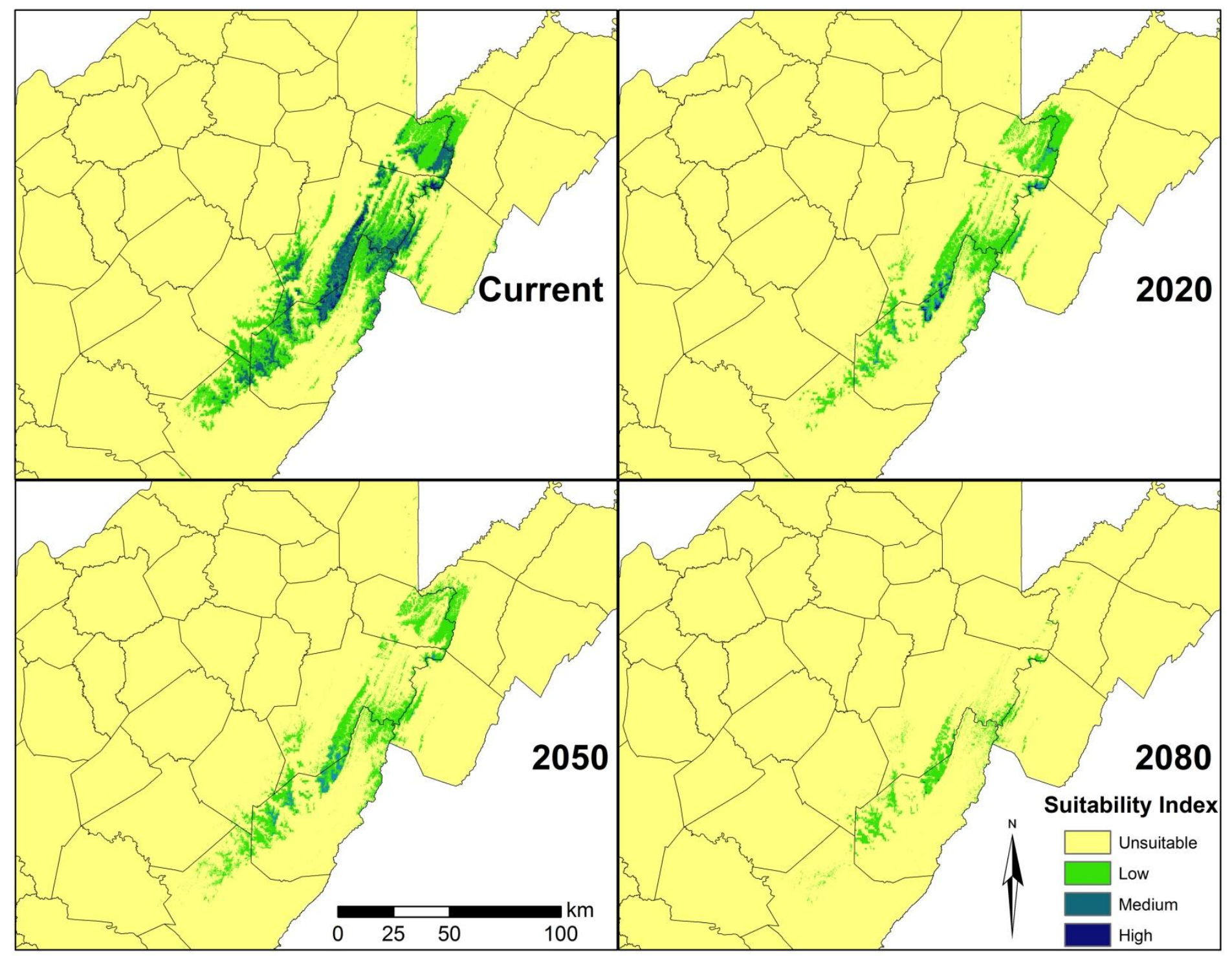

Figure 3.17. Areas modeled to possess red spruce habitat by suitability index in West Virginia for all time steps examined for the SRES-B2 model scenario. 


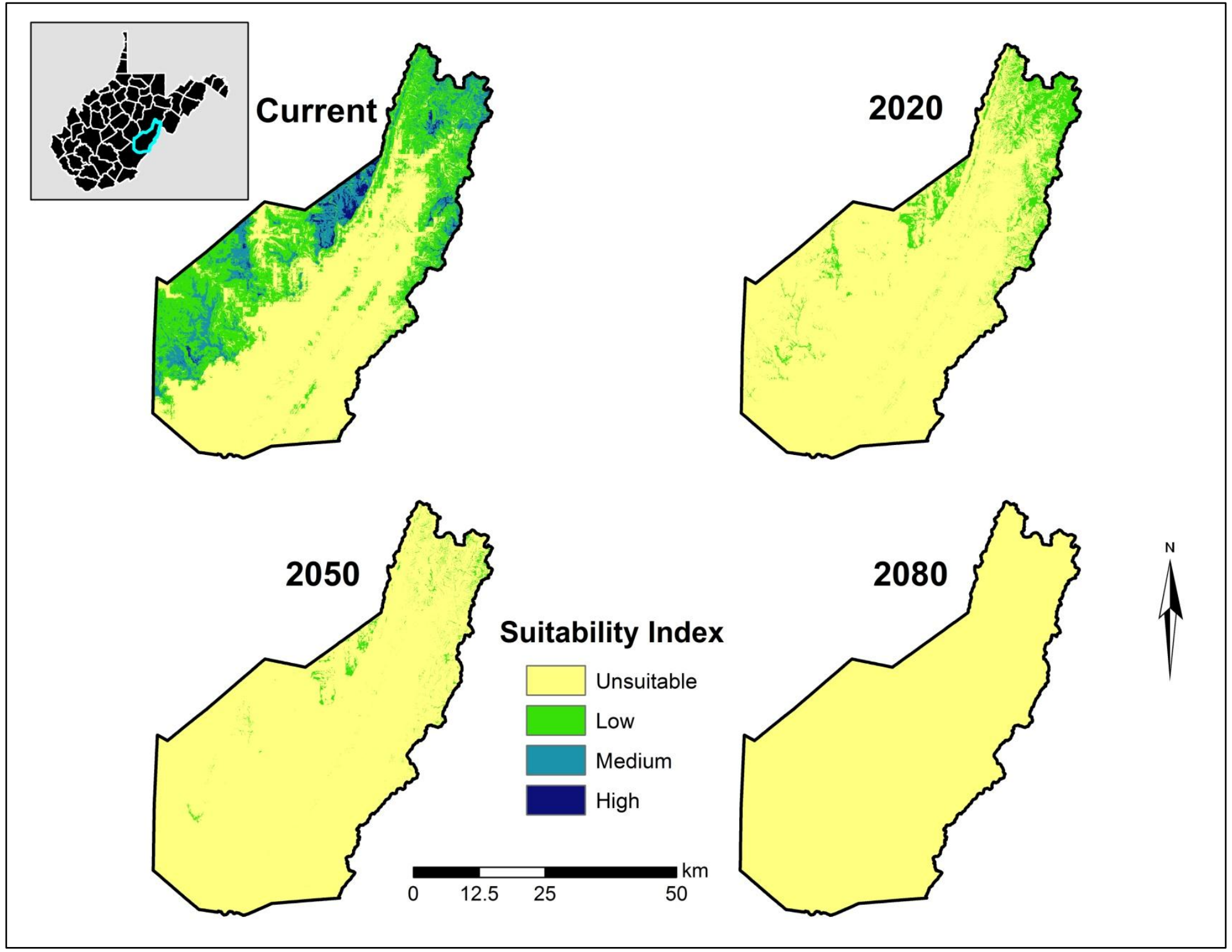

Figure 3.18. Areas within Pocahontas County, by time steps examined, modeled to possess red spruce habitat by suitability index for the SRES-A2 model scenario. 


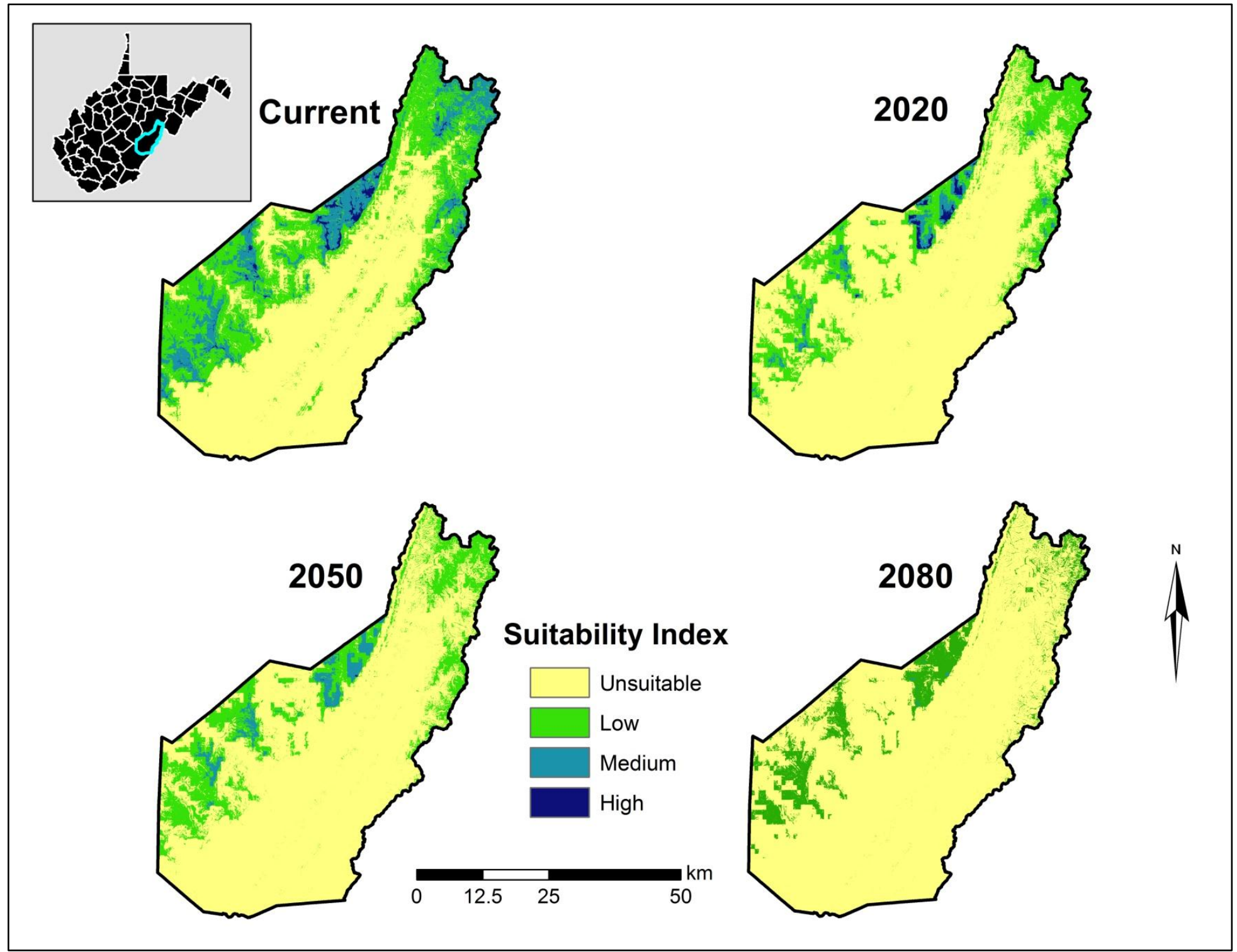

Figure 3.19. Areas within Pocahontas County, by time steps examined, modeled to possess red spruce habitat by suitability index for the SRES-B2 model scenario.. 
Appendix I. Plot coordinates ( $X$ and $Y$ respectively) for the 168 red spruce presence localities using the projected coordinate system: NAD83-UTM Zone 17S.

\begin{tabular}{|c|c|c|c|c|c|}
\hline 561368 & 4231748 & 577713 & 4276307 & 587822 & 4250166 \\
\hline 559866 & 4233239 & 575655 & 4275566 & 579454 & 4248544 \\
\hline 557020 & 4236068 & 574354 & 4249802 & 579656 & 4275653 \\
\hline 555080 & 4233713 & 573416 & 4250380 & 577446 & 4277031 \\
\hline 555922 & 4231552 & 573166 & 4253854 & 573299 & 4258684 \\
\hline 553864 & 4228881 & 573934 & 4258001 & 574567 & 4257552 \\
\hline 554131 & 4228389 & 572645 & 4257993 & 571173 & 4258196 \\
\hline 552006 & 4231999 & 572420 & 4259677 & 566162 & 4240479 \\
\hline 612500 & 4292835 & 573675 & 4256136 & 565642 & 4239273 \\
\hline 608138 & 4297253 & 594802 & 4258237 & 560288 & 4229678 \\
\hline 607666 & 4298751 & 593375 & 4256060 & 561958 & 4227800 \\
\hline 599283 & 4289689 & 592236 & 4256469 & 553944 & 4224098 \\
\hline 614597 & 4264473 & 566460 & 4230820 & 552088 & 4222178 \\
\hline 616392 & 4264217 & 566624 & 4231432 & 557118 & 4222460 \\
\hline 613018 & 4270569 & 563547 & 4227756 & 605835 & 4279131 \\
\hline 550677 & 4230946 & 566996 & 4231531 & 605130 & 4277515 \\
\hline 596288 & 4279075 & 566369 & 4237304 & 595277 & 4279389 \\
\hline 594781 & 4279324 & 566264 & 4236737 & 596756 & 4277824 \\
\hline 593933 & 4277208 & 562703 & 4229328 & 598149 & 4276672 \\
\hline 593683 & 4276557 & 562428 & 4230551 & 600350 & 4276191 \\
\hline 600296 & 4274107 & 566920 & 4244586 & 601244 & 4272855 \\
\hline 593393 & 4272705 & 560924 & 4228582 & 573733 & 4257068 \\
\hline 595773 & 4275847 & 556488 & 4223325 & 566534 & 4230434 \\
\hline 594726 & 4271015 & 572545 & 4244408 & 624589 & 4273363 \\
\hline 593352 & 4268930 & 571905 & 4244362 & 610425 & 4259292 \\
\hline 597950 & 4276527 & 573960 & 4242346 & 630665 & 4321438 \\
\hline 597824 & 4270737 & 573892 & 4243207 & 634707 & 4329660 \\
\hline 596189 & 4268014 & 606579 & 4281194 & 617775 & 4324196 \\
\hline 594991 & 4265573 & 607026 & 4277837 & 614639 & 4318863 \\
\hline 595090 & 4263942 & 598656 & 4278718 & 647004 & 4325769 \\
\hline 596131 & 4268242 & 600007 & 4273973 & 646046 & 4323197 \\
\hline 594817 & 4261865 & 597050 & 4271140 & 645198 & 4319110 \\
\hline 593315 & 4258507 & 595453 & 4268612 & 639625 & 4320174 \\
\hline 580143 & 4279091 & 595374 & 4262979 & 643613 & 4314928 \\
\hline 579664 & 4278456 & 593783 & 4256447 & 642102 & 4311358 \\
\hline 578906 & 4278499 & 589935 & 4255550 & 637835 & 4311819 \\
\hline 577048 & 4275474 & 587521 & 4253800 & 617570 & 4299834 \\
\hline
\end{tabular}




\begin{tabular}{|c|c|}
\hline 627490 & 4326359 \\
\hline 627789 & 4290728 \\
\hline 623389 & 4330291 \\
\hline 619460 & 4286395 \\
\hline 617222 & 4279413 \\
\hline 619970 & 4274944 \\
\hline 621538 & 4281445 \\
\hline 628152 & 4285488 \\
\hline 624671 & 4322728 \\
\hline 628833 & 4287940 \\
\hline 629907 & 4289095 \\
\hline 620366 & 4317114 \\
\hline 624706 & 4322677 \\
\hline 615377 & 4313029 \\
\hline 613767 & 4318265 \\
\hline 637449 & 4312277 \\
\hline 638453 & 4309800 \\
\hline 639240 & 4320872 \\
\hline 617769 & 4288410 \\
\hline
\end{tabular}

$\begin{array}{ll}626247 & 4288939 \\ 614574 & 4276713 \\ 618543 & 4289671 \\ 624386 & 4281683 \\ 628554 & 4286894 \\ 626016 & 4285739 \\ 612631 & 4252908 \\ 610105 & 4246772 \\ 610820 & 4264986 \\ 600894 & 4284453 \\ 601626 & 4290019 \\ 602978 & 4291617 \\ 603594 & 4291779 \\ 603545 & 4292655 \\ 603728 & 4293541 \\ 602412 & 4292511 \\ 603354 & 4288291 \\ 600880 & 4288796 \\ 599536 & 4287422\end{array}$

$599849 \quad 4285658$

$626762 \quad 4288451$

$624937 \quad 4292153$

$622525 \quad 4290296$

$607899 \quad 4286338$

$623616 \quad 4283293$

$626544 \quad 4282731$

$609490 \quad 4273151$

$612612 \quad 4260984$

6132724259116

$630464 \quad 4323583$

$632997 \quad 4319299$

$613411 \quad 4310287$

$638719 \quad 4310252$

$603860 \quad 4291849$

$598458 \quad 4285477$

$597375 \quad 4284290$

$600556 \quad 4284204$

$599301 \quad 4283705$ 
Appendix II. Site-specific Categorical Variable Descriptions for Soil Type (c_soil), Geologic series (c_geology), and Topographic Relative Moisture Index-

Modified Landform (c_trimimlf).

Soil Type (c_soil):

Category US General Soils Map (STATSGO2) Map Unit Name

1 Nelse-Bonnie-Allegheny (s2639)

2 Otwell-Huntington-Elk (s2640)

3 Marrowbone-Fedscreek-Dekalb (s2777)

4 Gilpin-Dekalb-Cookport-Calvin (s3168)

5 Meckesville-Dekalb (s3170)

6 Urban land-Pope-Philo-Atkins-Allegheny (s3172)

7 Waynesboro (s3174)

8 Upshur-Guernsey-Gilpin (s6107)

9 Upshur-Gilpin (s6108)

10 Westmoreland-Lowell (s6109)

11 Vandalia-Upshur-Newark-Guernsey-Elba (s6140)

12 Wheeling-Weinbach-Peoga-Nolin-Elkinsville (s6141)

13 Lakin-Conotton-Cidermill (s6142)

14 Watertown-Mentor-Huntington (s6143)

15 Otwell-Gilpin-Gallia-Allegheny (s6156)

16 Westmoreland-Morristown-Lowell (s6160)

17 Laidig-Hazleton-Dekalb-Buchanan (s6558)

18 Weikert-Berks (s6569)

19 Guernsey-Dormont-Culleoka (s6576)

20 Newark-Gilpin-Dormont-Culleoka (s6577)

21 Wharton-Weikert-Gilpin (s6580)

22 Urban land-Tyler-Rainsboro-Monongahela (s6581)

23 Weikert-Gilpin-Ernest (s6586)

24 Wharton-Rayne-Gilpin-Ernest-Cavode (s6587)

25 Leck kill-Klinesville-Calvin (s6588)

26 Hagerstown-Duffield-Clarksburg (s6592)

27 Westmoreland-Opequon-Edom (s6593)

28 Opequon-Frankstown-Elliber (s6594)

29 Weikert-Berks (s8261)

30 Lowell-Frederick-Chilhowie-Carbo (s8262)

31 Frederick-Carbo (s8263)

32 Vandalia-Sensabaugh (s8860) 
33 Vandalia-Otwell-Hackers-Gallia (s8861)

34 Moshannon-Monongahela-Markland-Hackers (s8862)

35 Tyler-Monongahela-Chavies (s8877)

36 Tyler-Meckesville-Dekalb-Blago (s8878)

37 Tygart-Philo-Monongahela-Cateache-Atkins (s8879)

38 Gilpin-Dekalb-Cookport (s8880)

39 Lehew-Berks (s8881)

40 Opequon-Murrill-Laidig-Hazleton-Dekalb (s8883)

41 Monongahela-Ernest variant-Ernest-Clarksburg (s8884)

42 Moomaw-Jefferson-Alonzville (s8264)

43 Wallen-Lily-Drypond-Dekalb (s8265)

44 Myersville-Catoctin (s8266)

45 Shottower-Laidig (s8276)

46 Weverton-Stumptown-Airmont (s8281)

47 Pineville-Berks (s8309)

48 Water (s8369)

49 Shouns-Gilpin-Cateache-Berks (s8809)

50 Kaymine-Gilpin-Clymer (s8810)

51 Monongahela-Kanawha-Chagrin (s8811)

52 Tilsit-Lily-Atkins (s8812)

53 Lily-Gilpin-Ernest-Berks (s8813)

54 Pineville-Kaymine-Cedarcreek-Berks (s8814)

55 Pineville-Guyandotte-Dekalb (s8815)

56 Shelocta-Berks (s8816)

57 Gilpin-Dekalb (s8817)

58 Ernest-Brinkerton-Atkins (s8818)

59 Rock outcrop-Gilpin-Dekalb (s8819)

60 Tilsit-Litz-Dekalb (s8820)

61 Weikert-Litz-Clarksburg (s8821)

62 Frederick-Frankstown (s8822)

63 Shouns-Cateache-Belmont (s8823)

64 Dekalb-Clymer (s8824)

65 Monongahela-Litz-Cateache-Atkins (s8825)

66 Weikert-Dekalb-Berks (s8826)

67 Tioga-Pope-Monongahela-Ernest (s8827)

68 Tioga-Potomac-Orrville-Lobdell-Chavies-Allegheny (s8828)

69 Elliber-Dekalb-Calvin-Berks (s8829)

70 Pineville-Gilpin-Dekalb-Buchanan (s8830)

71 Urban land-Laidig-Kanawha (s8831) 
72 Vandalia-Kanawha-Hackers (s8832)

73 Vandalia-Senecaville-Hackers (s8833)

74 Upshur-Gilpin (s8834)

75 Vincent-Vandalia-Gilpin-Allegheny (s8835)

76 Upshur-Gilpin-Dekalb-Clymer (s8836)

77 Vandalia-Moshannon (s8837)

78 Vincent-Monongahela (s8838)

79 Urban land-Melvin-Lindside-Kanawha (s8839)

80 Upshur-Gilpin (s8840)

81 Upshur-Latham-Gilpin-Dormont (s8841)

82 Kanawha-Guyan-Chagrin (s8842)

83 Pope-Chavies-Buchanan (s8843)

84 Zoar-Upshur-Senecaville-Moshannon-Markland-Hackers (s8844)

85 Wheeling-Sciotoville-Lakin-Ashton (s8845)

86 Vandalia-Chavies (s8846)

87 Moshannon-Monongahela-Hackers (s8847)

88 Lily-Gilpin-Buchanan (s8848)

89 Gilpin-Buchanan (s8849)

90 Purdy-Elkins-Cotaco-Buchanan (s8850)

91 Pope-Craigsville-Chavies (s8851)

92 Trussel-Simoda-Mandy-Gauley (s8852)

93 Faywood-Dekalb-Blackthorn-Berks (s8853)

94 Shouns-Calvin-Berks (s8854)

95 Shouns-Hagerstown-Frankstown-Belmont (s8855)

96 Udorthents-Tygart-Monongahela-Ernest (s8856)

97 Opequon-Berks (s8857)

98 Monongahela-Markland-Cotaco (s8858)

99 Vandalia-Upshur-Monongahela-Gilpin (s8859)

100 Wheeling-Urban land-Lindside-Huntington (s8863)

101 Wheeling-Urban land-Huntington (s8864)

102 Vandalia-Skidmore-Elk (s8865)

103 Monongahela-Lindside-Clarksburg (s8866)

104 Vandalia-Udorthents-Monongahela (s8867)

105 Zoar-Westmoreland-Urban land-Monongahela-Culleoka-Allegheny (s8868)

106 Westmoreland-Gilpin-Culleoka-Clarksburg (s8869)

107 Gilpin-Ernest-Culleoka (s8870)

108 Lily-Gilpin-Ernest (s8871)

109 Dekalb-Buchanan (s8872)

110 Dekalb-Clymer-Buchanan (s8873) 
111 Calvin-Berks (s8874)

112 Brinkerton-Atkins (s8875)

113 Rubble land-Gilpin-Dekalb (s8876)

114 Schaffenaker-Hazleton-Drall-Dekalb (s8882)

115 Tioga-Potomac (s8885)

116 Schaffenaker-Opequon-Murrill (s8886)

117 Lehew-Laidig-Dekalb (s8887)

118 Tygart-Pope-Monongahela (s8888)

119 Monongahela-Melvin-Lindside-Chagrin (s8889)

120 Frederick-Corydon (s8890)

121 Potomac-Ernest-Clarksburg (s8891)

122 Lehew-Hazleton-Dekalb (s8892)

123 Laidig-Elliber-Dekalb-Blackthorn (s8893)

124 Hazleton-Dekalb-Calvin (s8894)

125 Urban land-Monongahela-Kanawha-Gilpin-Allegheny (s8895)

126 Dormont-Cotaco-Chagrin-Allegheny (s8896)

127 Grigsby-Dormont-Cotaco-Chagrin-Allegheny (s8897)

128 Wheeling-Urban land (s8898)

129 Sciotoville-Melvin-Lakin-Ashton (s8899)

130 Westmoreland-Kaymine (s8900)

131 Gilpin-Berks-Allegheny (s8901)

132 Monongahela-Huntington-Clarksburg (s8902)

133 Waynesboro (s8903)

134 Rock outcrop-Laidig-Edgemont (s8904)

135 Muskingum (s8905)

136 Lily-Gilpin-Dekalb-Buchanan (s8906) 
Geologic series (c_geology):

Category West Virginia Geologic Series

0 Qal: Quaternary alluvium

1 Pna: Pennsylvanian sandstone, Conemaugh, Allegheny

2 Pnc: Pennsylvanian shale, Conemaugh, Casselman, Glenshaw

3 Pnm: Pennsylvanian sandstone, Monongahela, Uniontown, Pittsburgh

4 Pd: Pennsylvanian sandstone, Dunkard, Greene, Washington, Waynesburg

5 Dmn: Devonian shale, Marcellus Formation and Needmore Shale

6 Dmt: Devonian shale, Mahantango

7 Dohl: Devonian ss/ls, Helderberg, Oriskany Sandstone

8 Dbh: Devonian shale, Brallier and Harrell Shale

9 Dch: Devonian shale, Chemung

10 Pnpv: Pennsylvanian sandstone, Pottsville

11 Mmc: Mississippian shale, Mauch Chunk

12 Mg: Mississippian limestone, Greenbrier

13 Mp: Mississippian sandstone, Pocono

14 Dhs: Devonian shale, Hampshire

15 Stw: Silurian limestone, Tonoloway, Wills Creek, Williamsport

16 Smc: Silurian sandstone, Clinton, McKenzie

17 St: Silurian sandstone, Tuscarora Sandstone

18 Dhl: Devonian limestone, Helderberg

19 Do: Devonian sandstone, Oriskany Sandstone

20 Cc: Cambrian limestone, Conococheague

21 Ce: Cambrian limestone, Elbrook

22 Obrr: Ordovician limestone, Beekmantown, Rockdale Run

23 Obps: Ordovician dolostone, Beekmantown, Pinesburg Station

24 Omc: Ordovician limestone, Trenton, Black River

25 Om: Ordovician shale, Martinsburg

26 Ob: Ordovician limestone, Beekmantown

27 Obs: Ordovician limestone, Beekmantown, Stonehenge Limestone

28 Otbr: Ordovician limestone, Trenton, Black River

29 Db: Devonian shale, Brallier

30 Osp: Ordovician limestone, St. Paul

31 Ojo: Ordovician sandstone, Juniata, Oswego

32 Dh: Devonian shale, Harrell Shale

33 Cwy: Cambrian shale/ss, Waynesboro

34 Ct: Cambrian dolostone, Tomstown

35 Ca: Cambrian quartzite, Chilhowee, Antietam 
36 Ch: Cambrian phyllite, Chilhowee, Harpers

$37 \mathrm{Cw}$ : Cambrian quartzite, Chilhowee, Weverton-Loudoun

38 NA: Non-soil

39 Dmb: Devonian shale, Millboro Shale, Harrell, Mahantango, Marcellus

40 CPCc: Cambrian greenstone, Catoctin

41 Pnk: Pennsylvanian sandstone, Pottsville, Kanawha

42 Pnnr: Pennsylvanian sandstone, Pottsville, New River

43 Mbf: Mississippian shale, Mauch Chunk, Bluefield

44 Mh: Mississippian shale, Mauch Chunk, Hinton

45 Mbp: Mississippian shale/ss, Mauch Chunk, Bluestone, Princeton

46 Ot: Ordovician limestone, Trenton

47 Obr: Ordovician limestone, Black River

48 Mmcc: Mississippian shale, Maccrady

49 Pnp: Pennsylvanian sandstone, Pottsville, Pocahontas

50 Sct: Silurian sandstone, Clinton, McKenzie, Tuscarora Sandstone

51 Dm: Devonian shale, Marcellus

52 Mmp: Mississippian shale, Pocono, Maccrady

53 Dmu: Devonian shale 
Topographic Relative Moisture Index-Modified_LLandform (c_trimimlf):

Category Topographic Relative Moisture Index Modified, Landform

1 Valley flats

2 Toe slopes, bottoms, and swales

3 Gently sloping ridges and hills

4 Nearly level plateaus or terraces

5 Very moist steep slopes

6 Moderately moist steep slopes

7 Moderately dry slopes

8 Very dry steep slopes

9 Cool aspect cliffs, scarps, cirques, canyons

10 Hot aspect cliffs, scarps, cirques, canyons 
Appendix III. Area (ha) by county and suitability index for the SRES-A2 and SRES-B2 scenarios by current, 2002, 2050, and 2080 time steps.

SRES-A2 Current:

Suitability Index

\begin{tabular}{lccccc} 
Counties & Unsuitable & Low & Medium & High & Total Suitable \\
\hline Barbour & 88,688 & 30 & - & - & 30 \\
Preston & 167,028 & 740 & - & - & 740 \\
Tucker & 64,578 & 34,356 & 9,944 & 164 & 44,464 \\
Grant & 108,767 & 13,646 & 1,584 & 3 & 15,232 \\
Mineral & 83,873 & 6 & - & - & 6 \\
Pendleton & 157,012 & 16,948 & 4,650 & 406 & 22,005 \\
Pocahontas & 133,561 & 75,957 & 29,726 & 3,426 & 109,108 \\
Randolph & 152,226 & 76,727 & 35,277 & 4,945 & 116,949 \\
Webster & 123,928 & 19,526 & 499 & - & 20,025 \\
Nicholas & 167,685 & 1,659 & 12 & - & 1,672 \\
Summers & 95,016 & 132 & - & - & 132 \\
Fayette & 172,669 & 395 & - & - & 395 \\
Greenbrier & 230,865 & 29,367 & 3,760 & 4 & 33,131 \\
Hardy & 149,425 & 70 & - & - & 70 \\
Hampshire & 166,080 & 4 & - & - & 4 \\
Upshur & 91,660 & 164 & - & - & 164 \\
Monroe & 120,523 & 5 & - & - & 5 \\
All Counties & $2,273,585$ & 269,732 & 85,453 & 8,948 & 364,132
\end{tabular}


SRES-A2 2020:

Suitability Index

\begin{tabular}{lccccc}
\cline { 2 - 6 } Counties & Unsuitable & Low & Medium & High & Total Suitable \\
\hline Barbour & 88,718 & - & - & - & - \\
Preston & 167,609 & 159 & - & - & 159 \\
Tucker & 96,007 & 13,035 & - & - & 13,035 \\
Grant & 113,202 & 10,797 & - & - & 10,797 \\
Mineral & 83,875 & 4 & - & - & 4 \\
Pendleton & 171,714 & 7,300 & 3 & - & 7,303 \\
Pocahontas & 218,168 & 24,499 & 2 & - & 24,500 \\
Randolph & 245,387 & 23,782 & 6 & - & 23,788 \\
Webster & 143,945 & 8 & - & - & 8 \\
Nicholas & 169,346 & 11 & - & - & 11 \\
Summers & 95,146 & 2 & - & - & 2 \\
Fayette & 173,065 & - & - & - & - \\
Greenbrier & 262,557 & 1,439 & - & - & 1,439 \\
Hardy & 149,476 & 19 & - & - & 19 \\
Hampshire & 166,080 & 3 & - & - & 3 \\
Upshur & 91,824 & - & - & - & - \\
Monroe & 120,528 & - & - & - & - \\
All Counties & $2,556,647$ & 81,059 & 11 & - & 81,070
\end{tabular}


SRES-A2 2050:

Suitability Index

\begin{tabular}{lccccc}
\cline { 2 - 6 } Counties & Unsuitable & Low & Medium & High & Total Suitable \\
\hline Barbour & 88,718 & - & - & - & - \\
Preston & 167,764 & 4 & - & - & 4 \\
Tucker & 105,389 & 3,653 & - & - & 3,653 \\
Grant & 120,923 & 3,076 & - & - & 3,076 \\
Mineral & 83,880 & - & - & - & - \\
Pendleton & 177,051 & 1,966 & - & - & 1,966 \\
Pocahontas & 238,146 & 4,523 & - & - & 4,523 \\
Randolph & 262,400 & 6,775 & - & - & 6,775 \\
Webster & 143,953 & - & - & - & - \\
Nicholas & 169,357 & - & - & - & - \\
Summers & 95,148 & - & - & - & - \\
Fayette & 173,065 & - & - & - & - \\
Greenbrier & 263,994 & 2 & - & - & 2 \\
Hardy & 149,495 & - & - & - & - \\
Hampshire & 166,083 & - & - & - & - \\
Upshur & 91,824 & - & - & - & - \\
Monroe & 120,528 & - & - & - & - \\
All Counties & $2,617,716$ & 20,001 & - & - & 20,001
\end{tabular}


SRES-A2 2080:

Suitability Index

\begin{tabular}{|c|c|c|c|c|c|}
\hline Counties & Unsuitable & Low & Medium & High & Total Suitable \\
\hline Barbour & 88,718 & - & - & - & - \\
\hline Preston & 167,768 & - & - & - & - \\
\hline Tucker & 109,042 & - & - & - & - \\
\hline Grant & 123,999 & - & - & - & - \\
\hline Mineral & 83,880 & - & - & - & - \\
\hline Pendleton & 179,017 & - & - & - & - \\
\hline Pocahontas & 242,669 & - & - & - & - \\
\hline Randolph & 269,175 & - & - & - & - \\
\hline Webster & 143,953 & - & - & - & - \\
\hline Nicholas & 169,357 & - & - & - & - \\
\hline Summers & 95,148 & - & - & - & - \\
\hline Fayette & 173,065 & - & - & - & - \\
\hline Greenbrier & 263,996 & - & - & - & - \\
\hline Hardy & 149,495 & - & - & - & - \\
\hline Hampshire & 166,083 & - & - & - & - \\
\hline Upshur & 91,824 & - & - & - & - \\
\hline Monroe & 120,528 & - & - & - & - \\
\hline All Counties & $2,637,717$ & - & - & - & - \\
\hline
\end{tabular}


SRES-B2 Current:

Suitability Index

\begin{tabular}{|c|c|c|c|c|c|}
\hline Counties & Unsuitable & Low & Medium & High & Total Suitable \\
\hline Barbour & 88,686 & 32 & - & - & 32 \\
\hline Preston & 166,691 & 1,077 & - & - & 1,077 \\
\hline Tucker & 62,933 & 34,832 & 11,093 & 185 & 46,109 \\
\hline Grant & 108,410 & 13,512 & 2,072 & 5 & 15,589 \\
\hline Mineral & 83,869 & 11 & - & - & 11 \\
\hline Pendleton & 155,625 & 17,161 & 5,647 & 584 & 23,392 \\
\hline Pocahontas & 135,283 & 74,405 & 30,561 & 2,419 & 107,386 \\
\hline Randolph & 152,736 & 71,798 & 39,778 & 4,862 & 116,439 \\
\hline Webster & 125,715 & 17,746 & 492 & - & 18,238 \\
\hline Nicholas & 168,220 & 1,134 & 2 & - & 1,136 \\
\hline Summers & 94,934 & 214 & - & - & 214 \\
\hline Fayette & 173,040 & 24 & - & - & 24 \\
\hline Greenbrier & 231,771 & 28,246 & 3,976 & 3 & 32,225 \\
\hline Hardy & 149,432 & 63 & - & - & 63 \\
\hline Hampshire & 166,080 & 4 & - & - & 4 \\
\hline Upshur & 91,787 & 37 & - & - & 37 \\
\hline Monroe & 120,509 & 19 & - & - & 19 \\
\hline All Counties & $2,275,722$ & 260,315 & 93,621 & 8,058 & 361,995 \\
\hline
\end{tabular}


SRES-B2 2020:

Suitability Index

\begin{tabular}{lccccc}
\cline { 2 - 6 } Counties & Unsuitable & Low & Medium & High & Total Suitable \\
\hline Barbour & 88,718 & 1 & - & - & 1 \\
Preston & 167,452 & 316 & - & - & 316 \\
Tucker & 79,994 & 27,419 & 1,629 & - & 29,048 \\
Grant & 110,272 & 13,154 & 574 & - & 13,728 \\
Mineral & 83,878 & 2 & - & - & 2 \\
Pendleton & 167,532 & 9,867 & 1,463 & 155 & 11,485 \\
Pocahontas & 187,823 & 46,971 & 6,345 & 1,530 & 54,846 \\
Randolph & 215,581 & 49,326 & 3,766 & 502 & 53,594 \\
Webster & 143,260 & 693 & - & - & 693 \\
Nicholas & 169,350 & 7 & - & - & 7 \\
Summers & 95,046 & 102 & - & - & 102 \\
Fayette & 173,064 & 0 & - & - & 0 \\
Greenbrier & 255,336 & 8,636 & 24 & - & 8,660 \\
Hardy & 149,492 & 3 & - & - & 3 \\
Hampshire & 166,081 & 2 & - & - & 2 \\
Upshur & 91,822 & 1 & - & - & 1 \\
Monroe & 120,528 & - & - & - & - \\
All Counties & $2,465,228$ & 156,501 & 13,801 & 2,187 & 172,489
\end{tabular}


SRES-B2 2050:

Suitability Index

\begin{tabular}{lccccc} 
Counties & Unsuitable & Low & Medium & High & Total Suitable \\
\hline Barbour & 88,717 & 1 & - & - & 1 \\
Preston & 167,522 & 246 & - & - & 246 \\
Tucker & 83,373 & 25,669 & - & - & 25,669 \\
Grant & 113,585 & 10,414 & - & - & 10,414 \\
Mineral & 83,880 & - & - & - & - \\
Pendleton & 170,796 & 7,860 & 361 & - & 8,221 \\
Pocahontas & 188,907 & 47,057 & 6,683 & 21 & 53,762 \\
Randolph & 221,700 & 44,582 & 2,893 & - & 47,475 \\
Webster & 141,142 & 2,811 & - & - & 2,811 \\
Nicholas & 169,192 & 164 & - & - & 164 \\
Summers & 95,120 & 29 & - & - & 29 \\
Fayette & 173,004 & 61 & - & - & 61 \\
Greenbrier & 252,945 & 11,051 & - & - & 11,051 \\
Hardy & 149,493 & 2 & - & - & 2 \\
Hampshire & 166,082 & 2 & - & - & 2 \\
Upshur & 91,822 & 1 & - & - & 1 \\
Monroe & 120,528 & 0 & - & - & 0 \\
All Counties & $2,477,807$ & 149,952 & 9,937 & 21 & 159,910
\end{tabular}


SRES-B2 2080:

Suitability Index

\begin{tabular}{lccccc} 
Counties & Unsuitable & Low & Medium & High & Total Suitable \\
\hline Barbour & 88,718 & - & - & - & - \\
Preston & 167,765 & 3 & - & - & 3 \\
Tucker & 108,670 & 373 & - & - & 373 \\
Grant & 123,338 & 661 & - & - & 661 \\
Mineral & 83,880 & - & - & - & - \\
Pendleton & 174,252 & 4,725 & 41 & - & 4,765 \\
Pocahontas & 214,283 & 28,246 & 140 & - & 28,386 \\
Randolph & 251,919 & 17,210 & 46 & - & 17,256 \\
Webster & 143,097 & 856 & - & - & 856 \\
Nicholas & 169,349 & 8 & - & - & 8 \\
Summers & 95,135 & 13 & - & - & 13 \\
Fayette & 173,064 & 1 & - & - & 1 \\
Greenbrier & 262,484 & 1,513 & - & - & 1,513 \\
Hardy & 149,494 & 1 & - & - & 1 \\
Hampshire & 166,083 & - & - & - & - \\
Upshur & 91,824 & - & - & - & - \\
Monroe & 120,528 & - & - & - & - \\
All Counties & $2,583,880$ & 53,610 & 227 & - & 53,837
\end{tabular}

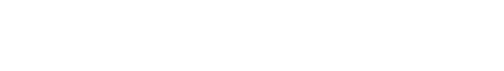

